Development and analysis of noncollinear wave mixing techniques for material properties evaluation using immersion ultrasonics

Andriejus Demčenko 


\section{Development and analysis of noncollinear wave mixing techniques for material properties evaluation using immersion ultrasonics}

Andriejus Demčenko 
De promotiecommissie is als volgt samengesteld:

Voorzitter en secretaris:

Prof.dr. G.P.M.R. Dewulf

University of Twente

Promotor:

Prof.dr.ir. R. Akkerman

University of Twente

Leden (in alfabetische volgorde):

Prof.dr.ir. A. de Boer

University of Twente

Prof.dr.ir. B.W. Drinkwater

Bristol University

Prof.dr.ir. C.H. Slump

Prof.dr. G.J. Vancso

University of Twente

dr.ir. M.D. Verweij

University of Twente

Delft University of Technology

Development and analysis of noncollinear wave mixing techniques for material properties evaluation using immersion ultrasonics

Andriejus Demčenko

$\mathrm{PhD}$ thesis, University of Twente, Enschede, The Netherlands

October 2014

ISBN 978-90-365-3761-2

DOI 10.3990/1.9789036537612

Copyright @2014 by A. Demčenko

Printed by Ipskamp Drukkers B.V., Enschede, The Netherlands

Cover: ultrasonic field (normal stress along z-axis $\left(\sigma_{33}\right)$ in aluminum and pressure in water) generated by bounded beams of $2 \mathrm{MHz}$ and $3 \mathrm{MHz}$ centre frequencies. 


\title{
DEVELOPMENT AND ANALYSIS OF NONCOLLINEAR WAVE MIXING TECHNIQUES FOR MATERIAL PROPERTIES EVALUATION USING IMMERSION ULTRASONICS
}

\author{
PROEFSCHRIFT
}

ter verkrijging van

de graad van doctor aan de Universiteit Twente, op gezag van de rector magnificus, prof.dr. H. Brinksma, volgens besluit van het College voor Promoties in het openbaar te verdedigen op donderdag 23 oktober 2014 om 14:45 uur

door

Andriejus Demčenko

geboren op 9 mei 1979

te Skuodas, Lithuania 
Dit proefschrift is goedgekeurd door de promotor:

Prof.dr.ir. R. Akkerman 
To my beloved family 


\section{Acknowledgments}

With thanks to Remko Akkerman, Valeri A. Korneev, Vitaly Koissin,

Leonas Jakevičius, Ton C. Bor, Arend Nijhuis, Bruce W. Drinkwater, Peter B. Nagy, friends, colleagues and sponsor

Wetsus, centre of excellence for sustainable water technology 


\section{Summary}

The sensitivity of ultrasonic measurements can be increased significantly by using nonlinear techniques instead of conventional linear ultrasonics. The nonlinear ultrasonics, based on a harmonic generation technique also known as collinear wave interaction, is used widely in practice due to its simplicity in implementation. The amplitudes of harmonics which are monitored with this technique not only originate in a test specimen, but also in electronics, the acoustic channel and the surrounding medium. This makes interpretation of the measurement results extremely complex.

Noncollinear wave mixing is an alternative technique to harmonic generation. This technique has multiple advantages in comparison with harmonic generation, and it is easy to implement in industrial applications when in-line and real-time measurements are required. With a proper selection of measurement conditions for noncollinear wave mixing it is possible to measure a nonlinear material response without an influence of nonlinearities in the electronics, the acoustic channel and the surrounding medium.

A mathematical model for prediction of nonlinear wave amplitude coefficients is presented in this thesis. All possible noncollinear wave interactions can be analyzed with this model and the nonlinear wave amplitude coefficients in isotropic solids can be predicted. Based on this model, a procedure is proposed for the selection of the optimal measurement conditions for noncollinear wave mixing experiments.

Three measurement techniques were developed based on noncollinear wave mixing. Firstly, a method was developed for the phase velocity measurement in an isotropic solid. The phase velocity in a solid can be determined with this method when one of the wave velocities (shear or longitudinal) is known. This method does not require an estimation of the phase time-of-flight and wave propagation path. It is only necessary to measure the wave incident angles.

Secondly, a method was developed to monitor the curing process of epoxy and experimental results were analyzed. This method enables in-line and real-time measurements of the epoxy cure dynamics in a thin layer (thickness about $0.2 \mathrm{~mm}$ ), with detection of the minimum viscosity, the gel onset, the gel peak and vitrification points.

Thirdly, a method was developed and the experimental results were analyzed for physical ageing measurements in glassy thermoplastics. The physical ageing dynamics and the current physical age in thermoplastics can be determined with this method.

The results of this study demonstrate that more accurate and more sensitive characterization of engineering materials can be achieved by making use of advanced ultrasonic measurement techniques. 


\section{Samenvatting}

De gevoeligheid van ultrasone metingen kan significant worden verhoogd door het gebruik van niet-lineaire in plaats van de gebruikelijke lineaire technieken. Door de eenvoudige implementatie wordt collineaire golfinteractie, een niet-lineaire techniek gebaseerd op harmonische generatie, veelvuldig in de praktijk toegepast. Echter, de amplituden van de gemeten harmonischen komen niet alleen voort uit het proefstuk, maar ook uit de elektronica, het akoestische kanaal en het omringende medium. Dit maakt interpretatie van de signalen extreem complex.

Niet-collineaire golfinteractie biedt meerdere voordelen als alternatief voor harmonische generatie. De techniek is relatief eenvoudig te implementeren in industriële toepassingen voor in-line en real-time metingen. Het is mogelijk om de nietlineaire respons van een materiaal te meten zonder beïnvloeding door niet-lineariteiten in de elektronica, het akoestische kanaal en het omringende medium; althans wanneer de juiste meetcondities zijn gecreëerd.

In dit proefschrift wordt een wiskundig model gepresenteerd dat dient om de nietlineaire amplitude coëfficiënten te voorspellen. Het model is geschikt om alle mogelijke niet-collineaire golfinteracties te analyseren en de niet-lineaire amplitude coëfficiënten in isotrope vaste stoffen te voorspellen. Op basis van dit model is een procedure opgesteld om de optimale meetcondities te bepalen voor niet-collineaire golfinteractie experimenten.

Drie meetmethoden zijn ontwikkeld op basis van niet-collineaire golfinteractie. Ten eerste is een methode ontwikkeld voor de meting van de golfsnelheid in een isotrope vaste stof. De fasesnelheid in een vaste stof kan worden bepaald wanneer één van de golfsnelheden (transversaal of longitudinaal) bekend is. De methode vereist geen schatting van de fasehoek en het golfvoortplantingspad. Het is voldoende om de invalsen reflectiehoeken van de golven te meten.

Ten tweede is een methode ontwikkeld om het uithardingsproces van epoxy te meten en te analyseren. De methode maakt het mogelijk om in-line en real-time de uithardingskinetiek in een dunne laag te meten, waarbij de minimale viscositeit, de start en voltooiing van gelering en de vitrificatie kunnen worden vastgesteld.

Ten derde is een methode ontwikkeld en toegepast voor het meten van fysische veroudering in thermoplastische kunststoffen in de glasfase. De verouderingssnelheid en de huidige fysische leeftijd van thermoplasten kunnen met deze methode worden bepaald.

De resultaten van deze studie laten zien dat geavanceerde ultrasone meetmethoden de mogelijkheden bieden om technische materialen nauwkeuriger en met een hogere gevoeligheid te karakteriseren. 


\section{Table of Contents}

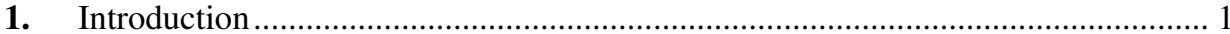

2. Possible second-order nonlinear interactions of plane waves in an isotropic solid. 7

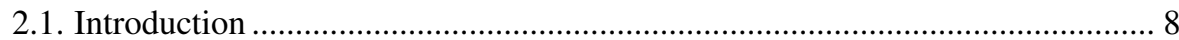

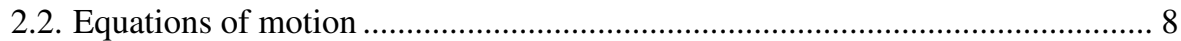

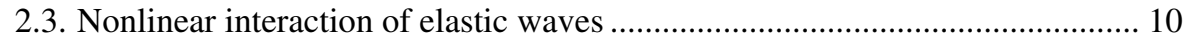

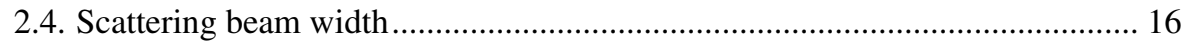

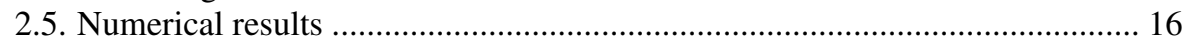

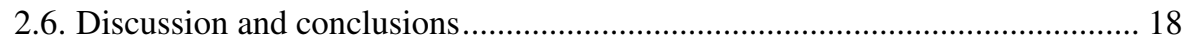

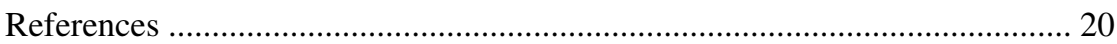

3. Noncollinear wave mixing for a bulk wave phase velocity measurement in an

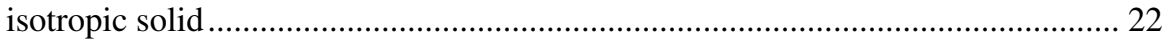

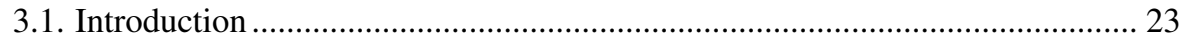

3.2. Bulk wave phase velocity measurement method based on noncollinear wave

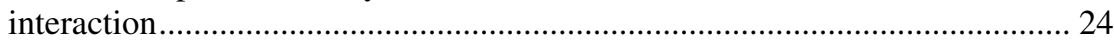

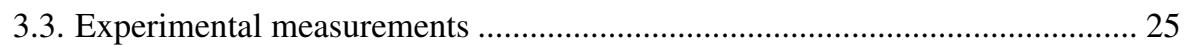

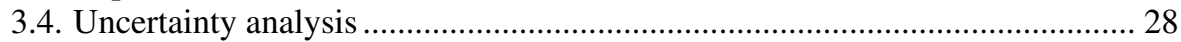

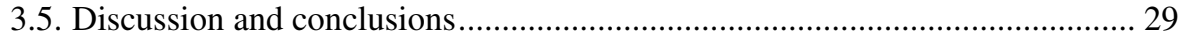

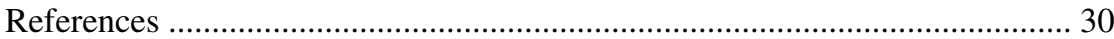

4. Noncollinear wave mixing for measurement of dynamic processes in polymers: physical ageing in thermoplastics and epoxy cure ........................................... 31

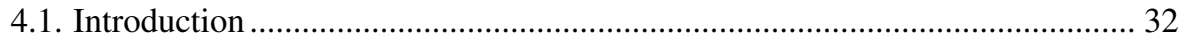

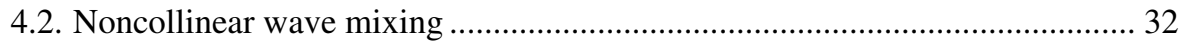

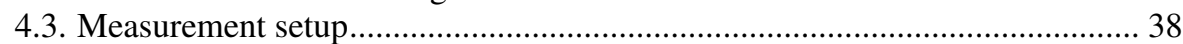

4.4. Monitoring of physical ageing process in thermoplastics ............................... 39

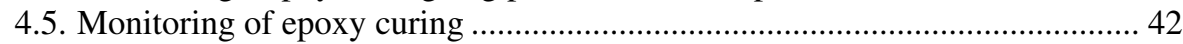

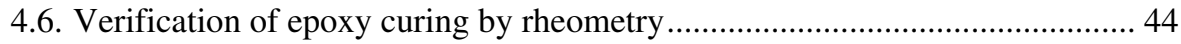

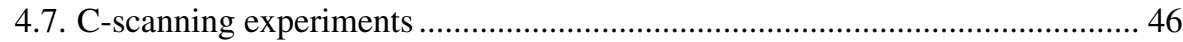

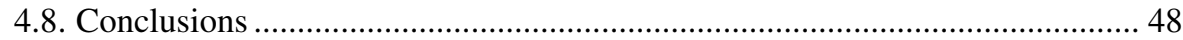

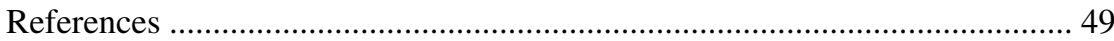

5. Isothermal epoxy-cure monitoring using nonlinear ultrasonics......................... 51

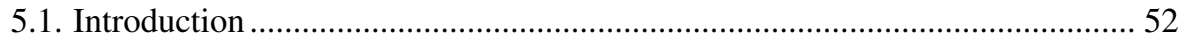

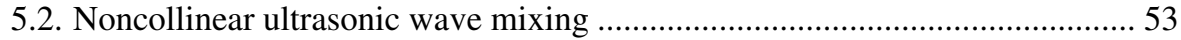

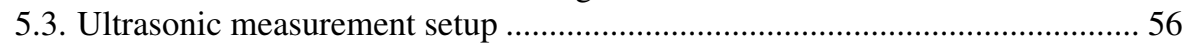

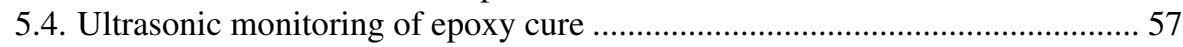

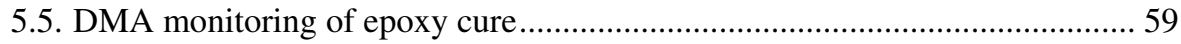

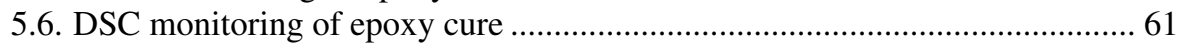

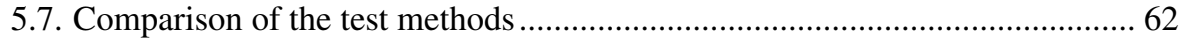

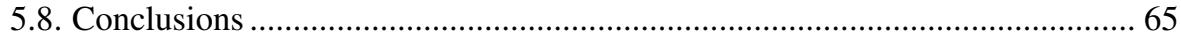

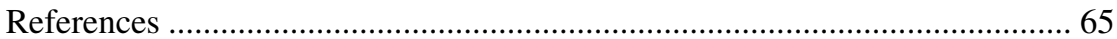


6. Noncollinear wave mixing for nonlinear ultrasonic detection of physical ageing in PVC 68

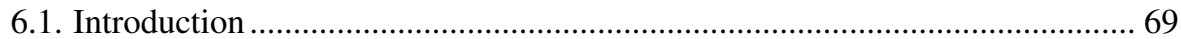

6.2. Measurement of phase velocity and attenuation of longitudinal waves........... 71

6.3. Noncollinear wave mixing measurement method ........................................ 71

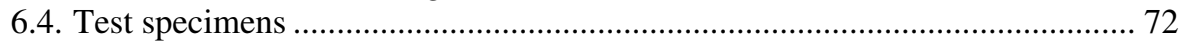

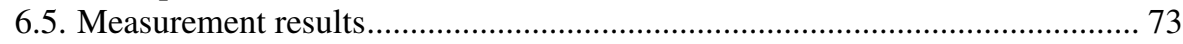

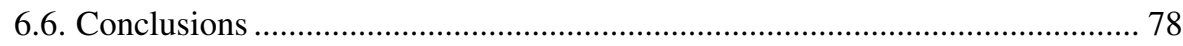

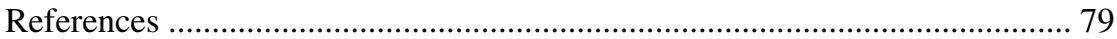

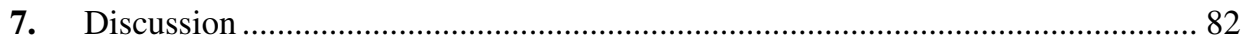

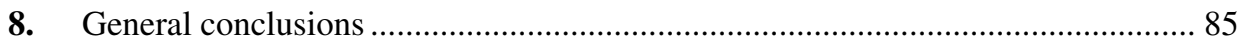

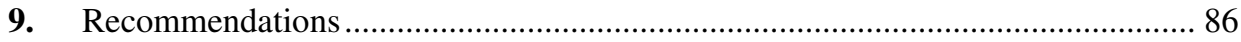




\section{Chapter 1}

\section{Introduction}

Recent needs in science and industry require more strict and detailed measurement techniques for material property evaluation and quality control in production and maintenance. Preferably, that the quality control would be performed in an automatic, possibly contactless and nondestructive way. For these purposes, common nondestructive techniques such as ultrasonics, radiography, eddy-current, visual inspection, etc. are used widely.

Ultrasonic measurements are used for nondestructive testing and evaluation of material properties in engineering and biological applications. In a general case, all mechanical waves above $20 \mathrm{kHz}$ are a subject of ultrasonics. The main advantages of ultrasonic techniques include relatively low cost, high sensitivity, in-line and real-time measurement possibilities. Current and future laboratory and industrial needs require the use of more sensitive measurement methods for evaluation of material properties. Conventional ultrasonic methods are limited in their detection of fatigue, physical ageing, micro-cracks, and various interface imperfections in engineering structures. More sensitive measurements are required to achieve a higher quality of production, for example, to detect various imperfections and defects in materials, and reduce risks in critical applications of engineering structures. Development of these more sensitive measurements also generates new scientific knowledge, revealing new applications and extending current applications of ultrasonic techniques.

All conventional ultrasonics, including guided wave ultrasonics, are based on the hypothesis of linear elasticity theory, which involves only the two second-order elasticity constants for isotropic solids. Therefore, only changes in the linear material properties are reflected in the measurement results. Thus, the sensitivity of linear ultrasonics is limited for certain applications such as evaluation of adhesive bonds, fatigue, micro-cracks, physical ageing of thermoplastics (where changes in the linear properties are not the main issue), and linear ultrasonics does not provide sufficient information for accurate characterization of such materials and structures in production or under inspection. For these applications, it is necessary to use more sensitive ultrasonic measurement methods or a combination of different measurement methods, such as, for example, a combination of ultrasonic and dielectric measurements.

The field of nonlinear ultrasonics provides an alternative to linear ultrasonics which provides this higher sensitivity of an ultrasonic measurement system. For isotropic materials, the nonlinear ultrasonic theory is based on five constants of elasticity: two second-order constants and three third-order constants. Therefore, the linearization assumptions are not valid anymore. The last three constants represent the material nonlinearity and thus potentially allow for a higher sensitivity to material changes. Up to now, a mathematical model of the nonlinear ultrasonics has been developed only for isotropic materials and not yet for anisotropic materials. Therefore, this work considers 
analysis of the 'simplest' nonlinear ultrasonics case, i.e. nonlinear ultrasonics in isotropic materials.

However, even in this isotropic case, the nonlinear ultrasonic measurements are not as trivial as the linear measurements. A harmonic generation approach is the simplest and currently most widely used nonlinear ultrasonics in engineering and biological applications. Harmonic generation involves high power ultrasonics to induce sufficient nonlinear effects. Using this technique, a high power quasi-monochromatic wave is invoked in an object, and the generation of multiple harmonics is monitored. Changes in harmonic amplitudes show a variation of linear and nonlinear properties of the material. The harmonic amplitudes are dependent on the initial wave power and they grow within the wave propagation path in a medium. The last dependency implies that the inspection of thin structures is complicated using the harmonic generation technique. The harmonic generation technique is easily implementable in practice, but interpretation of the measurement results becomes complex. The complexity occurs due to the origin of the harmonic generation method: nonlinearities arise in the electronics, in the acoustic channel, in the surrounding medium and they mask informative nonlinearity of the object under inspection. Therefore these measurements are not attractive and suitable for industrial engineering applications.

A more sophisticated approach - denoted as noncollinear wave mixing - is an alternative technique to harmonic generation, where the latter can be interpreted as a special case of the noncollinear wave mixing approach. In the harmonic generation case, two waves of the same frequency propagate in the same direction, and a nonlinear interaction between these two waves occurs. The noncollinear wave mixing technique has multiple advantages in comparison with the harmonic generation, and it is easily applied in industrial applications when in-line and real-time measurements are required.

A proper selection of measurement conditions for the noncollinear wave mixing enables the measurement of a nonlinear material response without an influence of nonlinearities in electronics, acoustic channel and surrounding medium. In this manner, the interpretation of the measurement results becomes simple and robust. Moreover, it is easy to combine the noncollinear wave mixing technique with the linear method, so nonlinear and linear responses of material can be measured simultaneously.

The noncollinear wave mixing technique is based on the interaction between two waves (at least) which intersect at a certain angle. This interaction occurs when special conditions - known as resonance conditions - are fulfilled. These conditions represent the conservation laws of energy and quasi-moments. The resonance conditions are necessary, but not sufficient to result in the wave interaction. When two initial waves interact, the third wave is generated with sum or difference frequencies of the two initial waves. A proper selection of the primary frequencies is required, by which the resulting nonlinear wave frequency is not a periodic frequency of one of the initial waves. This provides the means to generate a nonlinear wave which is easily filtered out from a raw acoustic signal containing fundamental frequencies and their multiple harmonics. This advantage is known as the frequency separation, which is one of the most important characteristics of the noncollinear wave mixing approach.

It is also important that the noncollinear wave mixing technique provides the possibility to maintain a mode separation. It means that it is possible to select two initial 
waves of a single mode, for example two shear waves, and to generate a nonlinear wave of a different mode, i.e. a longitudinal wave.

The noncollinear wave mixing is produced only in a volume, where the intersection of the initial waves occurs when the beams are well collimated in time and space. Therefore, it is possible to control a spatial position of the intersection volume within a solid, in other words to measure the nonlinear material response from a specific location without the influence of a surrounding medium. Moreover, this advantage enables the measurement of material properties in the $z$ axis direction (in the depth direction).

The propagation direction of the nonlinear wave can also be controlled using the noncollinear wave mixing phenomenon. It means that there is a possibility to steer (rotate) the nonlinear wave propagation direction. For example, this feature provides the possibility to avoid overlapping of multiple re-reflections in a received signal when thin plates are inspected. Also, it helps to put ultrasonic transducers in non-conflicting positions.

A detector mode possibility is another important advantage of the noncollinear wave mixing technique. It means that the wave interaction conditions can be selected in such a way that a nonlinear wave will be generated only when these conditions are fulfilled. Otherwise, an informative signal will not be generated.

The noncollinear wave mixing technique is currently rarely used for inspection and evaluation of material properties despite its various advantages. Pioneering noncollinear wave mixing experiments were performed using contact transducers on specimens with a special geometry ${ }^{1}$. However, modern ultrasonic instrumentation makes it possible to perform wave mixing measurements using contact, immersion and even air-coupled ultrasonics in specimens of various geometry. This obviously poses many challenges, not only for the laboratory scale, but also for the industrial applications.

Nevertheless, the noncollinear wave mixing technique still requires detailed analysis and preparation for experiments. It is necessary to select the measurement conditions in such a way that the signal-to-noise ratio would be maximal; otherwise it is possible that no informative signal will be received. This can be seen as an essential limitation of the technique. Moreover, the noncollinear wave mixing technique is difficult to apply for evaluation of: a) thin structures, b) highly attenuative materials, c) heterogeneous materials. Also, it can be difficult to achieve a fine spatial resolution using the noncollinear wave mixing techniques, which depends on the interaction volume of two primary wave beams.

Currently there is either no or too little information about proper preparation for noncollinear wave mixing measurements with application to viscous and non-viscous solid material characterization when the immersion ultrasonic technique is used. Therefore, the main objective of this work is the analysis-based development and implementation of noncollinear wave mixing techniques for material properties evaluation using immersion ultrasonic measurements. To achieve this objective, the following research tasks are identified:

1. Theoretical and experimental investigation of noncollinear wave interaction in an isotropic solid.

${ }^{1}$ F. R. Rollins, L. H. Taylor, and P. H. Todd, "Ultrasonic study of three-phonon interactions. II. Experimental results,” Phys. Rev. 136, A597-A601 (1964). 
2. Selection of the optimum measurement conditions for the noncollinear wave mixing measurements.

3. Determination of material properties.

4. Application and validation of the measurement method in material processing.

5. Application and validation of the measurement method in material performance.

The thesis consists of the introduction, five main chapters, an overall discussion, general conclusions and recommendations. An overview of the five main chapters (2-6) is given below:

Chapter 2 starts with a review of the noncollinear plane wave interaction theory in an isotropic solid. Subsequently, an analytical derivation of the amplitude coefficients of a nonlinear wave is presented for all possible wave interaction cases in isotropic solids. The third-order elastic constants are presented for polyvinyl chloride (PVC). The use of the presented coefficients and constants is illustrated by a prediction of the nonlinear wave amplitudes for PVC, including discussion of the far-field beamwidth of nonlinear waves.

Chapter 3 presents a new measurement method for a bulk wave phase velocity measurement in an isotropic solid. An analytical formulation of the method is presented which is based on the noncollinear wave mixing theory. The presented method is verified experimentally by measuring the phase velocity of the shear wave in aluminum. The measurements are performed using two different noncollinear wave interactions and employing the immersion ultrasonics. Measurement uncertainties are analyzed using a Monte Carlo method. The measured phase velocity can be used to determine elastic properties of an isotropic material.

Chapter 4 deals with measurements of transitions in thermoplastics and thermosets. The first part of the chapter presents an analysis of two different noncollinear wave interactions which are most attractive to practical experiments when the immersion ultrasonics is used. A procedure for selecting the optimum measurement conditions is presented in detail, and illustrated with a number of noncollinear wave mixing situations in aluminum and PVC.

The second part of Chapter 4 presents two measurement methods and experimental results for the measurement of the physical ageing dynamics in thermoplastics and the epoxy cure dynamics in a thin layer (thickness about $0.2 \mathrm{~mm}$ ). The process of physical ageing is measured in PVC and polymethyl methacrylate (PMMA), and the results can be used to detect the actual state of the physical ageing in these materials. These results are verified using linear ultrasonics, and it is shown that the linear ultrasonics technique is far less sensitive to physical ageing in thermoplastics.

Measurements of the isothermal epoxy cure dynamics are performed at $24.3^{\circ} \mathrm{C}$ and $40{ }^{\circ} \mathrm{C}$ conditions, using the noncollinear wave mixing technique. Four typical phase transition points are determined from the measurement data: maximum viscosity point, gel onset point, gel peak and vitrification points. The ultrasonic results are interpreted using dynamic mechanical analysis (DMA).

The last part of Chapter 4 presents a comparison of C-scan images obtained using linear and nonlinear ultrasonics. It is shown that the nonlinear ultrasonics, based on the noncollinear wave mixing, is also suitable for conventional nondestructive testing applications. 
Chapter 5 deals with the analysis of isothermal epoxy cure monitoring by means of three different measurement techniques: nonlinear ultrasonics, DMA and differential scanning calorimetry (DSC). Experimental results and their analysis are presented. Advantages and disadvantages of all three techniques are analyzed and discussed. It is shown that the nonlinear ultrasonic technique, based on the noncollinear wave mixing, has advantages over isothermal epoxy cure monitoring by means of DMA and DSC techniques.

Chapter 6 presents experimental results for the detection of physical ageing in laboratory and field PVC specimens. Results are presented for linear and nonlinear ultrasonic measurements. The results show that dispersion measurements are not suitable for detection of the physical ageing state in PVC, but these measurements are suitable to detect differences between different grades of PVC.

Chapter 7 covers a brief discussion of results presented in this study. Chapter 8 follows with the general conclusions. Finally, this work ends with recommendations for further research in the field of nonlinear ultrasonics with applications to material characterization. These recommendations are given in Chapter 9.

Chapters 2, 4, 5 and 6 were published in peer reviewed scientific journals, whereas Chapter 3 was published in annual conference proceedings. This implies that some duplication of background information in the chapters cannot be prevented.

Part of this research was funded via the Innowator project IWA-08019 as funded by the Dutch Ministry of Economic Affairs by means of Agentschap NL. This support is gratefully acknowledged.

\section{Approbation of the results}

The developed nonlinear ultrasonic measurement method for measurement of physical ageing in thermoplastic polymers was utilized in the 'Innowator' project IWA08019. It was shown that the nonlinear ultrasonic measurements, based on the noncollinear wave mixing, are suitable for detection of the actual state of the physical ageing in PVC pipelines. The effectiveness of the method was demonstrated using laboratory and field PVC specimens.

\section{Publications}

During research the following publications were prepared and published related to the nonlinear ultrasonics:

\section{Journal articles}

1. V. Koissin, A. Demčenko, V. A. Korneev, Isothermal epoxy-cure monitoring using nonlinear ultrasonics, International Journal of Adhesion and Adhesives, Vol. 52, p. 11-18, 2014.

2. V. A. Korneev, A. Demčenko, Possible second-order nonlinear interactions of plane waves in an elastic solid, Journal of Acoustical Society of America, Vol. 135, p. 591-598, 2014. 
3. A. Demčenko, V. Koissin, V. A. Korneev, Noncollinear wave mixing for measurement of dynamic processes in polymers: Physical ageing in thermoplastics and epoxy cure, Ultrasonics, Vol. 54, p. 684-693, 2014.

4. A. Demčenko, R. Akkerman, P. B. Nagy, R. Loendersloot, Non-collinear wave mixing for non-linear ultrasonic detection of physical ageing in PVC, NDT and E International, Vol. 49, p. 34-39, 2012.

\section{Conference proceedings}

1. A. Demčenko, Non-collinear wave mixing for a bulk wave phase velocity measurement in an isotropic solid, In: Proceedings of the IEEE International Ultrasonics Symposium (IUS) 2012, p. 1437-1440, 2012.

2. A. Demčenko, M. Ravanan, H. A. Visser, R. Loendersloot, R. Akkerman, Investigation of PVC physical ageing in field test specimens using ultrasonic and dielectric measurements, In: Proceedings of the IEEE International Ultrasonics Symposium (IUS) 2012, p. 1909-1912, 2012. 


\title{
Chapter 2
}

\section{Possible second-order nonlinear interactions of plane waves in an isotropic solid 1}

\begin{abstract}
There exist ten possible nonlinear elastic wave interactions for an isotropic solid described by three constants of the third order. All other possible interactions out of 54 combinations (triplets) of interacting and resulting waves are prohibited, because of restrictions of various kinds. The considered waves include longitudinal and two shear waves polarized in the interacting plane and orthogonal to it. The amplitudes of scattered waves have simple analytical forms, which can be used for experimental setup and design. The analytic results are verified by comparison with numerical solutions of initial equations. Amplitude coefficients for all ten interactions are computed as functions of frequency for polyvinyl chloride, together with interaction and scattering angles. The nonlinear equation of motion is put into a general vector form and can be used for any coordinate system.
\end{abstract}

\footnotetext{
${ }^{1}$ Reproduced from: V. A. Korneev and A. Demčenko "Possible second-order nonlinear interactions of plane waves in an isotropic solid,” J. Acoust. Soc Am. 135, 591-598 (2014).
} 


\subsection{Introduction}

Nonlinearity is defined as any deviation from the linear law regarding the transformation of an input signal, due to its propagation through a carrying system. Nonlinearity may appear in a signal at any stage: at elastic wave excitation, at wave propagation through elastic material, through a registration device, or also at the stage of numerical data processing. Here we consider nonlinearity arising as a result of the properties inherent in elastic material. Elastic nonlinearity of different materials, including rock samples, has been observed for ultrasonic frequencies by many authors [1-9]. In particular, it has been shown that the velocity of elastic waves changes with static deformation and hydrostatic pressure. This phenomenon, known as acoustoelasticity, is widely used for measurements of third-order elastic constants in solids. Waves of mixed frequencies as a result of nonlinear wave interaction have also been reported [10-17]. The fundamental equations of nonlinear elastic theory, by Murnaghan [18], effectively describe such classical nonlinear phenomena as harmonics generation and resonant wave scattering.

The results of this theory are well known among solid state physicists, but most of the information is scattered. Probably the most comprehensive description of the theory can be found in a monograph by Zarembo and Krasil'nikov [19] published in Russian. All possible nonlinear interactions were subsequently presented in a report by Korneev et al [20]. In response to the recent growing interest in this subject, and a new way of ultrasonic measurements using nonlinear interactions [16, 17], we reconsidered the subject of nonlinear interactions, put them in a more general analytical form and carefully rederived scattering coefficients because in the previous publications their expressions contain some typos and errors. The basic nonlinear equations are put in a vector form, which makes them easy to use in an arbitrary coordinate system. Besides basic equations, this paper presents analytical solutions for all possible nonlinear interactions of collimated beams in a volume of nonlinear elastic material. These solutions are used in Ref. [17] for laboratory observations of material nonlinearity, for nondestructive evaluation and testing purposes.

\subsection{Equations of motion}

The simplest extension of linear dynamic elasticity to a nonlinear (isotropic) form requires addition of three third order elastic (TOE) constants- $l, n$ and $m$ (Murnaghan notation [18]) —in addition to Lamé parameters $\lambda$ and $\mu$. However, in most previous publications, investigators have used other sets of nonlinear parameters $A, B$ and $C$ after Landau and Lifschitz [21], which have simple relations with the previous set

$A=n, B=m-n / 2, C=l-m+n / 2$.

Assuming elastic deformation in a solid, and that the displacement vector

$\mathbf{u}=\mathbf{u}(x, y, z)=\mathbf{u}\left(x_{1}, x_{2}, x_{3}\right)=\left(u_{1}\left(x_{1}, x_{2}, x_{3}\right), u_{2}\left(x_{1}, x_{2}, x_{3}\right), u_{3}\left(x_{1}, x_{2}, x_{3}\right)\right)$

is continuous together with its spatial derivatives, the stress components have the form 


$$
\begin{aligned}
\sigma_{i k}=\lambda \frac{\partial u_{s}}{\partial x_{s}} \delta_{i k}+ & \mu\left(\frac{\partial u_{i}}{\partial x_{k}}+\frac{\partial u_{k}}{\partial x_{i}}\right)+\left(\mu+\frac{A}{4}\right)\left(\frac{\partial u_{s}}{\partial x_{i}} \frac{\partial u_{s}}{\partial x_{k}}+\frac{\partial u_{k}}{\partial x_{s}} \frac{\partial u_{i}}{\partial x_{s}}+\frac{\partial u_{s}}{\partial x_{k}} \frac{\partial u_{i}}{\partial x_{s}}\right) \\
& +\frac{(B+\lambda)}{2}\left(\left(\frac{\partial u_{s}}{\partial x_{j}}\right)^{2} \delta_{i k}+2 \frac{\partial u_{i}}{\partial x_{k}} \frac{\partial u_{s}}{\partial x_{s}}\right)+\frac{A}{4} \frac{\partial u_{k}}{\partial x_{s}} \frac{\partial u_{s}}{\partial x_{i}} \\
& +\frac{B}{2}\left(\frac{\partial u_{s}}{\partial x_{j}} \frac{\partial u_{j}}{\partial x_{s}} \delta_{i k}+2 \frac{\partial u_{k}}{\partial x_{i}} \frac{\partial u_{s}}{\partial x_{s}}\right)+C\left(\frac{\partial u_{s}}{\partial x_{s}}\right)^{2} \delta_{i k} .
\end{aligned}
$$

(Here and below, repeated index $s$ and/or $j$ means summation.)

The equation of motion has the form

$\rho \frac{\partial^{2} u_{i}}{\partial t^{2}}=\frac{\partial \sigma_{i k}}{\partial x_{k}}$

or

$\rho \frac{\partial^{2} u_{i}}{\partial t^{2}}-\mu \frac{\partial^{2} u_{i}}{\partial x_{k}^{2}}-(\lambda+\mu) \frac{\partial^{2} u_{k}}{\partial x_{i} \partial x_{k}}=F_{i}$,

where $F_{i}$, the $i^{\text {th }}$ component of a "force" $\mathbf{F}$, is given by

$$
\begin{aligned}
F_{i}=C_{1}\left(\frac{\partial^{2} u_{s}}{\partial x_{k}^{2}} \frac{\partial u_{s}}{\partial x_{i}}\right. & \left.+\frac{\partial^{2} u_{s}}{\partial x_{k}^{2}} \frac{\partial u_{i}}{\partial x_{s}}+2 \frac{\partial^{2} u_{i}}{\partial x_{s} \partial x_{k}} \frac{\partial u_{s}}{\partial x_{k}}\right) \\
& +C_{2}\left(\frac{\partial^{2} u_{s}}{\partial x_{i} \partial x_{k}} \frac{\partial u_{s}}{\partial x_{k}}+\frac{\partial^{2} u_{k}}{\partial x_{s} \partial x_{k}} \frac{\partial u_{i}}{\partial x_{s}}\right)+C_{3} \frac{\partial^{2} u_{i}}{\partial x_{k}^{2}} \frac{\partial u_{s}}{\partial x_{s}} \\
& +C_{4}\left(\frac{\partial^{2} u_{k}}{\partial x_{s} \partial x_{k}} \frac{\partial u_{s}}{\partial x_{i}}+\frac{\partial^{2} u_{s}}{\partial x_{i} \partial x_{k}} \frac{\partial u_{k}}{\partial x_{s}}\right)+C_{5} \frac{\partial^{2} u_{k}}{\partial x_{i} \partial x_{k}} \frac{\partial u_{s}}{\partial x_{s}},
\end{aligned}
$$

and has a second-order value in size. In equation (2.6), the following notation is used:

$C_{1}=\mu+\frac{A}{4}, C_{2}=\lambda+\mu+\frac{A}{4}+B, C_{3}=\frac{A}{4}+B, C_{4}=B+2 C, C_{5}=\lambda+B$.

Expression (2.6) for $(i=1,2,3)$ can be converted into a general vector form

$\mathbf{F}=C_{1} \mathbf{W}_{1}+C_{2} \mathbf{W}_{2}+C_{3} \mathbf{W}_{3}+C_{4} \mathbf{W}_{4}+C_{5} \mathbf{W}_{5}$

where

$$
\begin{aligned}
\mathbf{W}_{1}= & {[\Delta \mathbf{u} \times \nabla \times \mathbf{u}]+\frac{1}{2} \nabla \Delta(\mathbf{u u})+\nabla \mathbf{u} \Delta \mathbf{u}-\Delta[\mathbf{u} \times \nabla \times \mathbf{u}]+\nabla \times[\mathbf{u} \times \Delta \mathbf{u}] } \\
& \quad-\mathbf{u} \Delta \nabla \mathbf{u},
\end{aligned}
$$


which is ready to use in systems other than Cartesian coordinate system. For most solids, the values of the nonlinear constants $(A, B, C)$ are significantly larger than those of constants $\lambda$ and $\mu$, which may be neglected in the nonlinear parts of wave solutions.

\subsection{Nonlinear interaction of elastic waves}

Under some circumstances, elastic waves with different frequencies $\omega_{1}$ and $\omega_{2}$ propagating in a solid may interact and produce secondary waves of mixed (sum or difference) frequencies $\omega_{g}$. Theoretically, this problem is similar to phonon-phonon interactions, a subject of quantum mechanics. The conditions for such resonant interactions existing are:

$\omega_{g}=\omega_{1} \pm \omega_{2}$

$\mathbf{k}_{g}=\mathbf{k}_{1} \pm \mathbf{k}_{2}$

where (2.15b) includes the corresponding wave vectors. The + sign in (2.15) corresponds to the case of sum resonant frequencies; the - sign corresponds to the case of difference resonant frequencies. Therefore, condition (2.15a) defines the frequencies of scattered waves, while condition (2.15b) defines their direction of propagation. In the case of a liquid medium without dispersion, condition $(2.15 \mathrm{~b})$ means that interaction is possible for collinear waves only. For solids, because of the existence of two velocities of propagation, a variety of different resonance interactions become possible. The geometries of sum and difference resonance interactions are illustrated in Fig. 2.1. The interaction angle $\alpha$ is a solution of the equation

$\left(\frac{\omega_{g}}{v_{g}}\right)^{2}=\left(\frac{\omega_{1}}{v_{1}}\right)^{2}+\left(\frac{\omega_{2}}{v_{2}}\right)^{2} \pm 2 \frac{\omega_{1}}{v_{1}} \frac{\omega_{2}}{v_{2}} \cos \alpha$,

which is the result of (2.15b). Velocities $v_{1}, v_{2}, v_{3}$ might be equal to either $v_{\mathrm{L}}$ or $v_{\mathrm{S}}$, depending on the types of interaction, where propagation velocities

$v_{\mathrm{L}}=\sqrt{\frac{\lambda+2 \mu}{\rho}}$ and $v_{\mathrm{S}}=\sqrt{\frac{\mu}{\rho}}$

correspondingly relate to longitudinal and shear waves in an elastic medium with material density $\rho$.

The two equations (2.15), together with conditions,

$-1 \leq \cos \alpha \leq 1$

might not be satisfied for some combinations of waves and frequencies, which means that certain types of interactions cannot exist. 

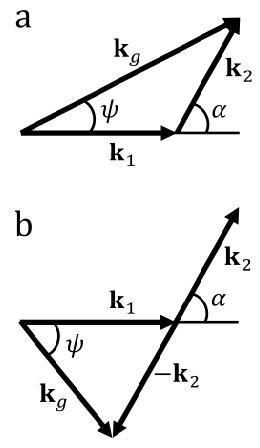

Figure 2.1. Angle definitions for sum (a) and difference (b) frequency generation.

The propagation angle $\psi$ of the resonant wave is defined by geometry in Fig. 2.1, and can be found from the following equation:

$\operatorname{tg} \psi=\frac{ \pm \frac{v_{1}}{v_{2}} d \sin \alpha}{1 \pm \frac{v_{1}}{v_{2}} d \cos \alpha}$,

where

$d=\frac{\omega_{2}}{\omega_{1}}$.

Basic expressions for the interaction of elastic waves in an isotropic solid were obtained by Jones and Kobett [22], Taylor and Rollins [23], Zarembo and Krasil'nikov [11]. They considered the sum of two incident plane waves:

$\mathbf{u}_{0}=A_{1} \cos \left(\omega_{1} t-\mathbf{k}_{1} \mathbf{r}\right) \mathbf{a}_{1}+A_{2} \cos \left(\omega_{2} t-\mathbf{k}_{2} \mathbf{r}\right) \mathbf{a}_{2}$

with amplitudes $A_{j}$ and polarizations $\mathbf{a}_{j},(j=1,2)$, which are substituted into the equation of motion (2.5). Polarization vectors $\mathbf{a}_{j}$ are parallel to wave-number vectors $\mathbf{k}_{j}$ for $\mathrm{L}$ waves and orthogonal to them for $S$ waves. S- waves with components polarized in the interaction plane will be referred as SV, while shear waves with polarization orthogonal to this plane will be referred as SH. Denoting by $\mathbf{p}$ that part of $\mathbf{F}$ from equation (2.6) which describes the interaction of waves, it can be written in the form

$$
\begin{aligned}
\mathbf{p}(r, t)=-A_{1} A_{2} & \left(\mathbf{I}^{+} \sin \left[\left(\omega_{1}+\omega_{2}\right) t-\left(\mathbf{k}_{1}+\mathbf{k}_{2}\right) \mathbf{r}\right]\right. \\
& \left.+\mathbf{I}^{-} \sin \left[\left(\omega_{1}-\omega_{2}\right) t-\left(\mathbf{k}_{1}-\mathbf{k}_{2}\right) \mathbf{r}\right]\right),
\end{aligned}
$$

where 


$$
\begin{aligned}
\mathbf{I}^{ \pm}=\frac{1}{2} C_{1}\left[\left(\mathbf{a}_{1} \mathbf{a}_{2}\right)\right. & \left(k_{2}^{2} \mathbf{k}_{1} \pm k_{1}^{2} \mathbf{k}_{2}\right)+\left(\mathbf{a}_{2} \mathbf{k}_{1}\right) k_{2}\left(k_{2} \pm 2 k_{1} \cos \alpha\right) \mathbf{a}_{1} \\
& \left.+\left(\mathbf{a}_{1} \mathbf{k}_{2}\right) k_{1}\left(2 k_{2} \cos \alpha \pm k_{1}\right) \mathbf{a}_{2}\right] \\
& +\frac{1}{2} C_{2} k_{1} k_{2} \cos \alpha\left[\left(\mathbf{a}_{1} \mathbf{a}_{2}\right)\left(\mathbf{k}_{2} \pm \mathbf{k}_{1}\right)+\left(\mathbf{a}_{2} \mathbf{k}_{2}\right) \mathbf{a}_{1} \pm\left(\mathbf{a}_{1} \mathbf{k}_{1}\right) \mathbf{a}_{2}\right] \\
& +\frac{1}{2} C_{3}\left[\left(\mathbf{a}_{1} \mathbf{k}_{2}\right)\left(\left(\mathbf{a}_{2} \mathbf{k}_{2}\right) \pm\left(\mathbf{a}_{2} \mathbf{k}_{1}\right)\right) \mathbf{k}_{1}\right. \\
& \left.+\left(\mathbf{a}_{2} \mathbf{k}_{1}\right)\left(\left(\mathbf{a}_{1} \mathbf{k}_{2}\right) \pm\left(\mathbf{a}_{1} \mathbf{k}_{1}\right)\right) \mathbf{k}_{2}\right] \\
& +\frac{1}{2} C_{4}\left(\mathbf{a}_{2} \mathbf{k}_{2}\right)\left[\left(\mathbf{a}_{1} \mathbf{k}_{2}\right) \mathbf{k}_{2} \pm\left(\mathbf{a}_{1} \mathbf{k}_{1}\right) \mathbf{k}_{1}\right] \\
& +\frac{1}{2} C_{5}\left[\left(\mathbf{a}_{1} \mathbf{k}_{1}\right) k_{2}^{2} \mathbf{a}_{2} \pm\left(\mathbf{a}_{2} \mathbf{k}_{2}\right) k_{1}^{2} \mathbf{a}_{1}\right] .
\end{aligned}
$$

Expressions of the forms (xy) in equation (2.23) and later denote scalar products.

If there is a volume $V$ inside the medium where the primary beams are well collimated, and if it is assumed that waves interact only in this volume, it is possible to obtain a solution for the scattered secondary field in the far field:

$\mathbf{u}_{1}(r, t)=\frac{A_{1} A_{2}}{4 \pi r \rho} \sum_{\xi=+,-}\left(\frac{\left(\mathbf{I}^{\xi} \hat{\mathbf{r}}\right) \hat{\mathbf{r}}}{v_{L}^{2}} V_{L}^{\xi}+\frac{\mathbf{I}^{\xi}-\left(\mathbf{I}^{\xi} \hat{\mathbf{r}}\right) \hat{\mathbf{r}}}{v_{S}^{2}} V_{S}^{\xi}\right)$,

where $\mathbf{r}=r \hat{\mathbf{r}},|\hat{\mathbf{r}}|=1$ is the radius vector from the center point of the interaction region and observation point. Here and later, $\xi=$ "+" indicates the sum frequency, and $\xi="-"$ indicates the difference frequency interactions.

Integrals

$V_{g}^{ \pm}=\int_{V} \sin \left(\Delta_{g}^{ \pm}-\left(\mathbf{k}_{1} \pm \mathbf{k}_{2}-\frac{\omega_{1} \pm \omega_{2}}{v_{g}} \hat{\mathbf{r}}\right) \mathbf{r}^{\prime}\right) d V$

from equation (2.24) are referred to as volume factors, and

$\Delta_{g}^{ \pm}=\left(\omega_{1} \pm \omega_{2}\right)\left(\frac{r}{v_{g}}-t\right)$

is the scattering phase. In equation (2.25) $\mathbf{r}^{\prime}$ is the radius vector of integration inside the volume $V$ (geometry shown in Fig. 2.2). Symbol $g$ can be either "L" or "S", denoting the type of scattered wave.

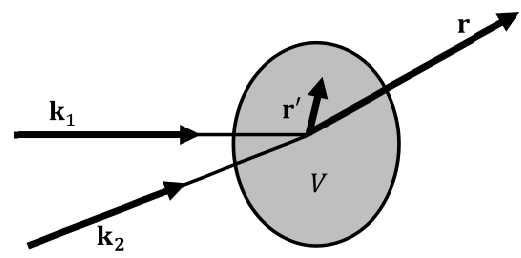

Figure 2.2. Interaction of two plane waves in a volume $V$ of a nonlinear elastic material. 
Equation (2.24) has four terms corresponding to both sum and difference frequencies for $\mathrm{L}$ and $\mathrm{S}$ waves. As we integrate over $d V$, the integrand in equation (2.25) oscillates with frequencies determined by the coefficients of $\mathbf{r}^{\prime}$, and the results of any integration will depend on just how the waves fit into the region $V$. Scattered waves have natural polarizations: parallel to $\mathbf{r}$ for L- waves and orthogonal to $\mathbf{r}$ for S-waves.

If we satisfy resonant conditions (2.15) by choosing an appropriate direction $\hat{\mathbf{r}}=\hat{\mathbf{r}}_{g}$, the corresponding coefficient of $\mathbf{r}^{\prime}$ in (2.25) becomes equal to zero, and the amplitude of the scattered wave in this direction becomes proportional to the volume $V$ of integration. From (2.24), it also follows that amplitudes of the scattered waves are proportional to their projections in the direction $\mathbf{a}_{g}^{\xi}$, which is the unit vector of the natural polarization of the wave. For L-waves, $\mathbf{a}_{g}^{\xi}$ is parallel to $\hat{\mathbf{r}}_{g}$; for $\mathrm{S}$-waves, it is perpendicular to this vector. That means that the resonant scattering amplitude may be zero even if resonant conditions (2.15) are satisfied. A zero value of the scattering amplitude due to polarization will be referred to as polarization restriction.

All types of elastic-wave resonant interactions are listed in Table 2.1, where signs " $\mathrm{x}$ " and " $\overline{\mathrm{x}}$ " signify that interaction is possible, and sign " $=$ " signifies that interaction is possible only when interacting waves are collinear. Sign " $\overline{\mathrm{x}}$ " indicates that interaction is also possible when waves propagate antilinearly (in opposite directions). All other types of interactions are forbidden. Sign "O" marks interactions that are forbidden because of polarization restrictions; all others are forbidden because the resonant conditions (2.23) for them cannot be satisfied. Only 10 out of 54 potential interactions are possible. Sum frequency resonance exists only for compressional scattered waves. Sum frequency interactions for $\mathrm{L}+\mathrm{SV} \rightarrow \mathrm{L}$ and $\mathrm{SV}+\mathrm{L} \rightarrow \mathrm{L}$ combinations are reciprocal.

Table 2.1. Forbidden and allowed scattering processes for an isotropic solid: " $=$ " - possible only when waves are collinear (propagate in one direction), " $\mathrm{x}$ " and " $\overline{\mathrm{x}}$ " - scattering possible for certain range of parameters, where " $\overline{\mathrm{x}}$ " also means that antilinear interaction is possible (waves propagate in opposite directions), "O" - polarization restriction, blank space - interaction restriction.

\begin{tabular}{llllllll}
\hline \hline & & \multicolumn{5}{c}{ Scattered waves } \\
\cline { 3 - 7 } & & $\omega_{g}=\omega_{1}+\omega_{2}$ & $\omega_{g}=\omega_{1}+\omega_{2}$ \\
\hline$N$ & Interaction waves & $\mathrm{L}$ & $\mathrm{SV}$ & $\mathrm{SH}$ & $\mathrm{L}$ & $\mathrm{SV}$ & $\mathrm{SH}$ \\
\hline 1 & $\mathrm{~L}\left(\omega_{1}\right)$ and $\mathrm{L}\left(\omega_{2}\right)$ & $=$ & & & $=$ & $\overline{\mathrm{x}}$ & $\mathrm{O}$ \\
2 & $\mathrm{~L}\left(\omega_{1}\right)$ and SV $\left(\omega_{2}\right)$ & $\overline{\mathrm{x}}$ & & & $\mathrm{x}$ & $\overline{\mathrm{x}}$ & $\mathrm{O}$ \\
3 & $\mathrm{SV}\left(\omega_{1}\right)$ and $\mathrm{L}\left(\omega_{2}\right)$ & $\mathrm{x}$ & & & & & \\
4 & $\mathrm{SV}\left(\omega_{1}\right)$ and SV $\left(\omega_{2}\right)$ & $\overline{\mathrm{x}}$ & $\mathrm{O}$ & $\mathrm{O}$ & & $\mathrm{O}$ & $\mathrm{O}$ \\
5 & $\mathrm{SH}\left(\omega_{1}\right)$ and $\mathrm{SH}\left(\omega_{2}\right)$ & $\overline{\mathrm{x}}$ & $\mathrm{O}$ & $\mathrm{O}$ & & $\mathrm{O}$ & $\mathrm{O}$ \\
6 & $\mathrm{~L}\left(\omega_{1}\right)$ and SH $\left(\omega_{2}\right)$ & $\mathrm{O}$ & & & $\mathrm{O}$ & $\mathrm{O}$ & $\overline{\mathrm{x}}$ \\
7 & $\mathrm{SH}\left(\omega_{1}\right)$ and $\mathrm{L}\left(\omega_{2}\right)$ & $\mathrm{O}$ & & & & & \\
8 & $\mathrm{SH}\left(\omega_{1}\right)$ and SV $\left(\omega_{2}\right)$ & $\mathrm{O}$ & $\mathrm{O}$ & $\mathrm{O}$ & & $\mathrm{O}$ & $\mathrm{O}$ \\
9 & $\mathrm{SV}\left(\omega_{1}\right)$ and $\mathrm{SH}\left(\omega_{2}\right)$ & $\mathrm{O}$ & $\mathrm{O}$ & $\mathrm{O}$ & & $\mathrm{O}$ & $\mathrm{O}$ \\
\hline \hline
\end{tabular}

A similar table of allowed and forbidden scattering processes for an isotropic solid published in the Zarembo and Krasil'nikov [11] contains 18 possible interactions. We believe their results are partly in error. Taylor and Rollins [23] have presented five possible interactions, omitting the problem of separation of SV and SH polarization for 
shear waves. Childress and Hambrick [24] present 8 interactions, while Holt and Ford [25] found 10 interactions by numerical search using parameters for copper.

If resonant conditions (2.15) are satisfied for any one type of interaction, the scattered field from (2.24) may be rewritten in the form

$\mathbf{u}_{1}(r, t)=\mathbf{a}_{g}^{\xi} W_{g}^{\xi} \frac{A_{1} A_{2}}{r} V_{g}^{\xi}$,

with amplitude coefficient

$W_{g}^{\xi}=\frac{\left(\mathbf{I}^{\xi} \mathbf{a}_{g}^{\xi}\right)}{4 \pi v_{g}^{2} \rho}$.

From (2.28), it is seen that the scattering amplitude is proportional to the coefficient $W_{g}^{\xi}$ with dimension length ${ }^{-3}$ and to the scattering volume $V_{g}^{\xi}$, so the product of these quantities is dimensionless.

Analytical expressions for $W_{g}^{\xi}$ of all ten possible scattering interactions are listed in Table 2.2 together with expressions for interacting angle, $\alpha$ and limits, $d_{\min }, d_{\max }$ of the frequency ratio $d$. In addition, the following notations are used:

$D_{g}=\frac{d}{4 \pi(\lambda+2 \mu)}\left(\frac{\omega_{1}}{v_{g}}\right)^{3}, \gamma=\sqrt{\frac{\mu}{\lambda+2 \mu}}=\frac{v_{\mathrm{S}}}{v_{\mathrm{L}}}$.

Approximate expressions for scattering amplitudes in Table 2.2 are derived from exact formulas, under the assumption that in coefficients (2.7) we may neglect Lamé constants for components containing nonlinear TOE constants. These expressions were verified by comparison with numerical solutions for equations (2.28) and (2.23). Note, that the Lamé constants are involved in the approximate $W_{g}^{\xi}$ expressions via coefficient $D_{g}$ (equation (2.29)). 
Table 2.2. Nonlinear scattering coefficients of two plane elastic wave interaction.

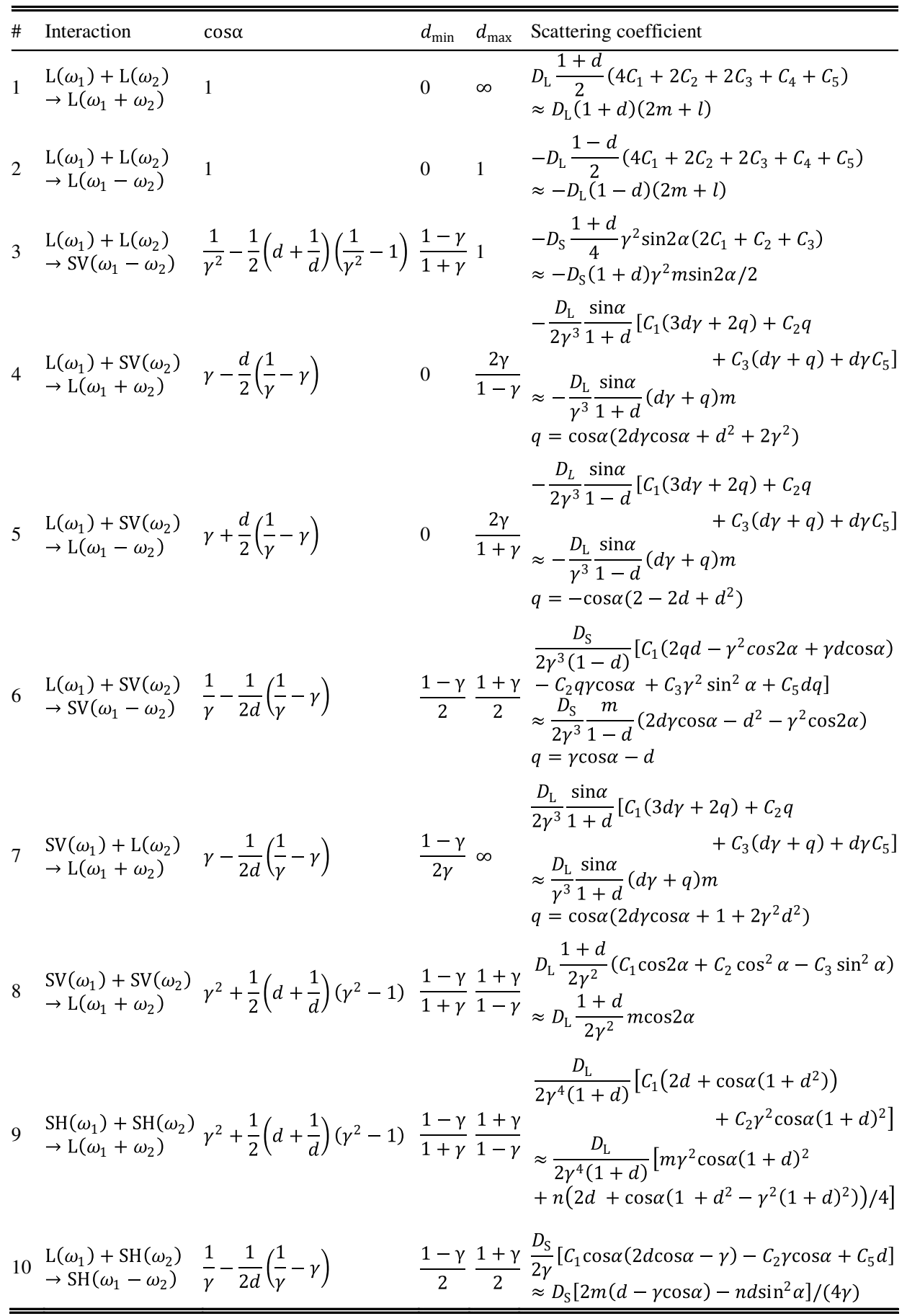




\subsection{Scattering beamwidth}

The scattered waves, given by (2.24), appear in the form of conical beams with vertexes at the interaction zone and maximum intensity in the direction $\hat{\mathbf{r}}_{\mathbf{r}}$. To investigate the amplitudes of the scattering beams as a function of observation position, it is convenient to assume that the interaction volume has the shape of a sphere of radius $R$. Any volume factor from (2.25) may then be reduced to the form:

$V_{g}^{ \pm}=\Delta_{g}^{ \pm} \int_{V} \sin a\left(\hat{\mathbf{r}} \mathbf{r}^{\prime}\right) d V=3 V \frac{j_{1}(a R)}{a R} \Delta_{g}^{ \pm}$,

$a=\left|\mathbf{k}_{1} \pm \mathbf{k}_{2}-\frac{\omega_{1} \pm \omega_{2}}{v_{g}} \hat{\mathbf{r}}\right|$

where $V=4 \pi / 3 R^{3}$ is the volume of the sphere, $j_{1}(x)$ is the spherical Bessel function of the first order.

If $\theta$ is the angle between resonant scattering direction $\hat{\mathbf{r}}_{g}$, and observation direction $\hat{\mathbf{r}}$, we obtain

$a R=\frac{2 \pi R}{\lambda_{g}} \sqrt{2(1-\cos \theta)}$,

where $\lambda_{g}$ is the wavelength of the scattered wave. Assuming the interaction volume is spherical, this analysis shows that the volume factor is proportional to the volume of the sphere. Using the asymptotic approximation for spherical Bessel functions in (2.30), we may estimate the total beamwidth $\theta_{w}$ of the scattering beam, where the amplitude of the scattering beam is not less than one half of its maximum. The result is

$\theta_{w} \approx 2 \arccos \left(1-\frac{1}{10}\left(\frac{\lambda_{g}}{R}\right)^{2}\right)$.

For small angles $\left(\theta_{w}<0.1\right)(2.33)$ reduces to

$\theta_{w} \approx \frac{\lambda_{g}}{R}$

\subsection{Numerical results}

Equations from Table 2.2 allow computation of the interaction angle, scattering angle, and scattering coefficient for any set of elastic parameters. Here we apply a set of parameters for polyvinyl chloride (PVC), as follows: $\lambda=3.64 \mathrm{GPa}, \mu=1.83 \mathrm{GPa}, l=$ $-33.43 \mathrm{GPa}, m=-20.88 \mathrm{GPa}, n=-15.86 \mathrm{GPa}$ and $\rho=1350 \mathrm{~kg} / \mathrm{m}^{3}$. The third-order elastic constants are measured using an acousto-elastic measurement method. Amplitude coefficients $W_{g}^{\xi}$ as well as interaction $\alpha$ and scattering $\gamma$ angles for all possible (ten) interactions from Tables 2.1 and 2.2, are shown in Figs. 2.3-2.12 as functions of the frequency ratio $d=\omega_{2} / \omega_{1}$. The calculations are performed when $\omega_{1}=2 \pi \times 1 \mathrm{MHz}$. 

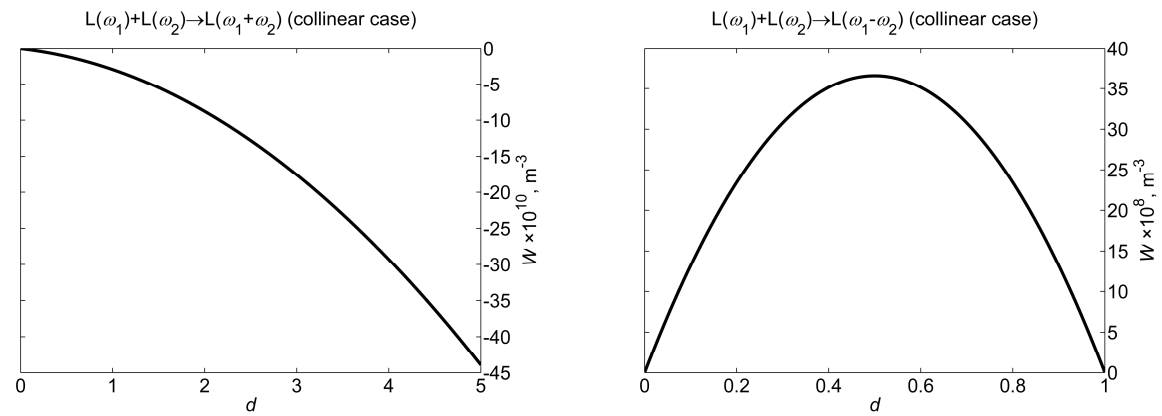

Figure 2.3. Interaction $\mathrm{L}\left(\omega_{1}\right)+\mathrm{L}\left(\omega_{2}\right) \rightarrow \mathrm{L}\left(\omega_{1}+\omega_{2}\right)$.

Figure 2.4. Interaction $\mathrm{L}\left(\omega_{1}\right)+\mathrm{L}\left(\omega_{2}\right) \rightarrow \mathrm{L}\left(\omega_{1}-\omega_{2}\right)$.
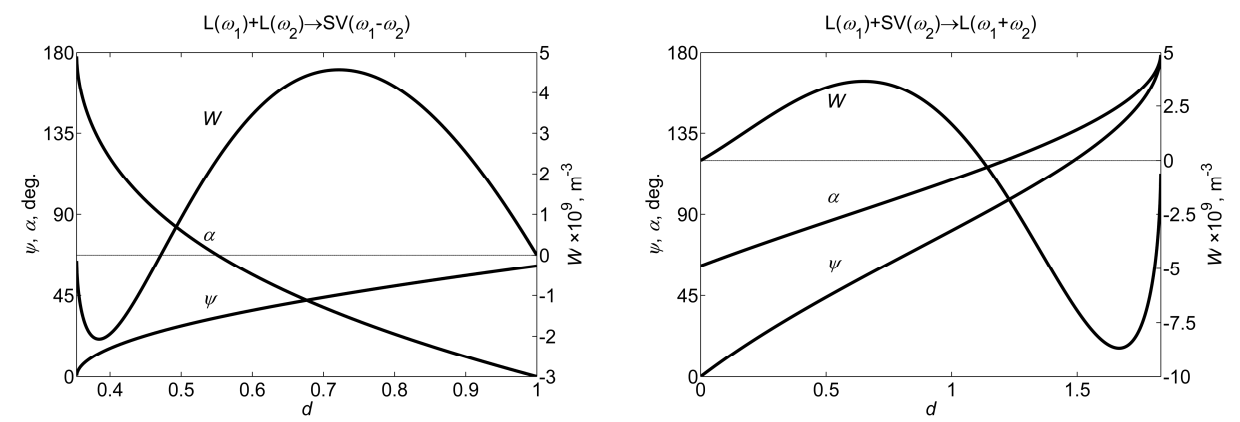

Figure 2.5. Interaction $\mathrm{L}\left(\omega_{1}\right)+\mathrm{L}\left(\omega_{2}\right) \rightarrow \mathrm{SV}\left(\omega_{1}-\omega_{2}\right)$. Figure 2.6. Interaction $\mathrm{L}\left(\omega_{1}\right)+\mathrm{SV}\left(\omega_{2}\right) \rightarrow \mathrm{L}\left(\omega_{1}+\omega_{2}\right)$.
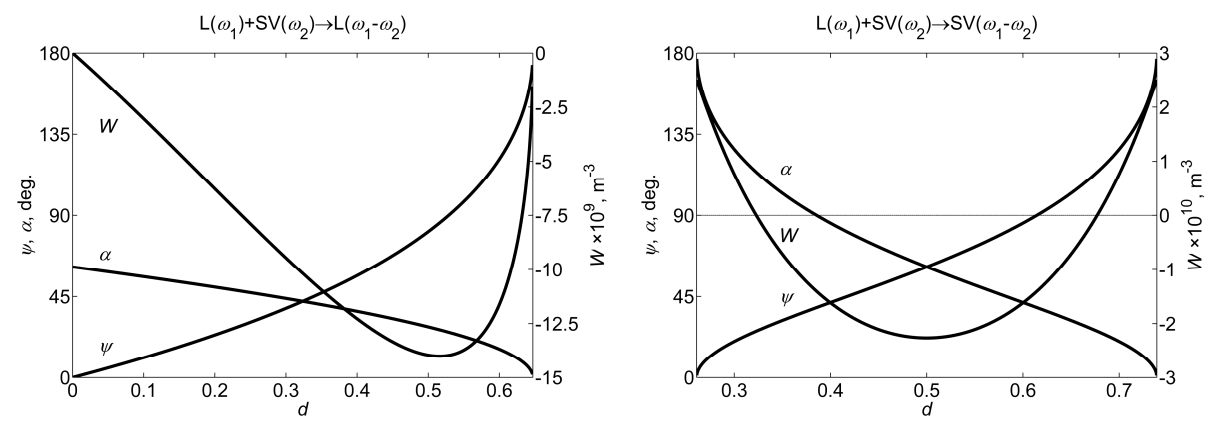

Figure 2.7. Interaction $L\left(\omega_{1}\right)+\operatorname{SV}\left(\omega_{2}\right) \rightarrow \mathrm{L}\left(\omega_{1}-\omega_{2}\right)$. Figure 2.8. $\mathrm{L}\left(\omega_{1}\right)+\operatorname{SV}\left(\omega_{2}\right) \rightarrow \operatorname{SV}\left(\omega_{1}-\omega_{2}\right)$. 

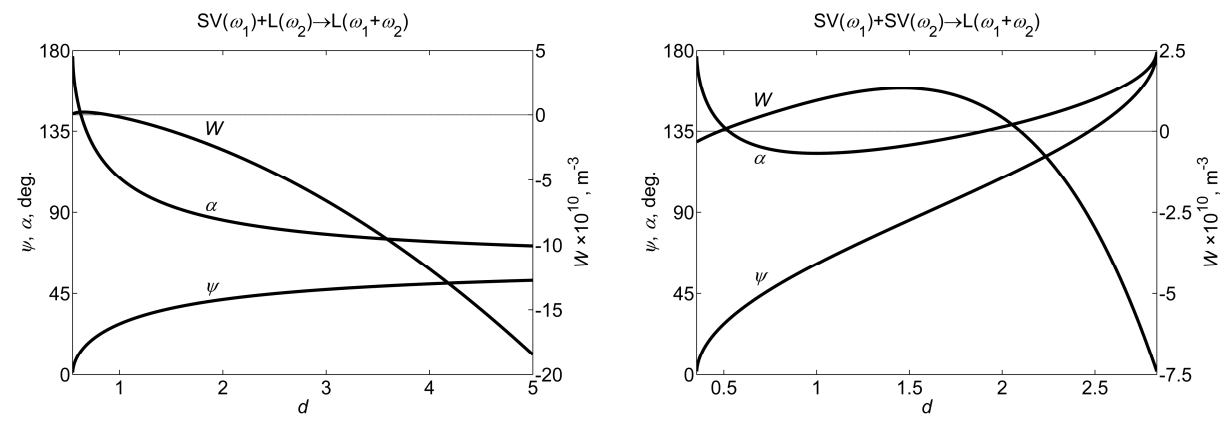

Figure 2.9. Interaction $\mathrm{SV}\left(\omega_{1}\right)+\mathrm{L}\left(\omega_{2}\right) \rightarrow \mathrm{L}\left(\omega_{1}+\omega_{2}\right)$.

Figure 2.10. Interaction $\operatorname{SV}\left(\omega_{1}\right)+\operatorname{SV}\left(\omega_{2}\right) \rightarrow$ $\mathrm{L}\left(\omega_{1}+\omega_{2}\right)$.
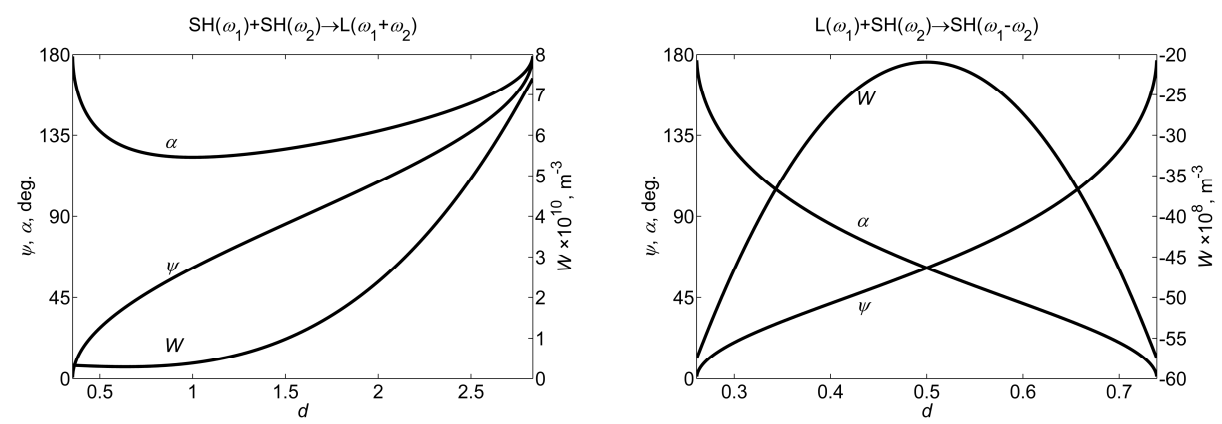

Figure 2.11. Interaction $\mathrm{SH}\left(\omega_{1}\right)+\mathrm{SH}\left(\omega_{2}\right) \rightarrow$ $\mathrm{L}\left(\omega_{1}+\omega_{2}\right)$.

Figure 2.12. Interaction $\mathrm{L}\left(\omega_{1}\right)+\mathrm{SH}\left(\omega_{2}\right) \rightarrow$ $\mathrm{SH}\left(\omega_{1}-\omega_{2}\right)$.

\subsection{Discussion and conclusions}

We confirm the possibility of just ten interactions for nonlinear wave mixing, as listed in Table 2.1. Sum frequency interactions \#4 for $\mathrm{L}+\mathrm{SV} \rightarrow \mathrm{L}$ and \#7 SV $+\mathrm{L} \rightarrow \mathrm{L}$ combinations are reciprocal. Indeed, if in an expression for scattering coefficient for interaction \#7 (Table 2.2), we exchange parameter $d$ for $1 / d$ and reverse the sign for angle $\alpha$, then the result is identical to that for interaction \#4.

The results in Table 2.2 reveal a rather simple dependence of scattering amplitudes on nonlinear elastic constants. Amplitudes of two collinear LL interactions are proportional to $2 m+l$, while six interactions are proportional to $m$ and independent of other constants. The remaining two interactions, in which SH waves are involved, have more complicated dependence on constants $m$ and $n$. Note that some frequency- ratio values cause zeroes for interaction coefficients, but this is an easily avoidable problem for nonlinear wave experiments. These zeroes, if detected, can be the extra constraints for determining model parameters.

Depending on the geometry of a sample, available sources, and nonlinear parameters of interest, an appropriate interaction should be chosen for reaching the largest possible amplitude of the resonant wave. Not only is this amplitude proportional 
to both amplitudes $A_{j},(j=1,2)$ of the primary waves, it is also proportional to the coefficients $W_{g}^{\xi}$ and the scattering volume $V_{g}^{\xi}$. Generally, the sum frequency interactions have higher amplitudes than those with difference frequencies.

A special interest might represent reactions marked by $\overline{\mathrm{x}}$ in Table 2.1, when the primary waves propagate in exactly opposite directions. A laboratory setup for such a situation might be preferable because in this case computation of interaction angles is not needed.

The approximate expressions in Table 2.2 are derived in assumption that TOE constants are much larger than Lame constants, which may be neglected in equations (2.7). This assumption is supported by a number of measurements for a variety of materials [11, 26-29]. It should be noticed that in many publications, for evaluations of TOE constants were used the equations from Jones and Kobett (1963), which apparently have some errors in them [30]. These errors are likely affected the values of some of the published TOE constants, although not affecting their orders of magnitude.

Different nature of restrictions on interaction types from Table 2.1 suggests that in some circumstances some of the restrictions can vanish. Thus, the polarization restriction can vanish in anisotropic medium where wave vectors and polarization vectors are not perfectly collinear (orthogonal). Also, in such a medium the interaction restriction between two shear waves might disappear because of different velocities of those waves.

Determination of the interaction volume is generally an important issue because the actual objects of study might have a complex shape and finite sizes when an assumption about an infinite nonlinear material is invalid. We considered a spherical interaction volume because this case allows an analytical solution. In practical applications (e.g. nonlinear scanning), the shape of the material sample can be arbitrary and the interaction volume can be evaluated by a numerical computation of integrals (2.25). For simple shapes this computation should be performed just once because of repeating geometry. We also assumed that the interaction volume has nonzero TOE constants while the other material parameters in that volume have the same values as in the surrounding medium. In a general case when all the parameters change, a correspondent linear diffraction problem should be involved. Thus, for a spherical geometry, a linear canonical diffraction problem can be solved using spherical harmonics [31], and then used for evaluating of the nonlinear part. Equations (2.8-2.14) can be simply converted into the spherical coordinate system for this purpose. Consideration of such general case is beyond the scope of this paper. The results obtained here were applied for measurements of plastic ageing and epoxy curing and published in Demčenko et al (2014) [32] using an immersion method with a thorough discussion on the optimal choice of laboratory parameters. In particular, some of these measurements revealed that the observed changes indeed can appear just in the nonlinear part of the field when the linear part remain insensitive to the changes.

The immersion method does not require a direct contact between the measuring hardware and a specimen which allows scanning and/or monitoring of nonlinear properties. Nonlinear wave mixing in this application is likely to become a routine nondestructive testing technique. 


\section{Acknowledgments}

This work was supported by the Director, Office of Energy Research, Office of Basic Energy Sciences, Engineering and Geosciences Division, of the U.S. Department of Energy under Contract No. DE-ACO2 -05CH11231. This work was also carried out in partial collaboration with Vitens and ApplusRTD within the 'Innowator' project IWA-08019, as funded by the Dutch Ministry of Economic Affairs, by means of Agentschap NL. Tania Vulfs helped to verify some analytical results from Table 2.2. Comments of two anonymous reviewers helped to improve the paper.

\section{References}

1. M. A. Breazeale and D. O. Thompson, "Finite-amplitude ultrasonic waves in aluminum," Appl. Phys. Lett. 3, 77-78 (1963).

2. P. H. Carr, "Harmonic generation of microwave phonons in quartz," Phys. Rev. Lett. 13, 332-335 (1964).

3. P. H. Carr, "Harmonic generation of microwave phonons by radiation pressure and by the phonon-phonon interaction," IEEE T. Son. Ultrason. 13, 103-108 (1966).

4. K. K. Ermilin, L. K. Zarembo, and V. A. Krasil'nikov, "Generation of superhigh frequency acoustic harmonics in a lithium niobate crystals," Sov. Phys.-Solid State 12, 1045-1052 (1970).

5. A. A. Gedroits and V. A. Krasil'nikov, "Finite-amplitude elastic waves amplitude in solids and deviations from the Hooke's law," JETP Lett. 16, 1122 (1963).

6. N. S. Shiren, "Nonlinear acoustic interaction in $\mathrm{MgO}$ at $9 \mathrm{Gc} / \mathrm{sec}$," Phys. Rev. Lett. 11, 3-6 (1963).

7. A. Hikata, B. B. Chick, and C. Elbaum, "Dislocation contribution to the second harmonic generation of ultrasonic waves," J. Appl. Phys. 36, 229-236 (1965).

8. P. A. Johnson and K. R. McCall, "Observation and implications of nonlinear elastic wave response in rock," Geophys. Res. Lett. 21, 165-168 (1994).

9. Y. Hiki and K. Mukai, "Ultrasonic three-phonon process in copper crystal," J. Phys. Soc. Jpn. 34, 454-461 (1973).

10. F. R. Rollins, L. H. Taylor, and P. H. Todd, "Ultrasonic study of three-phonon interactions. II. Experimental results," Phys. Rev. 136, A597-A601 (1964).

11. L. K. Zarembo and V. A. Krasil'nikov, "Nonlinear phenomena in the propagation of elastic waves in solids," Sov. Phys. Usp. 13, 778-797 (1971).

12. P. A. Johnson, T. J. Shankland, R. J. O'Connell, and J. N. Albright, "Nonlinear generation of elastic waves in crystalline rock," J. Geophys. Res. 92, 3597-3602 (1987).

13. P. A. Johnson and T. J. Shankland, "Nonlinear generation of elastic waves in granite and sandstone: continuous wave and travel time observations," J. Geophys. Res. 94, 17,72917,733 (1989).

14. H. H. Barrett and J.H. Matsinger, "Interaction of almost-collinear longitudinal phonons," Phys. Rev. 154, 877-886 (1967).

15. R. W. Dunham and H. B. Huntington, "Ultrasonic beam mixing as a measure of the nonlinear parameters of fused silica and single-crystal NaCl," Phys. Rev. B 2, 1098-1107 (1970).

16. A. J. Croxford, P. D. Wilcox, B. W. Drinkwater, and P. B. Nagy, "The use of non-collinear mixing for nonlinear ultrasonic detection of plasticity and fatigue," J. Acoust. Soc. Am. 126, EL117-EL122 (2009). 
17. A. Demčenko, R. Akkerman, P. B. Nagy, and R. Loendersloot, "Non-collinear wave mixing for non-linear ultrasonic detection of physical ageing in PVC," NDT \& E Int. 49, 34-39 (2012).

18. F. D. Murnaghan, "Finite deformation of an elastic solid," (John Wiley \& Sons, New York, 1951), pp. 140.

19. L. K. Zarembo and V. A. Krasil'nikov, "Introduction in nonlinear acoustics" (In Russian), (Science, Moscow, 1966), Chap. 8.

20. V. A. Korneev, K. T. Nihei, and L. R. Myer, Nonlinear interaction of plane elastic waves, Tech. Rep. LBNL-41914, Lawrence Berkeley National Laboratory, USA (1998).

21. L. D. Landau and E. M. Lifshitz, "Theory of elasticity," (Pergamon Press, New York, 1959), pp. 134.

22. G. L. Jones and D. R. Kobett, "Interaction of elastic waves in an isotropic solid," J. Acoust. Soc. Am. 35, 5-10 (1963).

23. L. H. Taylor and F. R. Rollins, "Ultrasonic study of three-phonon interactions. I. Theory," Phys. Rev. 136, A591-A596 (1964).

24. J. D. Childress and C. G. Hambrick, "Interactions between elastic waves in an isotropic solid," Phys. Rev. 136, A411-A418 (1964).

25. A. C. Holt and J. Ford, "Theory of ultrasonic three-phonon interactions in single-crystal solids," J. Appl. Phys. 40, 142-148 (1969).

26. P. A. Johnson and P. N. J. Rasolofosaon, "Nonlinear elasticity and stress-induced anisotropy in rock," J. Geophys. Res. 101, 3,113-3,124 (1996).

27. V. E. Nazarov, L. A. Ostrovsky, I. A. Soustova, and A.M. Sutin, "Nonlinear acoustics of micro-inhomogeneous media," Phys. Earth Planet. In. 50, 65-73 (1988).

28. R. Prioul, A. Bakulin, and V. Bakulin, "Nonlinear rock physics model for estimation of 3d subsurface stress in anisotropic formations: theory and laboratory verification," Geophysics $69,415-425$ (2004).

29. D. Sarkar, A. Bakulin, and R. L. Kranz, "Anisotropic inversion of seismic data for stressed media: theory and a physical modeling study on Berea sandstone," Geophysics 68, 690-704 (2003).

30. V. Korneev and S. Glubokovskikh, "Seismic velocity changes caused by an overburden stress," Geophysics 78, WC25-WC31 (2013).

31. V. A. Korneev and L. R. Johnson, "Scattering of P and S waves by spherically symmetric inclusion," Pure Appl. Geophys. 147, 675-718 (1996).

32. A. Demčenko, V. Koissin, and V. A. Korneev, "Noncollinear wave mixing for measurement of dynamic processes in polymers: Physical ageing in thermoplastics and epoxy cure," Ultrasonics 54, 684-693 (2014). 


\title{
Chapter 3
}

\section{Noncollinear wave mixing for a bulk wave phase velocity measurement in an isotropic solid 1}

\begin{abstract}
A measurement method is presented to estimate the bulk wave phase velocity in an isotropic solid when longitudinal or shear wave velocity is known. This method is based on the noncollinear plane wave interaction theory and it does not need to estimate the phase time-of-flight and wave propagation path of ultrasonic wave in a specimen. It is necessary to measure incident angles of pump waves for estimation of the longitudinal or shear wave phase velocity. Using the proposed method, the shear wave phase velocity is measured in an aluminum specimen to be $3189 \mathrm{~m} / \mathrm{s} \pm 202 \mathrm{~m} / \mathrm{s}$ and $3174 \mathrm{~m} / \mathrm{s}$ $\pm 112 \mathrm{~m} / \mathrm{s}$ at a level of confidence of $95 \%$ depending on a selected wave mixing method.
\end{abstract}

\footnotetext{
${ }^{1}$ Reproduced from: A. Demčenko "Non-collinear wave mixing for a bulk wave phase velocity measurement in an isotropic solid," In: Proceedings of the IEEE International Ultrasonics Symposium (IUS) 2012, 1437-1440 (2012).
} 


\subsection{Introduction}

In linear elasticity an isotropic solid with a given material density $\rho$ is characterized by two independent stiffness constants $c_{12}$ and $c_{44}$ known as Lamé parameters $\lambda$ and $\mu$. Knowing all three material parameters $c_{12}, c_{44}$ and $\rho$, one can estimate longitudinal and shear wave velocities in an isotropic solid from the well-known relations:

$v_{\mathrm{L}}=\sqrt{\frac{\lambda+2 \mu}{\rho}}$,

$v_{\mathrm{S}}=\sqrt{\frac{\mu}{\rho}}$.

However, the sound velocities or stiffness constants can be estimated from ultrasonic measurements directly, especially the longitudinal wave velocity, because transduction of the longitudinal waves does not require special techniques or special transducers as in a case of shear wave transduction [1]. Therefore the shear wave phase velocity measurements are analyzed more in detail. The shear wave velocity can be measured using a) shear wave transducers [1] or b) mode conversion when a longitudinal wave is incident to a solid at oblique angle $[2,3]$. Both ways are widely used in research and industry. Alternative measurement techniques such as laserultrasonic techniques, ultrasonic interferometry, etc. are not discussed in this chapter.

The piezoelectric shear wave transducers are used for contact measurements only. Due to that, the measurement results are influenced by the contact properties between the shear wave transducers and test specimen. The measurements of the shear wave velocity employing the mode conversion can be carried out in a contactless way, e.g. using an immersion ultrasonic measurement technique. In some cases electromagnetic ultrasonic transducers can be used for contactless ultrasonic transduction of the shear wave [4]. Summarizing shear wave velocity measurement methods, one can conclude that the shear wave velocity is estimated from the following generalized expression:

$v=\frac{d}{t}$

where $d$ is the wave propagation path in the specimen and $t$ is the time-of-flight of the wave in the path $d$. In this measurement complications occur with estimation of correct time-of-flight $t$, because it is not easy to measure the correct phase time-of-flight, especially if the wave propagation is in a dispersive medium. Moreover, determination of the wave propagation path $d$ also becomes complicated when the oblique incidence of ultrasonic waves is used in the measurements. In this case $d$ becomes a function of the wave incidence angle $\theta$.

In this work we present a measurement method to estimate the bulk wave phase velocity in an isotropic solid when longitudinal or shear wave velocity is known. The suggested measurement method is based on the noncollinear plane wave interaction theory. Applying the method, longitudinal or shear wave phase velocity can be measured in an isotropic solid directly. It does not need to estimate the phase time-offlight and wave propagation path of ultrasonic wave in a specimen. However, it is 
necessary to measure the incident angles of pump waves. Measurements of the shear wave phase velocity are analyzed in more detail, because it is more complex than the longitudinal wave phase velocity measurements.

\subsection{Bulk wave phase velocity measurement method based on noncollinear wave interaction}

The synchronism conditions for two interacting phonons $\mathbf{k}_{1}$ and $\mathbf{k}_{2}$ can be written in terms of conservation laws for quasi-momentum and energy of interacting phonons [5, 6]:

$\mathbf{k}_{1} \pm \mathbf{k}_{2}=\mathbf{k}_{3}$

$\omega_{1} \pm \omega_{2}=\omega_{3}$,

where $\mathbf{k}_{i}$ ( $\left.i=1,2,3\right)$ is the wave-vector of the phonon, $\omega_{i}$ is the angular frequency of the phonon and $\omega_{i}=2 \pi f_{i} . f_{i}$ is the frequency. The synchronism conditions are necessary, but not sufficient. The allowed interaction cases and their conditions are presented in the literature [5, 6], and will not be discussed here. Let us analyze the wave interaction process which is denoted by $\operatorname{SV}\left(\omega_{1}\right)+\mathrm{L}\left(\omega_{2}\right) \rightarrow \mathrm{L}\left(\omega_{1}+\omega_{2}\right)$, where $\operatorname{SV}\left(\omega_{1}\right)$ and $\mathrm{L}\left(\omega_{2}\right)$ are the shear and longitudinal pump waves, respectively, and $L\left(\omega_{1}+\omega_{2}\right)$ is the longitudinal nonlinear wave. In this case (3.4) is solved in the following form:

$\left(\frac{\omega_{1}}{v_{\mathrm{S}}}\right)^{2}+\left(\frac{\omega_{2}}{v_{\mathrm{L}}}\right)^{2}+2 \frac{\omega_{1}}{v_{\mathrm{S}}} \frac{\omega_{2}}{v_{\mathrm{L}}} \cos \phi=\left(\frac{\omega_{1}+\omega_{2}}{v_{\mathrm{L}}}\right)^{2}$,

where $\phi$ is the angle between two interacting waves (see Fig. 3.1). Equation (3.6) contains two unknown parameters: velocity of ultrasonic pump wave (the second one is known) and interaction angle $\phi$. Therefore it is necessary to eliminate one unknown parameter in this equation. For this, the interaction angle $\phi$ is expressed as a sum of refraction angles of the pump waves (see Fig. 3.1):

$\phi=\arcsin \left(\frac{v_{\mathrm{S}}}{v_{0}} \sin \theta_{1}\right)+\arcsin \left(\frac{v_{\mathrm{L}}}{v_{0}} \sin \theta_{2}\right)$,

where $v_{0}$ is the known ultrasonic wave velocity in the surrounding liquid. Substituting (3.7) into (3.6), the latter transforms into the following form:

$$
\begin{aligned}
\left(\frac{\omega_{1}}{v_{\mathrm{S}}}\right)^{2}+\left(\frac{\omega_{2}}{v_{\mathrm{L}}}\right)^{2}+ & 2 \frac{\omega_{1}}{v_{\mathrm{S}}} \frac{\omega_{2}}{v_{\mathrm{L}}} \cos \left(\arcsin \left(\frac{v_{\mathrm{S}}}{v_{0}} \sin \theta_{1}\right)+\arcsin \left(\frac{v_{\mathrm{L}}}{v_{0}} \sin \theta_{2}\right)\right) \\
& =\left(\frac{\omega_{1}+\omega_{2}}{v_{\mathrm{L}}}\right)^{2} .
\end{aligned}
$$

Equation (3.8) can be solved for one of the unknown parameters: either for the longitudinal wave velocity $v_{\mathrm{L}}$ or for the shear wave velocity $v_{\mathrm{S}}$. One can see that (3.8) is a nonlinear function; therefore it is solved numerically by minimization of the objective function: 
$\min \left(f_{1}-f_{2}\right)^{2}$,

where $f_{1}$ and $f_{2}$ are the left and right sides of (3.8), respectively.

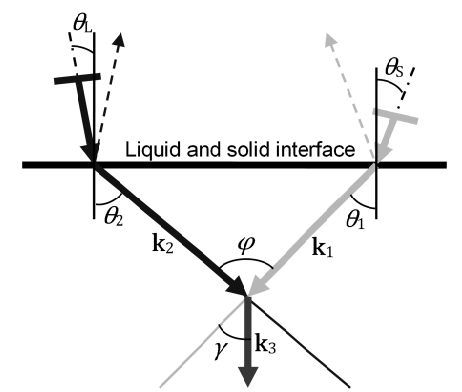

Figure. 3.1. Wave interaction geometry for $\operatorname{SV}\left(\omega_{1}\right)+\mathrm{L}\left(\omega_{2}\right) \rightarrow \mathrm{L}\left(\omega_{1}+\omega_{2}\right)$ process.

\subsection{Experimental measurements}

Experimental measurements were performed for an aluminum specimen with dimensions $286 \mathrm{~mm} \times 124 \mathrm{~mm} \times 60 \mathrm{~mm}$. Initially a pulse-echo measurement was carried out for estimation of the longitudinal wave velocity in the specimen, using a spherically focused broadband ultrasonic transducer of $10 \mathrm{MHz}$ central frequency. A single pulse excitation was used. A phase-spectrum method was employed for the phase velocity data extraction from the received ultrasonic signals [7]. Very little dispersion was observed in the aluminum specimen (see Fig. 3.2).

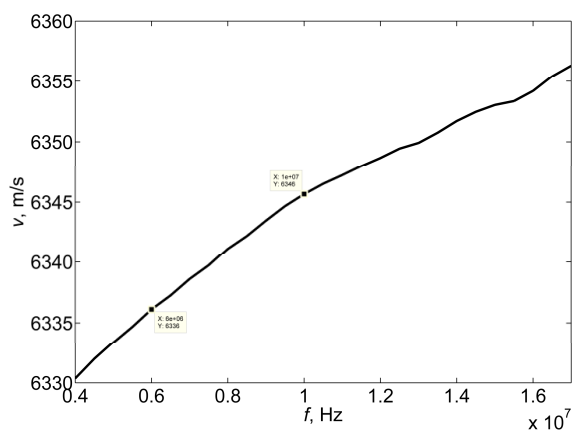

Figure. 3.2. Measured longitudinal wave phase velocity in the aluminum specimen.

In the noncollinear wave mixing experiment an arrangement of the test specimen and ultrasonic transducers in the pulse-echo mode is presented in Fig. 3.3, when the 
maximum amplitude of the nonlinear ultrasonic wave is measured. Frequencies of the two pump waves were selected such that the nonlinear wave would strike the aluminum and water interface perpendicularly. From geometry (Fig. 3.1) it is seen that the refraction angle of the scattered wave can be calculated from the Snell's law in the following way when the wave propagates over a solid and liquid interface:

$\theta=\arcsin \left(\frac{v_{0}}{v_{3}} \sin \left(\theta_{1}-\gamma\right)\right)$

where $v_{0}$ is the ultrasonic wave velocities in the liquid, $v_{3}$ is the scattered wave's velocity. $\gamma$ is the angle at which the scattered wave emerges from the point of interaction [5].

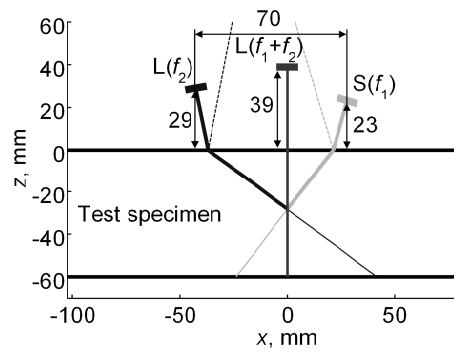

Figure. 3.3. Arrangement of ultrasonic transducers for the nonlinear wave mixing process $\operatorname{SV}\left(\omega_{1}\right)+\mathrm{L}\left(\omega_{2}\right) \rightarrow \mathrm{L}\left(\omega_{1}+\omega_{2}\right)$ in the aluminum specimen (pulse-echo measurement mode).

Two broadband transducers of $5 \mathrm{MHz}$ central frequency were used to generate the pump waves. The shear wave pump transducer was inclined at angle $\theta_{\mathrm{S}}=14^{\circ}$ initially and driven by a burst of 30 cycles of rectangular pulses of $f_{1}=4 \mathrm{MHz}$. The longitudinal wave pump transmitter was inclined at angle $\theta_{\mathrm{L}}=9^{\circ}$ initially and driven by a burst of 30 cycles rectangular pulses of $f_{2}=6 \mathrm{MHz}$. A fine adjustment of the angles was performed manually using rotary stages with a tuning resolution of $0.08^{\circ}$. The maximum amplitude of the nonlinear ultrasonic wave was measured when $\theta_{\mathrm{L}}=10.7^{\circ}$ and $\theta_{\mathrm{S}}=16.2^{\circ}$. The generated wave of $10 \mathrm{MHz}$ was received by the spherically focused broadband receiver of $10 \mathrm{MHz}$ central frequency which was perpendicular to the water and aluminum interface. Reception of ultrasonic waves was carried out from both sides of the test specimen for demonstration of the pulse-echo and through-transmission measurement capabilities. The received signals were filtered using a narrowband FIR filter with a Kaiser window and stored on a personal computer for further analysis.

Typical ultrasonic signals are presented in Figs. 3.4 and 3.5 when the pulse-echo and the through-transmission arrangements of transducers were used in the noncollinear wave mixing experiments. One can see that the through-transmission arrangement of transducers enables receiving the nonlinear ultrasonic wave with a better signal-to-noise ratio, because specularly reflected pump waves do not interfere with the ultrasonic receiver. 

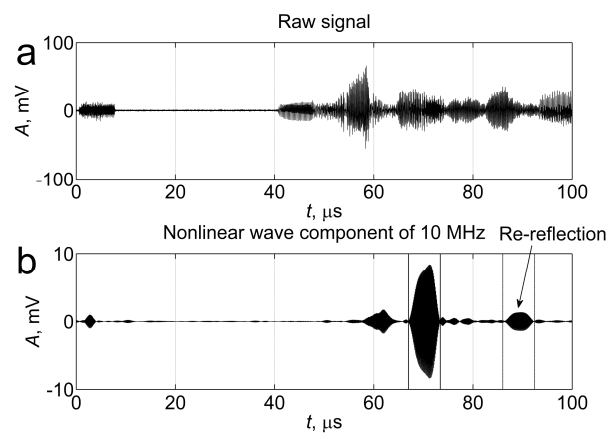

Figure 3.4. $\operatorname{SV}\left(\omega_{1}\right)+\mathrm{L}\left(\omega_{2}\right) \rightarrow \mathrm{L}\left(\omega_{1}+\omega_{2}\right)$ wave interaction process and the pulse-echo arrangement of transducers: raw time-domain signal (a) and nonlinear wave component (b). Two vertical solid lines show the first informative signal, and two vertical dashed lines show the rereflection of the first informative signal.
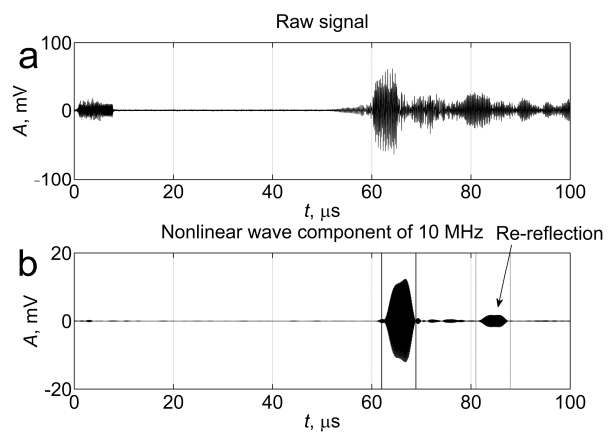

Figure 3.5. $S V\left(\omega_{1}\right)+\mathrm{L}\left(\omega_{2}\right) \rightarrow \mathrm{L}\left(\omega_{1}+\omega_{2}\right)$ wave interaction process and the throughtransmission arrangement of transducers: raw time-domain signal (a) and nonlinear wave component (b). Two vertical solid lines show the first informative signal, and two vertical dashed lines show the re-reflection of the first informative signal.

The measurement procedure for bulk wave phase velocity measurement contains the following steps:

1. Initial measurement of one of the ultrasonic wave phase velocities in a specimen (in our case longitudinal wave phase velocity). This step can be skipped if the velocity is known.

2. Initialization of the noncollinear wave mixing measurement assuming that the shear wave phase velocity is approximately half of the longitudinal wave velocity.

3. Iterative adjustment of the angles of the pump wave transducers until the maximum amplitude of the nonlinear ultrasonic wave is measured.

A capturing of the re-reflected informative signal (see Figs. $3.4 \mathrm{~b}$ and $3.5 \mathrm{~b}$ ) is a good stop feature for adjustment cancelation of the angles $\theta_{\mathrm{L}}$ and $\theta_{\mathrm{S}}$. 
Using experimental data (incident angles $\theta_{\mathrm{L}}$ and $\theta_{\mathrm{S}}$, longitudinal wave velocity $v_{\mathrm{L}}=6336 \mathrm{~m} / \mathrm{s}$ for the pump wave of $6 \mathrm{MHz}$, and $v_{\mathrm{L}}=6346 \mathrm{~m} / \mathrm{s}$ for the generated nonlinear wave of $10 \mathrm{MHz}$ in the aluminum specimen (see Fig. 3.2) and wave velocity in water $v_{0}=1481 \mathrm{~m} / \mathrm{s}$ ), the shear wave phase velocity was estimated minimizing (3.9). The shear wave phase velocity was found to be $3194 \mathrm{~m} / \mathrm{s}$ at $4 \mathrm{MHz}$ frequency. After complete disassembling and assembling of the measurement setup, the measurement was repeated. The following wave incidence angles were measured: $\theta_{\mathrm{L}}=10.74^{\circ}$ and $\theta_{\mathrm{S}}=16.2^{\circ}$. In this case the estimated shear wave phase velocity was $3186 \mathrm{~m} / \mathrm{s}$ at $4 \mathrm{MHz}$ frequency.

The measurement results are validated employing the wave interaction process which is denoted by $\operatorname{SV}\left(\omega_{1}\right)+\operatorname{SV}\left(\omega_{2}\right) \rightarrow \mathrm{L}\left(\omega_{1}+\omega_{2}\right)$, where $\operatorname{SV}\left(\omega_{1}\right)$ and $\operatorname{SV}\left(\omega_{2}\right)$ are the shear pump waves and $\mathrm{L}\left(\omega_{1}+\omega_{2}\right)$ is the longitudinal nonlinear wave. The throughtransmission measurement mode was used in the experiment. The following pump wave incident angles were measured: $\theta_{\mathrm{S}}=27^{\circ}$ and $\theta_{\mathrm{S}}=20.12^{\circ}$. The corresponding ultrasonic signal is presented in Fig. 3.6. The longitudinal wave velocity $c_{l}$ was substituted by $v_{\mathrm{S}}$ on the left side in (3.8). It is important to note that the possible dispersion of the shear wave phase velocity was neglected. This assumption was used, because the shear wave phase velocity was not measured at $6 \mathrm{MHz}$ frequency. Taking into account the presented assumption, the estimated shear wave phase velocity was $3174 \mathrm{~m} / \mathrm{s}$ in the aluminum specimen.
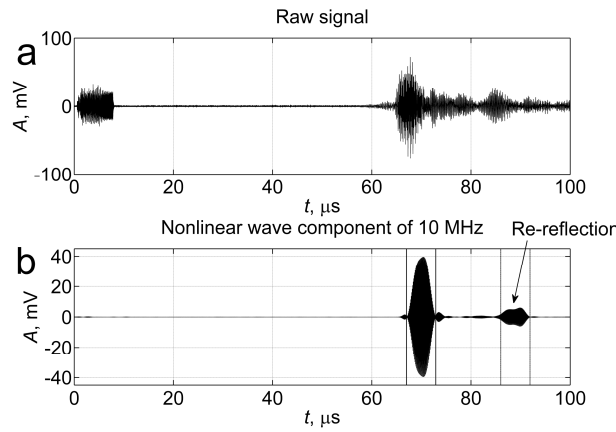

Figure 3.6. $\operatorname{SV}\left(\omega_{1}\right)+\operatorname{SV}\left(\omega_{2}\right) \rightarrow \mathrm{L}\left(\omega_{1}+\omega_{2}\right)$ wave interaction process and the throughtransmission arrangement of transducers: raw time-domain signal (a) and nonlinear wave component (b). Two vertical solid lines show the first informative signal and two vertical dashed lines show the re-reflection of the first informative signal.

\subsection{Uncertainty analysis}

The Monte Carlo analysis is used here for uncertainty analysis of the measured shear phase velocity in the aluminum specimen. Both of the used noncollinear wave mixing cases are analyzed. The following measurement models are used in the analysis: 


$$
\begin{aligned}
\min \left[\left(\frac{\omega_{1}}{v_{\mathrm{S}}}\right)^{2}+\left(\frac{\omega_{2}}{v_{\mathrm{L}}}\right)^{2}-\left(\frac{\omega_{1}+\omega_{2}}{v_{\mathrm{L}}^{\prime}}\right)^{2}\right. \\
\left.+2 \frac{\omega_{1}}{v_{\mathrm{S}}} \frac{\omega_{2}}{v_{\mathrm{L}}} \cos \left(\arcsin \left(\frac{v_{\mathrm{S}}}{v_{0}} \sin \theta_{1}\right)+\arcsin \left(\frac{v_{\mathrm{L}}}{v_{0}} \sin \theta_{2}\right)\right)\right]^{2} \\
{\left[\left(\frac{\omega_{1}}{v_{\mathrm{S}}}\right)^{2}+\left(\frac{\omega_{2}}{v_{\mathrm{S}}^{\prime}}\right)^{2}-\left(\frac{\omega_{1}+\omega_{2}}{v_{\mathrm{L}}^{\prime}}\right)^{2}\right.} \\
\left.+2 \frac{\omega_{1}}{v_{\mathrm{S}}} \frac{\omega_{2}}{v_{\mathrm{S}}^{\prime}} \cos \left(\arcsin \left(\frac{v_{\mathrm{S}}}{v_{0}} \sin \theta_{1}\right)+\arcsin \left(\frac{v_{\mathrm{S}}^{\prime}}{v_{0}} \sin \theta_{2}\right)\right)\right]^{2}
\end{aligned}
$$

where (3.11) and (3.12) correspond to the wave mixing cases $\operatorname{SV}\left(\omega_{1}\right)+\mathrm{L}\left(\omega_{2}\right) \rightarrow$ $\mathrm{L}\left(\omega_{1}+\omega_{2}\right)$ and $\mathrm{SV}\left(\omega_{1}\right)+\mathrm{SV}\left(\omega_{2}\right) \rightarrow \mathrm{L}\left(\omega_{1}+\omega_{2}\right)$, respectively. $v_{\mathrm{L}}^{\prime}$ and $v_{\mathrm{S}}^{\prime}$ are the longitudinal and shear wave phase velocities at $10 \mathrm{MHz}$ and $6 \mathrm{MHz}$ frequencies, respectively. $v_{\mathrm{L}}$ and $v_{\mathrm{S}}$ are the longitudinal and shear wave phase velocities at $6 \mathrm{MHz}$ and $4 \mathrm{MHz}$ frequencies, respectively. Variables and their corresponding inputs used for the uncertainties analysis are listed in Table 3.1. It is important to note that all variables are B type and have $\infty$ degree of freedom. $1.5 \mathrm{M}$ iterations are made in the uncertainty analysis. In Table 3.1, the following notation is introduced: $\Delta x_{i}$ is the deflection of the source $x_{i}, \mathrm{D}$ is the probability distribution, $\mathrm{N}$ and $\mathrm{R}$ are the normal and rectangular distributions, respectively, $u_{\mathrm{C}}$ and $U$ are the combined standard and expanded uncertainties, respectively.

The Monte Carlo analysis shows that expanded uncertainties are $6.3 \%$ and $3.5 \%$ for the measured shear wave phase velocity in the aluminum specimen using $\operatorname{SV}\left(\omega_{1}\right)+$

\begin{tabular}{|c|c|c|c|c|c|c|}
\hline \multirow{2}{*}{ Source $x_{i}$} & \multicolumn{3}{|c|}{$\mathrm{S}\left(\omega_{1}\right)+\mathrm{L}\left(\omega_{2}\right) \rightarrow \mathrm{L}\left(\omega_{1}+\omega_{2}\right)$} & \multicolumn{3}{|c|}{$\mathrm{S}\left(\omega_{1}\right)+\mathrm{S}\left(\omega_{2}\right) \rightarrow \mathrm{L}\left(\omega_{1}+\omega_{2}\right)$} \\
\hline & Value & $\Delta x_{i}$ & $\mathrm{D}$ & Value & $\Delta x_{i}$ & $\mathrm{D}$ \\
\hline$\theta_{1}$, deg. & 10.7 & \pm 0.5 & $\mathrm{~N}$ & 27 & \pm 0.5 & $\mathrm{~N}$ \\
\hline$\theta_{2}$, deg. & 16.2 & \pm 0.5 & $\mathbb{N}$ & 20.1 & \pm 0.5 & $\mathbb{N}$ \\
\hline$v_{\mathrm{L}}, \mathrm{m} / \mathrm{s}$ & 6336 & \pm 10 & & & & \\
\hline$v_{0}, \mathrm{~m} / \mathrm{s}$ & 1481 & \pm 1 & & 1481 & \pm 1 & \\
\hline $\mathrm{v}_{\mathrm{L}}, \mathrm{m} / \mathrm{s}$ & 6346 & \pm 10 & $\mathrm{R}$ & 6346 & \pm 10 & $\mathrm{R}$ \\
\hline$v_{\mathrm{S}}^{\prime}, \mathrm{m} / \mathrm{s}$ & & & & 3174 & \pm 5 & \\
\hline$u_{\mathrm{C}}, \mathrm{m} / \mathrm{s}$ & \pm 101 & & $\mathrm{~N}$ & \pm 56 & & $\mathrm{~N}$ \\
\hline$U, \mathrm{~m} / \mathrm{s}$ & \pm 202 & & $\mathrm{~N}$ & \pm 112 & & $\mathrm{~N}$ \\
\hline
\end{tabular}
$\mathrm{L}\left(\omega_{2}\right) \rightarrow \mathrm{L}\left(\omega_{1}+\omega_{2}\right)$ and $\mathrm{SV}\left(\omega_{1}\right)+\mathrm{SV}\left(\omega_{2}\right) \rightarrow \mathrm{L}\left(\omega_{1}+\omega_{2}\right)$ wave mixing cases, respectively. The level of confidence is $95.45 \%$.

Table 3.1. Uncertainties budget.

\subsection{Discussion and conclusions}

A bulk wave phase velocity measurement method is proposed in this work. This method is experimentally verified measuring shear wave phase velocity in an aluminum specimen. Using the Monte Carlo analysis, it is demonstrated that in the aluminum 
specimen the shear wave phase velocity is measured with $6.3 \%$ and $3.5 \%$ expanded uncertainties depending on a selected wave mixing method. In the uncertainty analysis it is assumed that the incident angles of two pump waves are known with a $\pm 0.5^{\circ}$ deflection. A lower incident angle deflection results in a lower uncertainty. For example, when the deflection is $\pm 0.25^{\circ}$ only, the expected uncertainty of the shear wave phase velocity becomes $1.6 \%$ for the $\operatorname{SV}\left(\omega_{1}\right)+\mathrm{L}\left(\omega_{2}\right) \rightarrow \mathrm{L}\left(\omega_{1}+\omega_{2}\right)$ wave mixing process. Multiple measurements of the wave velocity at different frequencies enable to establish the system of equations. Therefore it is possible to develop a more advanced objective function for a more accurate estimation of the phase velocity from experimental data.

The suggested bulk wave phase velocity measurement method has the following advantages: a) direct measurement of the phase velocity without the need to estimate time-of-flight of wave and wave propagation path; b) contactless measurements are possible in through-transmission or pulse-echo modes; c) it is possible to measure ultrasonic wave phase velocity in a bonded structure without the need to know ultrasonic properties of the whole structure. It allows steering the pump wave beams to a certain location or layer in a joined or layered structure. This advantage can be applied for quality control of embedded structures. However, synchronism conditions for the noncollinear wave interaction and employment of three transducers are to be used in the suggested measurement method.

\section{References}

1. C. D. Ferris and A. Ambardar, "A simple ultrasonic transducer for measuring shear wave velocities,” J. Acoust. Soc. Am. 63, 1937-1938 (1978).

2. M. A. De Billy, "A new simple method for measuring the velocities of sound in isotropic, nondispersive solids," J. Phys. D: Appl. Phys. 13, 767-771 (1980).

3. S. I. Rokhlin and W. Wang, "Double through-transmission bulk wave method for ultrasonic phase velocity measurement and determination of elastic constants of composite materials," J. Acoust. Soc. Am. 91, 3303-3312 (1992).

4. R. B. Thompson, "Electromagnetic, noncontact transducers," in Proc. IEEE International Ultrasonics Symposium, Monterey, CA, USA, 385-392 (1973).

5. J. D. Childress and C. G. Hambrick, "Interactions between elastic waves in an isotropic solid," Phys. Rev. 136, A411-A418 (1964).

6. L. K. Zarembo and V. A. Krasil'nikov, "Nonlinear phenomena in the propagation of elastic waves in solids," Sov. Phys. Usp. 13, 778-797 (1971).

7. W. Sachse and Y. H. Pao, "On the determination of phase and group velocities of dispersive waves in solids," J. App. Phys. 49, 4320-4327 (1978). 


\title{
Chapter 4
}

\section{Noncollinear wave mixing for measurement of dynamic processes in polymers: physical ageing in thermoplastics and epoxy cure ${ }^{1}$}

\begin{abstract}
Elastic wave mixing using an immersion method has shown effective monitoring and scanning capabilities when applied to thermoplastic ageing, epoxy curing, and nondestructive testing. In water, excitation and reception of waves do not require physical contact between the tools and the specimen, making the acquisition of highresolution $\mathrm{C}$-scans possible. The nonlinear material parameters exhibit a much higher sensitivity to the specimen state compared to linear ones. Thus, the nonlinear data for polymethyl methacrylate (PMMA) have a $40 \%$ difference between zones of "young" and "aged" material, while the linear data show no difference at all. Methodology and logistics of the immersion wave-mixing method are discussed in detail. Monitoring of epoxy curing has also revealed a good sensitivity of the method to this complex process including several characteristic stages, such as the time of maximal viscosity, the gel time, and the vitrification time. These stages are independently verified in separate rheometry measurements. The presented method allows for a number of possibilities: wave-mode and frequency separations, elimination of surrounding medium influence, "steering" (scanning) a scattered wave, controlling the location of the intersection volume, single-sided or double-sided measurements, and operation in detector mode.
\end{abstract}

\footnotetext{
${ }^{1}$ Reproduced from: A. Demčenko, V. Koissin, and V. A. Korneev "Noncollinear wave mixing for measurement of dynamic processes in polymers: Physical ageing in thermoplastics and epoxy cure," Ultrasonics 54, 684-693 (2014).
} 


\subsection{Introduction}

Elastic wave mixing can be used for nondestructive material testing and monitoring. This possibility has emerged after an immersion method was introduced recently in which an entire measurement assembly is immersed in a water tub [1-3]. In water, excitation and reception of waves occur without requiring physical contact between the tools and the specimen, making possible the acquisition of high-resolution C-scans [2]. The importance of the wave-mixing method is emphasized by observations, reported in this paper, showing that nonlinear material parameters have a higher sensitivity to the specimen state compared to linear parameters. In keeping with these observations, we show that the detection of the physical ageing of thermoplastics $[1,4,5]$ and epoxy curing, e.g. [6-8], is higher when a nonlinear wave-mixing method is used.

Elastic nonlinearity of different materials, including rock samples, has been observed for ultrasonic frequencies by many authors [9-18]. In particular, it has been shown that the velocity of elastic waves changes with static deformation and hydrostatic pressure. This phenomenon, known as acousto-elasticity, is widely used for measurements of third-order elastic constants in solids. Waves of mixed frequencies as a result of nonlinear wave interaction have also been reported [19-22]. The fundamental equations of nonlinear elastic theory, by Murnaghan [23], effectively describe such classical nonlinear phenomena as harmonics generation and resonant wave scattering.

This paper presents experimental noncollinear wave mixing for testing of polymers, and it is structured as follows: The opening two sections are devoted to the logistics of the immersion wave-mixing method, describing a hierarchy of observation-parameter choices and various tradeoffs. Then, the aging process is studied in two examples of thermoplastics: polymethyl methacrylate (PMMA) and polyvinyl chloride (PVC). Changes in these materials were monitored after erasing a previous thermo-history of the polymer by heating. In other experiments, some, but not all, of the thermoplastic samples were rejuvenated and then scanned using linear and nonlinear techniques, revealing pronounced transition zones. Then we describe the monitoring of epoxy curing at two different temperatures-a complex process with several characteristic stages. This monitoring allowed us to detect these stages, which were verified in separate rheometry measurements. In the last experiment, we obtain a C-scan of an epoxy layer cured between two aluminum plates with naturally formed bubbles. The obtained nonlinear image is found to have comparable information to the information obtained by the linear ultrasonics technique.

\subsection{Noncollinear wave mixing}

In isotropic nonlinear materials, described by the third order elastic constants $l, m$, $n$ or $A, B, C$ [24], where can exist the resonant conditions when two elastic waves can interact to generate scattered waves with mixed (sum and difference) frequencies. The equations

$\omega_{g}=\omega_{1} \pm \omega_{2}$ 
$\mathbf{k}_{g}=\mathbf{k}_{1} \pm \mathbf{k}_{2}$

express these conditions, where frequencies $\omega_{1}, \omega_{2}$ and $\omega_{g}$ respectively represent two initial waves and a resonant wave, and $\mathbf{k}_{1}, \mathbf{k}_{2}$, and $\mathbf{k}_{g}$ are their wave vectors. Even if the resonant conditions were satisfied, the amplitude of the scattered wave might be zero for all parameter combinations (polarization restriction). In Korneev et. all [24] it is shown that only 10 out of 54 possible combinations of compressional L, shear SV, and shear SH waves generate scattered waves. Among the allowed combinations, two of them are collinear, meaning that the two primary waves propagate in the same direction. Use of collinear waves for material testing is limited, because it is technically difficult to generate them in an independent manner. Interaction of waves propagating in exactly opposite directions is possible for seven wave combinations [24].

There are several reasons to use noncollinear wave mixing for testing of materials. First, as will be shown below, some nonlinear material properties can be much more sensitive to changes caused by variations in temperature, aging, solidification etc., when compared to the corresponding linear properties. Second, the nonlinear resonant scattered waves can be easily extracted from the total wave field by narrow-band filtering, because the target and initial wave frequencies are different and pre-chosen. Third, the wave-mixing conditions allow convenient placement of transducers in different nonconflicting locations, making the entire installation easy to assemble and operate.

In the first wave-mixing measurements $[15,16]$, the wave resonant conditions (interaction and scattering angles) were satisfied by preparing the specimens with a special geometry in which emitting as well as receiving transducers were glued to the specimen's sides. This kind of measurement technique requires a laborious preparation and is not flexible to changes in the model (wave propagation velocities) or observation (angles and frequencies) parameters. Some recently developed methods [1-3] with both submerged specimens and transducers are nondestructive and assume no physical contact between the specimen and measurement devices. Figure 4.1 shows a submerged wave-mixing technique scheme with two modifications, using either reflected or transmitted scattered waves. For thick objects, the transmitted wave might be preferred, because the target scattered wave has a shorter path (less attenuation) and can be better detected. The advantage of the reflected wave scheme is in single-side-access to the specimen.

Knowing the longitudinal and shear wave velocities in the specimen, we can compute the incident angles of the sample boundary for the pump waves from the resonant conditions, also taking into account the angles of refraction on the water and specimen interface. We choose the sets of initial frequencies and angles to generate the propagation of scattered waves perpendicular to the interface, providing a maximum detectable signal above or below the specimen. When the specimen is thick and the source angles are inaccurately chosen, there is the risk that the scattered wave signal will deflect significantly from where the wave would be expected to propagate. This deflection is stronger in single-side-access measurements. Use of long, monochromatic primary signals ensures narrow spectral peaks for the recorded traces and robust detection of the scattered wave. The long signals also enable a certain misalignment of the pump wave sources in the vertical axis $z$ (see Fig. 4.1). The choice of primary 
frequencies should also allow easy separation of the mixed frequencies from the primary waves and their multiples.

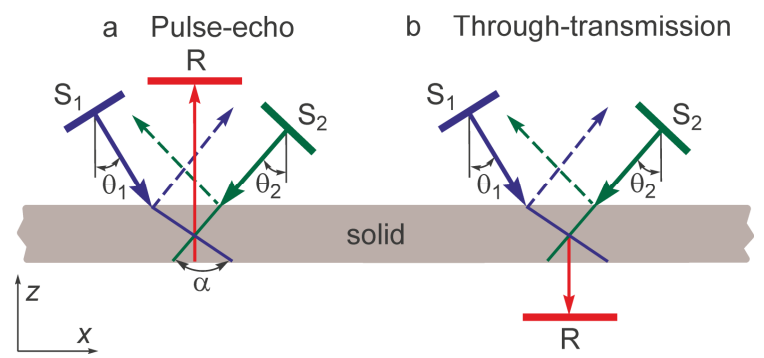

Figure 4.1. Pulse-echo and through-transmission arrangement of transducers for single-side (a) and double-side (b) access measurements. Shown are the scattered wave receiver R, the pump wave sources $S_{1,2}$ having inclination angles $\theta_{1,2}$. Red lines show propagation paths of the resonant wave. Dashed lines mark the specularly reflected pump waves. $\alpha$ is the interaction angle between the two pump waves.

For the submerged wave mixing, the most interesting interactions are

1. $\operatorname{SV}\left(\omega_{1}\right)+\mathrm{L}\left(\omega_{2}\right) \rightarrow \mathrm{L}\left(\omega_{1}+\omega_{2}\right)$

2. $\operatorname{SV}\left(\omega_{1}\right)+\operatorname{SV}\left(\omega_{2}\right) \rightarrow \mathrm{L}\left(\omega_{1}+\omega_{2}\right)$,

in which SV and L are the in-plane shear and longitudinal waves, respectively. The corresponding nonlinear wave amplitude coefficients (with dimension length ${ }^{-3}$ ) are [24]:

$$
\begin{aligned}
& W_{1}=\frac{D_{L}}{2 \gamma^{3}} \frac{\sin \alpha}{1+d}\left[C_{1}(3 d \gamma+2 q)+C_{2} q+C_{3}(d \gamma+q)+C_{5} d \gamma\right] \\
& \approx \frac{D_{L}}{\gamma^{3}} \frac{\sin \alpha}{1+d}(d \gamma+q) m \\
& W_{2}=D_{\mathrm{L}} \frac{1+d}{2 \gamma^{2}}\left(C_{1} \cos 2 \alpha+C_{2} \cos ^{2} \alpha-C_{3} \sin ^{2} \alpha\right) \approx D_{\mathrm{L}} \frac{1+d}{2 \gamma^{2}} m \cos 2 \alpha,
\end{aligned}
$$

where the following notations are used

$q=\cos \alpha\left(2 d \gamma \cos \alpha+1+2 \gamma^{2} d^{2}\right)$,

$D_{\mathrm{L}}=\frac{d}{4 \pi v_{\mathrm{L}}^{2} \rho}\left(\frac{\omega_{1}}{v_{g}}\right)^{3}$,

$\gamma=\frac{v_{\mathrm{S}}}{v_{\mathrm{L}}}$

$d=\omega_{2} / \omega_{1}$.

Parameter $\alpha$ is the wave interaction angle (see Fig. 4.1a), $v_{\mathrm{L}}$ and $v_{\mathrm{S}}$ are the longitudinal and shear wave velocities in a medium, respectively, $\rho$ is the material density, $v_{g}$ is the nonlinear wave velocity in a medium and in our case $v_{g}=v_{\mathrm{L}}$. The constants $C_{i}$ have simple relations 
$C_{1}=\mu+\frac{A}{4}, C_{2}=\lambda+\mu+\frac{A}{4}+B, C_{3}=\frac{A}{4}+B, C_{4}=B+2 C, C_{5}=\lambda+B$,

with third order elastic constants and Lamé parameters $\lambda$ and $\mu$.

Both of the interactions considered here can be used in single-sided or doublesided-access measurement modes using contact or immersion ultrasonic measurement techniques, which allow the generated longitudinal wave to strike the specimen and liquid interface perpendicularly. Interaction SV $\left(\omega_{1}\right)+\operatorname{SV}\left(\omega_{2}\right) \rightarrow \mathrm{L}\left(\omega_{1}+\omega_{2}\right)$ between two shear waves appears most promising, because it has a wave mode separation in this case. However, this interaction requires a large angle between two interacting waves (usually more than $120^{\circ}$ ), and thus it cannot be used for materials with low ultrasonic wave velocities, when a conventional immersion measurement technique is employed. Both PMMA and PVC materials used in our ageing experiments have low ultrasonic wave velocities and therefore we used the interaction $\operatorname{SV}\left(\omega_{1}\right)+\mathrm{L}\left(\omega_{2}\right) \rightarrow \mathrm{L}\left(\omega_{1}+\omega_{2}\right)$. In the epoxy cure experiments the other interaction $\operatorname{SV}\left(\omega_{1}\right)+\operatorname{SV}\left(\omega_{2}\right) \rightarrow \mathrm{L}\left(\omega_{1}+\omega_{2}\right)$ was used allowing the wave mode separation. The use of both interactions in our experiments proved their practical applicability in ultrasonic measurements. Note that both chosen interactions are the functions of just one third-order elastic constant $m$. Imaging and testing of the other two nonlinear elastic constants $l$ and $n$ require other interactions.

Measurement techniques, based on wave interactions when a nonlinear wave of difference frequency is generated, are limited to double-side-access measurement mode.

Knowing the properties of a test specimen and using the analytical results obtained in Korneev et. all [24], we have developed a procedure that enables to tune an acoustical channel for noncollinear wave mixing. For example, the tuning procedure for the through-transmission measurement case includes the following steps:

1. Prediction of nonlinear scattering coefficients $W$ (Eq. 4.3 and 4.4) for the twoplane elastic-wave interactions in an allowed or selected frequency range;

2. Calculation of possible combinations of inclination angles $\theta_{1}$ and $\theta_{2}$ for the pump wave sources (Fig. 4.1);

3. Evaluation of transmission coefficients $\mathrm{T}_{1}\left(\theta_{1}\right)$ and $\mathrm{T}_{2}\left(\theta_{2}\right)$ between a liquid and solid interface for Step 2;

4. Calculation of nonlinear wave propagation angle $\alpha$, which is a function of the $\theta_{1}$ angle (angle $\alpha$ is between the scattered wave direction and surface normal of the test specimen);

5. Calculation of the energy transmission coefficient $\mathrm{T}(\alpha)$ between a solid and liquid interface for Step 4;

6. Calculation of the amplitude function $W_{\mathrm{T}}=W \times \mathrm{T}_{1} \times \mathrm{T}_{2} \times \mathrm{T}$;

7. Estimation of the frequency range after setting $\alpha=0$, when the nonlinear wave strikes the solid and water interface perpendicularly.

8. Fine tuning of $\theta_{2}$ by maximization of the recorded scattered energy.

An example of calculations is shown in Fig. 4.2 for aluminum analyzed in [25] and PVC, when attenuation is not taken into account. The material properties are listed in Table 4.1. Two different noncollinear wave-mixing measurements are allowed in aluminum when an immersion ultrasonic technique is used: $\operatorname{SV}\left(\omega_{1}\right)+\mathrm{L}\left(\omega_{2}\right) \rightarrow$ 
$\mathrm{L}\left(\omega_{1}+\omega_{2}\right) \quad$ (Fig. 4.2a) and $\operatorname{SV}\left(\omega_{1}\right)+\mathrm{SV}\left(\omega_{2}\right) \rightarrow \mathrm{L}\left(\omega_{1}+\omega_{2}\right)$ (Fig. 4.3). One noncollinear wave interaction case, $\mathrm{SV}\left(\omega_{1}\right)+\mathrm{L}\left(\omega_{2}\right) \rightarrow \mathrm{L}\left(\omega_{1}+\omega_{2}\right)$, is allowed in PVC according to results obtained for aluminum when an immersion ultrasonic technique is used (Fig. 4.2b). It means that the conventional ultrasonic immersion technique enables to achieve conditions only for the $\mathrm{SV}\left(\omega_{1}\right)+\mathrm{L}\left(\omega_{2}\right) \rightarrow \mathrm{L}\left(\omega_{1}+\omega_{2}\right)$ interaction in PVC.
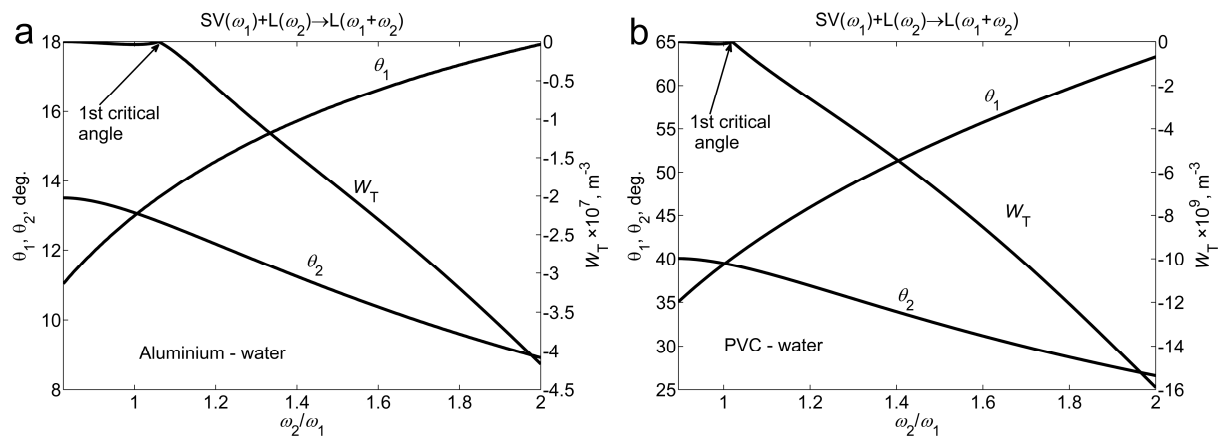

Figure 4.2. Amplitude function $W_{\mathrm{T}}$ vs frequency ratio $\omega_{1} / \omega_{2}$ for $\operatorname{SV}\left(\omega_{1}\right)+\mathrm{L}\left(\omega_{2}\right) \rightarrow$ $\mathrm{L}\left(\omega_{1}+\omega_{2}\right)$ wave mixing when the nonlinear wave strikes the specimen aluminum - water (a), and PVC - water (b) interfaces perpendicularly. Also shown are inclination angles $\theta_{1}$ and $\theta_{2}$ for the pump waves.

Table 4.1. Material properties used in the nonlinear wave analysis.

\begin{tabular}{lllllll}
\hline \hline Material & $\lambda, \mathrm{GPa}$ & $\mu, \mathrm{GPa}$ & $l, \mathrm{GPa}$ & $m, \mathrm{GPa}$ & $n, \mathrm{GPa}$ & $\rho, \mathrm{kg} / \mathrm{m}^{3}$ \\
\hline Aluminum & 54.308 & 27.174 & -281.5 & -339 & -416 & 2704 \\
PVC & 3.64 & 1.83 & -33.43 & -20.88 & -15.86 & 1350 \\
\hline \hline
\end{tabular}

Analytical estimation of aluminum and PVC shows (Fig. 4.2) that a higher (by two orders) amplitude of nonlinear wave is expected in PVC. This is due to the higher nonlinearity of PVC and lower energy losses in transmissions of ultrasonic waves at water-PVC and PVC-water interfaces. First, the critical angle is seen in $W_{\mathrm{T}}$ predictions for aluminum and PVC. For the case of aluminum, the influence of the first critical angle is seen when the frequency ratio $\omega_{2} / \omega_{1}$ is 1.06 . The incident angle $\theta_{2}$, at which the longitudinal wave is generated in aluminum, is $12.82^{\circ}$, less than the first critical angle. Consequently, the ultrasonic wave energy is transmitted from water to aluminum. The incident angle $\theta_{1}$ at which the shear wave is excited in aluminum is $13.52^{\circ}$, which corresponds to the first critical angle in the specimen. Hence, no ultrasonic shear wave energy is generated in the solids, and coefficient $W_{\mathrm{T}}$ becomes 0 . When the interaction occurs between two shear waves (Fig. 4.3), both incident angles $\theta_{1}$ and $\theta_{2}$ are larger than the first critical angle, so there is no local minimum in the $W_{\mathrm{T}}$ curve. 


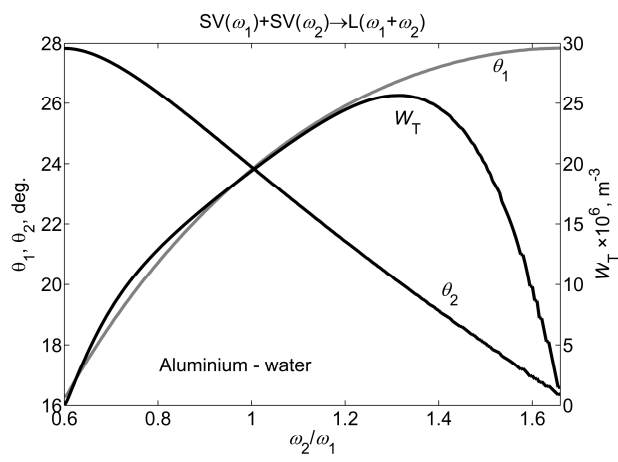

Figure 4.3. Amplitude function $W_{\mathrm{T}}$ vs frequency ratio $\omega_{2} / \omega_{1}$ for $\operatorname{SV}\left(\omega_{1}\right)+\operatorname{SV}\left(\omega_{2}\right) \rightarrow \mathrm{L}\left(\omega_{1}+\right.$ $\omega_{2}$ ) wave mixing in aluminum when the nonlinear wave strikes the specimen and water interface perpendicularly. Also shown are inclination angles $\theta_{1}$ and $\theta_{2}$ for the pump waves.

The calculations show that for aluminum, a nonlinear wave of higher amplitude is expected in the second wave-mixing case when the frequency ratio $\omega_{2} / \omega_{1}<1$.6. As seen in Fig. 4.2a, within the calculated frequency range $\left(0.6<\omega_{2} / \omega_{1}<2\right)$, the highest amplitude of the nonlinear wave is expected when the frequency ratio is the highest. But it may be practically difficult to use higher frequency ratios (at $\mathrm{MHz}$ frequency range), because attenuation of ultrasonic waves increases with frequency, and the beamwidth of resonant waves becomes very sharp. Therefore, the scattered wave will be affected by any inhomogeneity in a specimen, and especially in heterogeneous materials like rock and concrete. For example, when the frequency of the scattered wave is $12 \mathrm{MHz}$ in the aluminum specimen, the beamwidth of the scattered wave, generated by an interaction volume of $5 \mathrm{~mm}$ radius, is less than $5^{\circ}$ [26].

Since commercially available ultrasonic transducers of standard frequencies are available, it is practical to choose the frequency ratio of pump waves in such a way that both the performance of the transducers and the sensitivity of the receiver to the nonlinear wave stay high. With this in mind, we selected the frequency ratio $\omega_{2} / \omega_{1}$ to be 1.5 , and the corresponding frequencies of the pump waves to be $6 \mathrm{MHz}$ and $4 \mathrm{MHz}$, respectively. Further increase in $\omega_{2}$ can be affected by a higher attenuation of the pump and nonlinear waves. A nonlinear wave of $10 \mathrm{MHz}$ frequency has good separation from the $4 \mathrm{MHz}$ and $6 \mathrm{MHz}$ harmonics of the pump waves. Thus, the informative signal can be filtered easily from unwanted harmonics in the raw acoustic signal.

In some cases, when measurements are limited to single-side-access measurement mode, a signal-to-noise ratio can be increased employing interaction between reflections of pump waves from specimen bottom. The generated nonlinear wave will not lose energy during reflection from the specimen boundary. This option may be useful for evaluation of heterogeneous materials. 


\subsection{Measurement setup}

A typical arrangement of ultrasonic transducers for immersion noncollinear wavemixing measurements in the through-transmission mode is shown in Fig. 4.4. The employed geometrical parameters are listed in Table 4.2, with the following notation: $f_{1}$ and $f_{2}$ are the frequencies of the pump waves generated by sources $\mathrm{S}_{1}$ and $\mathrm{S}_{2}$, respectively. The numbers of cycles used for pump wave generation are listed in brackets after the frequencies. Inclination angles $\theta_{1}$ and $\theta_{2}$, as well as vertical offsets $\Delta z_{1}$ and $\Delta z_{2}$ are related to the sources $S_{1}$ and $S_{2}$ respectively. Also shown are the distance $\Delta x$ between the pump wave sources, and the distance $\Delta z$ between receiver $\mathrm{R}$ and the specimen surface. Immersion planar broadband transducers with $10 \mathrm{~mm}$ diameters were used for generation of the pump waves. A planar broadband sensor with a $5 \mathrm{MHz}$ central frequency was used for signal reception in the physical ageing monitoring experiments. For the epoxy curing monitoring, we used a spherically focused broadband sensor with $10 \mathrm{MHz}$ central frequency. The received ultrasonic signals were amplified by a $20 \mathrm{~dB}$ preamplifier, digitized, and stored on a personal computer for further analysis. The received signals were filtered using a narrowband filter with a Kaiser window.

Table 4.2. Geometrical parameters used for the noncollinear wave mixing experiments.

\begin{tabular}{llllllllll}
\hline \hline Structure & $\begin{array}{l}f_{1}, \mathrm{MHz} \\
{[\text { cycles] }}\end{array}$ & $\begin{array}{llll}f_{2}, \mathrm{MHz} \\
\text { [cycles] }\end{array}$ & $\begin{array}{l}f_{g}, \\
\mathrm{MHz}\end{array}$ & $\begin{array}{l}\theta_{1}, \\
\text { deg. }\end{array}$ & $\begin{array}{l}\theta_{2}, \\
\text { deg. }\end{array}$ & $\begin{array}{l}\Delta z_{1}, \\
\mathrm{~mm}\end{array}$ & $\begin{array}{l}\Delta z_{2}, \\
\mathrm{~mm}\end{array}$ & $\begin{array}{l}\Delta z, \\
\mathrm{~mm}\end{array}$ & $\begin{array}{l}\Delta x, \\
\mathrm{~mm}\end{array}$ \\
\hline PVC & $2[40]$ & $3[40]$ & 5 & 52 & 31 & 12 & 19 & 32 & 35 \\
PMMA & $2[30]$ & $3[50]$ & 5 & 36 & 25 & 15 & 20.5 & 32 & 30 \\
Al-Ep-Al & $4[30]$ & $6[30]$ & 10 & 22 & 15.5 & 18 & 22 & 80 & 21 \\
\hline \hline
\end{tabular}

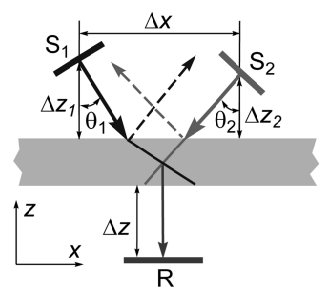

Figure 4.4. Arrangement of ultrasonic transducers for the noncollinear wave mixing in the through-transmission measurement mode. Dashed lines mark the specularly reflected pump waves.

For evaluations of nonlinear wave signals we used a peak-to-peak amplitude, energy, and change of time-of-flight. In an ideal case, the peak-to-peak amplitude and energy of ultrasonic signals would give similar results, but when an ultrasonic signal has a complex wave-shape, the results may differ. Previous work has shown that for the analysis of nonlinear wave signals, it is more practical to evaluate the energy of signals [2]. When we can compare the behavior of both parameters-the peak-to-peak amplitude and energy - we present both of them. 


\subsection{Monitoring of physical ageing process in thermoplastics}

For the physical ageing investigation in PMMA and PVC plates (commercially available grades), we employed the $\operatorname{SV}\left(\omega_{1}\right)+\mathrm{L}\left(\omega_{2}\right) \rightarrow \mathrm{L}\left(\omega_{1}+\omega_{2}\right)$ wave-mixing process. The plate thicknesses were $9 \mathrm{~mm}$ and $10 \mathrm{~mm}$, respectively, and the in-plane whole specimen size was $\sim 65 \mathrm{~mm} \times 160 \mathrm{~mm}$ in both cases.

First, a specimen was heated in boiled water for $10 \mathrm{~min}$ and immediately quenched in an antifreeze liquid of temperature $T=-27^{\circ} \mathrm{C}$. The heating was above the glass transition temperature $T_{g}$, thus erasing the previous thermo-history of the polymer. Then, the quenched specimen was placed into a water bath, where the nonlinear ultrasonic measurements were performed with a $30 \mathrm{~s}$ sampling rate. A magnetic stirrer was used to maintain a uniform room temperature distribution in the water bath: $18.3 \pm 0.1^{\circ} \mathrm{C}$ or $22.2 \pm 0.2^{\circ} \mathrm{C}$ for PMMA and PVC, respectively.

Figure 4.5 shows typical curves sampled during the monitoring of PMMA and PVC ageing. In the beginning, when the temperature of the polymer is lower than that of water, a high nonlinear ultrasonic wave energy is measured in both polymers. An increase in the energy of the nonlinear wave simultaneous with a decrease in temperature was reported [2]. During the experiment, the specimen temperature increases because of the heat exchange. Therefore, the energy of the nonlinear ultrasonic wave decreases, with this trend ending when the specimen temperature becomes equal to that of water. This temperature equilibrium is seen in Fig. 4.5, when the energy of the nonlinear wave becomes lowest, which was observed after about 9 min and 7.5 min for PMMA and PVC, respectively. Further, the nonlinear wave energy starts to increase due to the physical ageing in the polymers. The highest energyincrease ratio is observed between $9 \mathrm{~min}$ and $100 \mathrm{~min}$, signifying that the ageing rate is also the highest in this range. As time progresses, the ageing slows down, especially for PMMA.

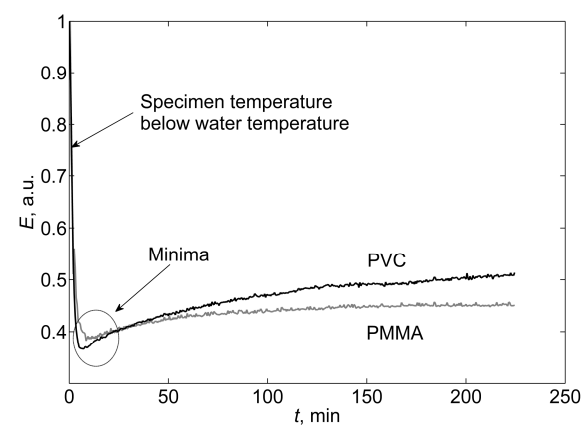

Figure 4.5. Measured nonlinear wave energy evolution during physical ageing process in PMMA and PVC. Minima location shows when the specimen and water temperatures become equivalent.

Typically, the physical ageing process is presented in a logarithmic time scale, as is done in Fig. 4.6. This figure shows the relative changes in the energy of nonlinear 
waves $\Delta E=\left(E-E_{0}\right) / E_{0} \times 100 \%$, where $E_{0}$ is the minimal measured magnitude (see Fig. 4.5). The curves show that the ageing is faster in PMMA than in PVC-in agreement with the reported results in [27].

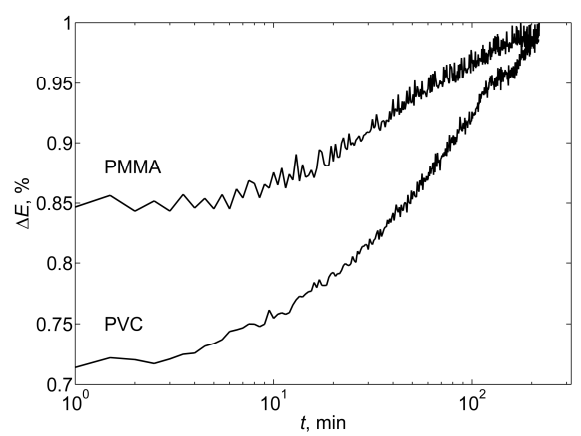

Figure 4.6. Measured dynamics of the physical ageing processes in PMMA and PVC.

The test curves (Figs. 4.5 and 4.6) show that the ageing process is relatively complete for PMMA after about two hours, because the energy of the nonlinear wave increases very slowly after this time. This is not as apparent in Fig. 4.6, because of the logarithmic scale. The shape of the measured curve for PMMA corresponds closely to the theoretical shape-reported in [4], where it is shown that the parametric curve obtains a sigmoidal shape. Knowing that temperature accelerates physical ageing (and despite the fact that the temperature was $4^{\circ} \mathrm{C}$ higher than for PMMA), we observed that in the PVC specimen, the ageing process was not completed in the same time window as in the PMMA specimen.

To illustrate the physical ageing influence on material properties, additional measurements were performed for the PMMA and PVC specimens. Each specimen was prepared as follows: one half of the plate was isolated from both sides, to protect the specimens from heating as much as possible. After that, the uncovered part was immersed in boiling water for $10 \mathrm{~min}$, to rejuvenate the material locally. Finally, the entire specimen was immediately quenched in an antifreeze liquid at a temperature $T=-27^{\circ} \mathrm{C}$. Then the specimens were scanned using linear and nonlinear ultrasonics with a $1 \mathrm{~mm}$ step, along a central line. The linear scanning was performed using a 5 $\mathrm{MHz}$ broadband transducer in a pulse-echo mode employing single-pulse excitation.

Scanning results for the PMMA plate are presented in Fig. 4.7. The figure clearly shows a high nonlinear wave energy difference between the rejuvenated and unprocessed zones. In the measured energy of the nonlinear wave, a transient zone is observed between both the rejuvenated and nonrejuvenated plate parts. Obviously, this transient zone was affected by water vapor as well as by heat conduction from the immersed part. At the same time, the linear ultrasonic measurement of the peak-to-peak amplitude shows very little sensitivity to the physical ageing of PMMA. Moreover, the transient zone is not seen in this data. A small linear trend, seen in the linear measurements of time-of-flight, could be caused by a specimen misalignment; and it is 
clearly seen that there is no correlation between the nonlinear wave signal and the timeof-flight of the linear ultrasonic signals.

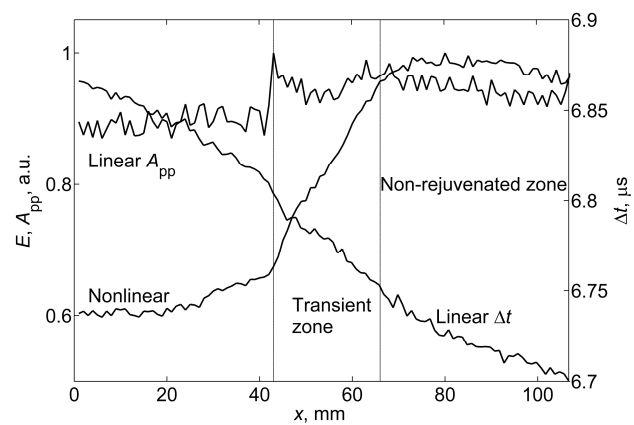

Figure 4.7. Measured physical ageing state in PMMA plate using nonlinear and linear ultrasonics; one central line was scanned along the specimen.

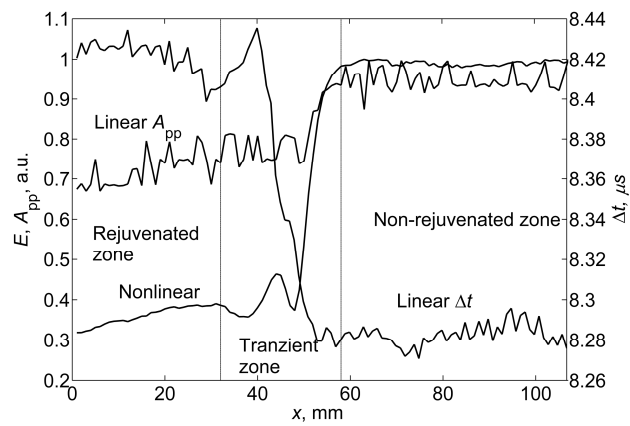

Figure 4.8. Physical ageing state in PVC plate using nonlinear and linear ultrasonics.

The ultrasonic scans for the PVC plate are shown in Fig. 4.8. The nonlinear wave energy exhibits a pronounced difference (relative change is up to 230\%) between rejuvenated and nonrejuvenated zones. This difference could be caused not only by physical ageing, but also by the effects of ageing combined with thermal expansion. Mechanical measurements of plate thickness and ultrasonic measurements of the timeof-flight for ultrasonic waves confirmed that plate thickness increased locally by about $0.1 \mathrm{~mm}$ after heating in the boiling water. This conforms with test data for thermal expansion reported in [27], which show that heating above $\approx 75^{\circ} \mathrm{C}$ results in a drastic (and probably partially irreversible) "jump" in PVC volume, whereas the thermal expansion of PMMA is still relatively low. Thus, we believe that the linear ultrasonics detected different zones in the PVC not because of its sensitivity to material properties, but due to thermal expansion and probable water absorption-in accord with previous studies [1, 28], which demonstrated that the linear ultrasonics is insensitive to the physical ageing of PVC. 


\subsection{Monitoring of epoxy curing}

Epoxy curing processes are well studied with linear ultrasonic measurement techniques (for example, see reported works [6-8, 29-33]. The linear ultrasonic technique is shown to be applicable for monitoring of thin (about $0.5 \mathrm{~mm}$ ) epoxy layers [33] and for detection of the gelation time (when a viscous liquid transforms into an elastic gel) [31, 32, 34]. However, there is insufficient information about detection of the vitrification time (when the mobility of reactive groups vanishes) [35]. In this section, we present a nonlinear ultrasonic measurement technique that enables us to monitor epoxy curing in a thin layer, with robust detection of the typical points (gelation and vitrification). A verification and explanation of the ultrasonic measurement results are presented in the next section.

To monitor isothermal epoxy curing, we used the $\operatorname{SV}\left(\omega_{1}\right)+\operatorname{SV}\left(\omega_{2}\right) \rightarrow \mathrm{L}\left(\omega_{1}+\omega_{2}\right)$ wave-mixing process. The epoxy we employed was a typical commercial system comprising 3/4 of Araldite ${ }^{\circledR}$ LY1564SP resin and 1/4 of XB3486 hardener, by mass [36]. The components were degassed for $20 \mathrm{~min}$ after mixing, and then the mix was directly (with only a 5-10 min delay) used for the tests. In the rheometry tests reported in the next section, the preparations required more time, and the delay was about 20 $\min$.

The prepared epoxy was spread on a $4 \mathrm{~mm}$ thick aluminum plate and then covered by a second identical aluminum plate. (To provide a uniform thickness for the epoxy layer, a $0.2 \mathrm{~mm}$ thick double-sided tape was placed to form a $1 \mathrm{~cm}$ wide barrier on the sides of the plate). Then, the aluminum plates were fixed (using bolts) and sealed (using a tacky "gum") to isolate the epoxy from water. Finally, the specimen was placed in a water bath under an acoustic channel adjusted for mixing the ultrasonic waves in a single $4 \mathrm{~mm}$ thick aluminum plate.

Arrangement of the ultrasonic transducers and specimen was chosen in such a way that the central beams of pump waves would intersect in the epoxy layer. Because of this arrangement and finite beam width (which was of the same order as the pump wave-transducer diameters), the following three volumes (where the nonlinear wave interactions occurred) could be separated:

1. Volume 1 in the upper aluminum layer. The interaction of pump waves occurred without the influence of epoxy. Consequently, a constant amount of nonlinear wave energy was generated.

2. Volume 2 in the epoxy layer. The nonlinear wave was either not generated or very poorly generated, because the wave-interaction conditions for aluminum were chosen.

3. Volume 3 in the lower layer of aluminum. The resulting amount of nonlinear wave energy in this volume was expected to be strongly dependent on the epoxy-layer properties. Because of changes in the longitudinal and shear-wave velocities during epoxy curing, transmission and refraction of ultrasonic waves varied between the epoxy and aluminum interfaces. Hence, the synchronistic conditions of wave interaction were not completely fulfilled (i.e., generation of the nonlinear wave was ineffective). Moreover, these conditions varied, owing to changes in the acoustic properties of epoxy. Therefore, the amount of the generated wave energy varied considerably in this volume. 
Monitoring of the curing process was performed at $24.3^{\circ} \mathrm{C}$ or at $40^{\circ} \mathrm{C}$ with a $30 \mathrm{~s}$ sampling rate. Three parameters of the nonlinear ultrasonic wave were analyzed: the peak-to-peak amplitude, energy, and group time-of-flight of signal. The time-of-flight for the nonlinear signal was determined using the first measurement signal as the reference.

Test data for the $24.3^{\circ} \mathrm{C}$ case are presented in Fig. $4.9 \mathrm{a}$; they clearly show three typical points, seen at $1.3 \mathrm{~h}, 6.7 \mathrm{~h}(10 \mathrm{~h})$ and $20 \mathrm{~h}$. The first peak at $1.3 \mathrm{~h}$ is well indicated by all three parameters. The measured minimum at $6.7 \mathrm{~h}$ is clearly indicated by the nonlinear wave peak-to-peak amplitude and energy. However, in the time-offlight curve, this peak has shifted further and is situated at about $10 \mathrm{~h}$. Fig. 4.9 shows that a small deviation occurred (different slopes) between the peak-to-peak amplitude and energy curves within the time interval $10 \mathrm{~h}-20 \mathrm{~h}$. The third typical point (at about $20 \mathrm{~h}$ ) is not easily determined in the curves, but the time-of-flight curve has a clear change of phase at this point. The measured energy and peak-to-peak amplitude tend to become constant after passing this point.
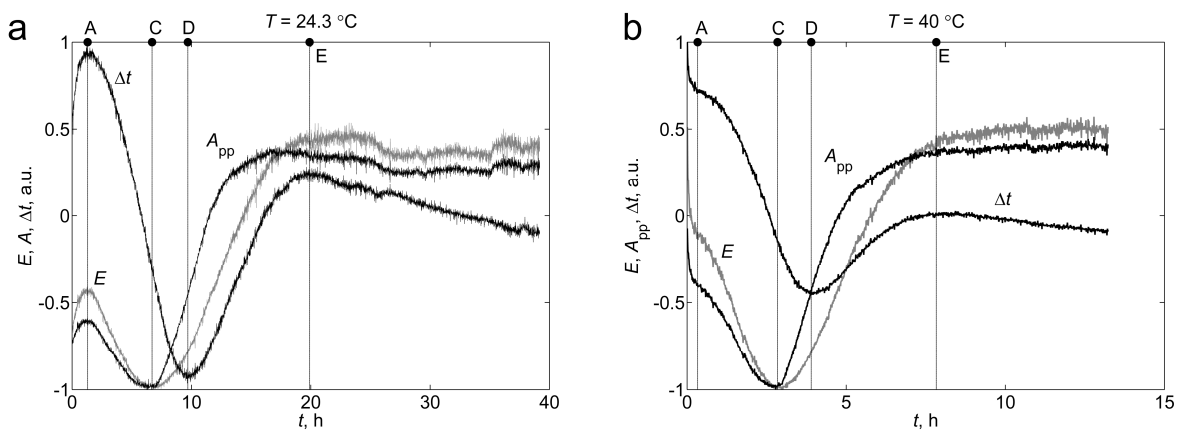

Figure 4.9. Dynamics of the nonlinear ultrasonic signal parameters during epoxy curing at $24.3^{\circ} \mathrm{C}$ (a) and $40^{\circ} \mathrm{C}$ (b). The parameters are scaled by their maxima and centred.

Fig. 4.10 shows typical nonlinear ultrasonic signals at the characteristic points discussed above. The signals are scaled by the maximum amplitude of the signal measured at $20 \mathrm{~h}$. We see here that the informative signal duration becomes shorter during the curing process, which indicates solidification of the epoxy. 


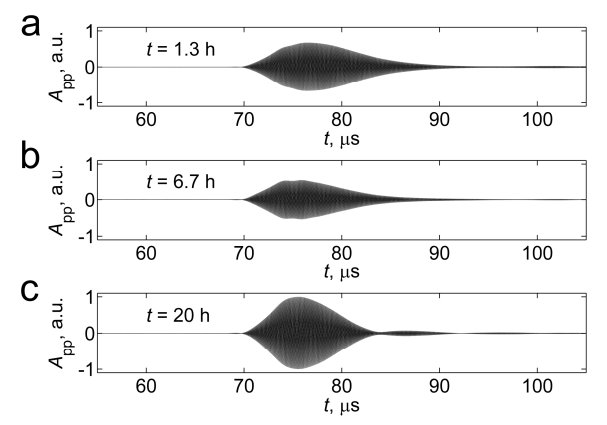

Figure 4.10. Typical nonlinear ultrasonic signals during epoxy curing at $24.3^{\circ} \mathrm{C}$ : minimum viscosity point (a), gelation point (b) and vitrification point (c).

Test data for the $40^{\circ} \mathrm{C}$ case are presented in Fig. $4.9 \mathrm{~b}$. Clearly, the curing process has been accelerated by the higher temperature in comparison with the $24.3^{\circ} \mathrm{C}$ case. The initial linear decrease in energy and amplitude was caused by the lower initial temperature of the specimen. These results agree very well with the measurement results for physical ageing in PMMA and PVC (see Fig. 4.5). The following characteristic points can be derived from Fig. $4.9 \mathrm{~b}: 0.3 \mathrm{~h}, 2.8 \mathrm{~h}(3.9 \mathrm{~h})$ and $7.8 \mathrm{~h}$. However, the first point $(0.3 \mathrm{~h})$ is not so well pronounced in this measurement as before for the $24.3^{\circ} \mathrm{C}$ case. This point is now seen only indirectly, as a local inflection of the curves.

Note that these ultrasonic measurements were performed in a large water bath, without a forced control of temperature, which changed slightly during the day-night cycle. This change caused small "jumps" in the curves, seen, for example, in Fig. 4.9a between $25 \mathrm{~h}$ and $37 \mathrm{~h}$.

\subsection{Verification of epoxy curing by rheometry}

An alternative cure characterization was performed using an Anton Paar®MCR501 parallel plate rheometer. This test method is widely used for this purpose (for example, see [37]), and its results can easily be interpreted in rheologic terms (viscosity, damping, etc.).

First, a $26 \mathrm{~mm}$ diameter ring was mounted on the bottom plate and partially filled with a 3-4 mm epoxy layer. Then, a $25 \mathrm{~mm}$ diameter top plate was sunk into this ring until it contacted the epoxy. After closing the chamber and setting the gained temperature, the shear viscosity was measured at a $1 \mathrm{~Hz}$ frequency and a $1.8^{\circ}$ amplitude of rotational oscillations. 

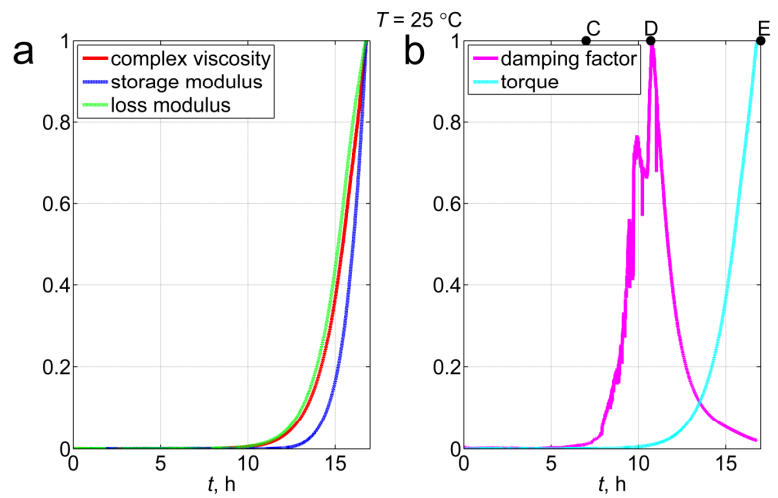

Figure 4.11. Cure monitoring using rheometry, $25^{\circ} \mathrm{C}$ case.
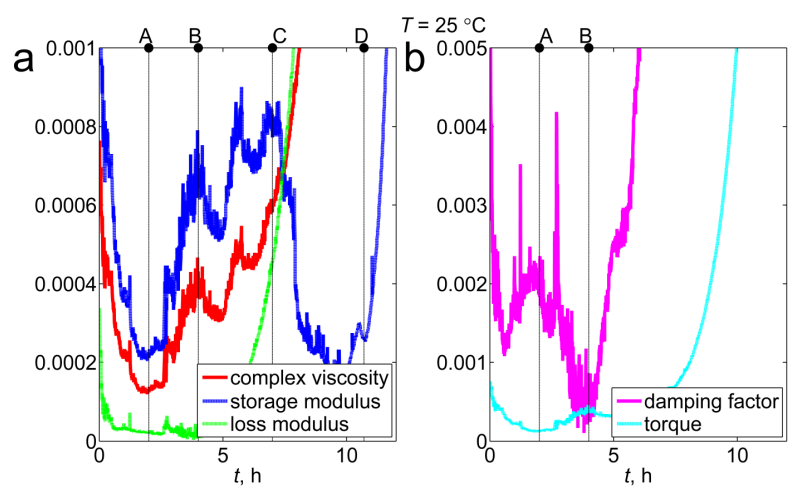

Figure 4.12. Cure monitoring using rheometry, $25^{\circ} \mathrm{C}$ case (zoomed).
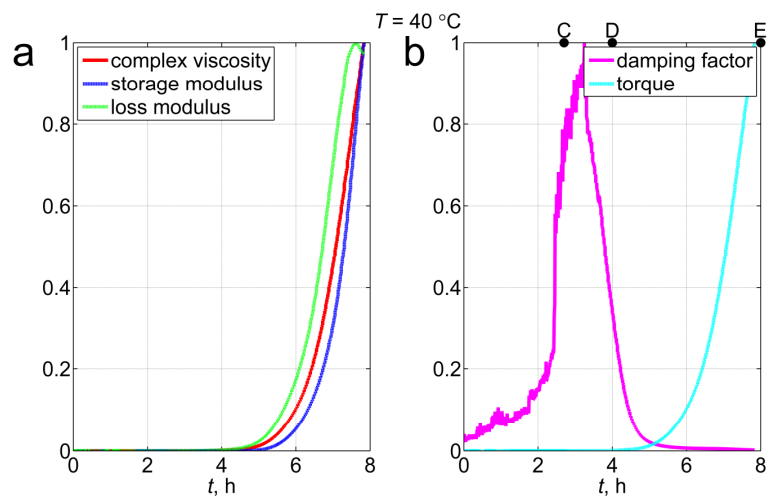

Figure 4.13. Cure monitoring using rheometry, $40^{\circ} \mathrm{C}$ case. 
Results for $25^{\circ} \mathrm{C}$ are shown in Figs. 4.11 and 4.12, while Fig. 4.13 shows results for the $40^{\circ} \mathrm{C}$ case. Figure 4.12 depicts a zoomed part of Fig. 4.11, showing details of the low-signal behavior (similar curves are not shown for $40^{\circ} \mathrm{C}$ case from Fig. 4.13 , since no local changes are seen in the quite smooth curves). The following characteristic points can be observed in these figures, enabling a better understanding of their physical backgrounds:

1. The first extremum, point A, corresponds to the minimum viscosity, which obviously occurs not directly after mixing of the resin and hardener, but (due to inertia in the chemical processes) is postponed for some time: about $2 \mathrm{~h}$ at $25^{\circ} \mathrm{C}$. This effect is not visible in the $40^{\circ} \mathrm{C}$ test conditions; in the $25^{\circ} \mathrm{C}$ case, it roughly corresponds to $1.3 \mathrm{~h}$, noted above when discussing Fig. 4.9a.

2. After a while, at point $\mathrm{B}, \sim 4 \mathrm{~h}$ at $25^{\circ} \mathrm{C}$, the reaction rate increases. This is seen as a minor local maximum of viscosity or a minor local minimum of the damping factor (then it starts to grow rapidly), and the onset of the loss modulus growth, again for the $25^{\circ} \mathrm{C}$ case only. Point $\mathrm{B}$ is not detected for the $40^{\circ} \mathrm{C}$ case, likely owing to the absence of any reaction-rate change in this case.

3. The following extremum, point $\mathrm{C}$, is the onset of gelation; it occurs at about 7 $\mathrm{h}$ at $25^{\circ} \mathrm{C}$ or $2.7 \mathrm{~h}$ at $40^{\circ} \mathrm{C}$. At this moment, the storage modulus reaches its local maximum, and the damping-factor rate becomes yet higher. This feature corresponds well to the $6.7 \mathrm{~h}$ and $2.8 \mathrm{~h}$ points noted above when discussing Fig. 4.9.

4. The next extremum, point $\mathrm{D}$, occurring at about $10-11 \mathrm{~h}$ at $25^{\circ} \mathrm{C}$ or $4 \mathrm{~h}$ at $40^{\circ} \mathrm{C}$, is the peak of gelation and, therefore, of the damping factor as well. Afterwards, the damping ability of the material vanishes rapidly. All other rheometry variables start to increase in magnitude, also very rapidly. Point $\mathrm{D}$ is also visible in Fig. 4.9 (10 h or $3.9 \mathrm{~h}$ estimated for $25^{\circ} \mathrm{C}$ and $40^{\circ} \mathrm{C}$ cases, respectively).

5. The last extremum is the onset of vitrification, point $\mathrm{E}$, at about $17 \mathrm{~h}$ for $25^{\circ} \mathrm{C}$ or $8 \mathrm{~h}$ for $40^{\circ} \mathrm{C}$. The rheometry is automatically stopped at this stage, due to exceeding the allowable torsional moment. When the specimens are then taken out of the machine, they appear completely solidified. This final point also agrees well with the vitrification times derived from Fig. 4.9 (roughly $20 \mathrm{~h}$ or $7.8 \mathrm{~h}$, respectively).

\subsection{C-scanning experiments}

The key issue of this research is the comparison of the linear and nonlinear ultrasonic measurement techniques with application to a nondestructive evaluation in a three-layered structure. Currently, there is too little information about those investigations in which nonlinear and immersion-ultrasonic-measurement techniques are used.

To approach this, we used two $4 \mathrm{~mm}$ thick aluminum plates bonded with the same epoxy resin. When the epoxy cure was completed at room temperature, the specimen was placed in a water bath, and C-scanning was performed at $1 \mathrm{~mm}$ steps in $x$ and $y$ 
directions, using both linear and nonlinear ultrasonic techniques. The linear pulse-echo measurements employed a spherically focused $10 \mathrm{MHz}$ transducer. The nonlinear scanning was performed using the same arrangement of ultrasonic transducers as in the epoxy cure monitoring discussed above, i.e. employing the interaction $\operatorname{SV}\left(\omega_{1}\right)+$ $\operatorname{SV}\left(\omega_{2}\right) \rightarrow \mathrm{L}\left(\omega_{1}+\omega_{2}\right)$

A peak-to-peak amplitude C-scan image, given by the linear ultrasonic measurement, is presented in Fig. 4.14. The nonlinear ultrasonic results are presented in Fig. 4.15 for the same specimen. Bubbles (naturally appearing during the epoxy cure) are seen as the low-amplitude spots (Figs. 4.14 and 4.15). The bubbles are not as prominent in the nonlinear ultrasonics C-scan image in comparison with Fig. 4.14. This can be explained by a better focused beam during the pulse-echo scanning. Actually, an elongation of inhomogeneity dimensions during the nonlinear ultrasonics scanning is similar to situation when Lamb waves are used to visualize the imperfections [38]. Therefore, forming of high resolution ultrasonic images (with a resolution of a few millimeters or parts of millimeter) can be complicated using the noncollinear wave mixing technique.

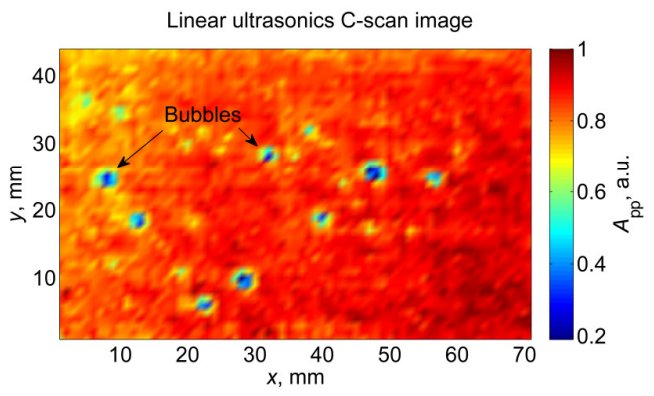

Figure 14. Amplitude C-scan image, by the linear ultrasonic measurement.

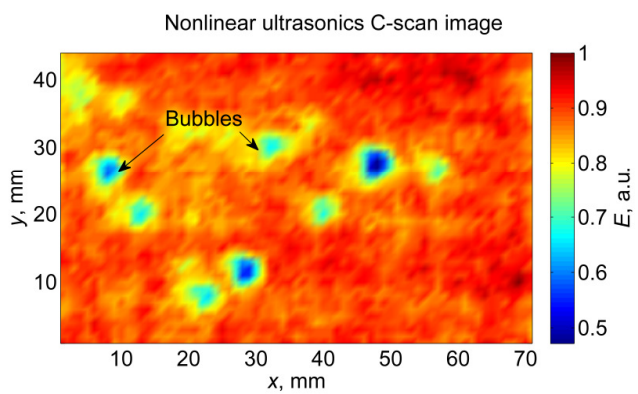

Figure 15. Energy C-scan image, by the nonlinear ultrasonic measurement. 


\subsection{Conclusions}

Nonlinear immersion ultrasonic-measurement techniques are presented in this study, with applications for monitoring the material transformations in polymers. We demonstrate that the nonlinear ultrasonics, based on noncollinear wave mixing, can be very sensitive to small changes in materials - changes that are hardly detectible (or undetectable) using linear ultrasonic-measurement techniques. The nonlinear technique can be used for contactless in situ monitoring of dynamic material properties, as well as for nondestructive testing.

The most remarkable results are obtained for the physical ageing processes in thermoplastics (PMMA and PVC). The ageing is well detected by the nonlinear ultrasonic technique, while the linear technique is insensitive to physical ageing. For example, the nonlinear data for PMMA show a $40 \%$ difference between zones of "young" and "aged" material, whereas the linear data show no difference at all. For PVC, while the linear ultrasonics indicates a $45 \%$ difference (presumably caused by an irreversible thermal expansion of the material), the nonlinear ultrasonics shows as much as a $230 \%$ difference.

The nonlinear ultrasonic method is also shown to effectively detect the main characteristics of the epoxy cure process: the time of maximal viscosity, the gel time, and the vitrification time. These results agree closely with those obtained using a conventional parallel-plate DMA method.

Finally, a simple test demonstrates the ability of the nonlinear ultrasonic technique for a nondestructive testing with results comparable with the linear ultrasonic technique. However, the nonlinear technique seems to provide a lower spatial resolution to imperfections in the specimen geometry. (This disadvantage can be minimized by using more dedicated pump wave sources.)

Possible advantages offered by the presented nonlinear ultrasonic technique include: a) the wave-mode and frequency separations, b) elimination of surrounding medium influence, c) steering (scanning) the scattered wave and controlling the intersection volume location, d) single or double-sided measurements, and e) operating in the detector mode (for example, no informative signal excitation until the material properties are homogenous).

\section{Acknowledgments}

This work was performed partially in collaboration with Vitens and ApplusRTD, within the 'Innowator' project IWA-08019, as funded by the Dutch Ministry of Economic Affairs by means of Agentschap NL. This support is gratefully acknowledged. This work was also supported by the Director, Office of Energy Research, Office of Basic Energy Sciences, Chemical Sciences, Geosciences, and Biosciences Division, of the U.S. Department of Energy under Contract No. DE-AC0205CH11231. 


\section{References}

1. A. Demčenko, R. Akkerman, P. B. Nagy, and R. Loendersloot, "Non-collinear wave mixing for non-linear ultrasonic detection of physical ageing in PVC," NDT \& E Int. 49, 34-39 (2012).

2. A. Demčenko, M. Ravanan, H. A. Visser, R. Loendersloot, and R. Akkerman, "Investigation of PVC physical ageing in field test specimens using ultrasonic and dielectric measurements," in Proceedings of the IEEE International Ultrasonics Symposium, 19091912, (2012).

3. A. Demčenko, "Non-collinear wave mixing for a bulk wave phase velocity measurement in an isotropic solid," in Proceedings of the IEEE International Ultrasonics Symposium, 14371440, (2012).

4. K. Chen and K. S. Schweizer, "Theory of physical aging in polymer glasses," Phys. Rev. E 78, 031802-1-031802-15 (2008).

5. K. Chen and K. S. Schweizer, "Molecular theory of physical aging in polymer glasses," Phys. Rev. Lett 98, 167802 (2007).

6. W. P. Winfree, "Ultrasonic characterization of changes in viscoelastic properties during cure," IEEE Ultrasonic Symposium Proceedings, 1: 866-869 (1983).

7. R. J. Freemantle and R. E.Challis, "Combined compression and shear wave ultrasonic measurements on curing adhesive," Meas. Sci. Technol. 9, 1291-1302 (1998).

8. S. Dixon, D. Jaques, S. B. Palmer, and G. Rowlands, "The measurement of shear and compression waves in curing epoxy adhesives using ultrasonic reflection and transmission techniques simultaneously,” Meas. Sci. Technol. 15, 939-947 (2004).

9. M. A. Breazeale and D. O. Thompson, Finite-amplitude ultrasonic waves in aluminum, Appl. Phys. Lett. 3, 77-78 (1963).

10. P. H. Carr, "Harmonic generation of microwave phonons in quartz," Phys. Rev. Lett. 13, 332-335 (1964).

11. P. H. Carr, "Harmonic generation of microwave phonons by radiation pressure and by the phonon-phonon interaction," IEEE T. Son. Ultrason. 13, 103-108 (1966).

12. K. K. Ermilin, L. K. Zarembo, and V. A. Krasil'nikov, "Generation of superhigh frequency acoustic harmonics in a lithium niobate crystals," Sov. Phys.-Solid State 12, 1045-1052 (1970).

13. A. A. Gedroits and V. A. Krasil'nikov, "Finite-amplitude elastic waves amplitude in solids and deviations from the Hooke's law," JETP Lett. 16, 1122 (1963).

14. P. A. Johnson and K. R. McCall, "Observation and implications of nonlinear elastic wave response in rock," Geophys. Res. Lett. 21, 165-168 (1994).

15. Y. Hiki and K. Mukai, "Ultrasonic three-phonon process in copper crystal," J. Phys. Soc. Jpn. 34, 454-461 (1973).

16. F. R. Rollins, L. H. Taylor, and P. H. Todd, "Ultrasonic study of three-phonon interactions. II. Experimental results," Phys. Rev. 136, A597-A601 (1964).

17. L. K. Zarembo and V. A. Krasil'nikov, "Nonlinear phenomena in the propagation of elastic waves in solids," Sov. Phys. Usp. 13, 778-797 (1971).

18. P. A. Johnson, T. J. Shankland, R. J. O'Connell, and J. N. Albright, "Nonlinear generation of elastic waves in crystalline rock," J. Geophys. Res. 92, 3597-3602 (1987).

19. P. A. Johnson and T. J. Shankland, "Nonlinear generation of elastic waves in granite and sandstone: continuous wave and travel time observations," J. Geophys. Res. 94, 17,72917,733 (1989).

20. H. H. Barrett and J.H. Matsinger, "Interaction of almost-collinear longitudinal phonons," Phys. Rev. 154, 877-886 (1967). 
21. R. W. Dunham and H. B. Huntington, "Ultrasonic beam mixing as a measure of the nonlinear parameters of fused silica and single-crystal NaCl," Phys. Rev. B 2, 1098-1107 (1970).

22. A. J. Croxford, P. D. Wilcox, B. W. Drinkwater, and P. B. Nagy, "The use of non-collinear mixing for nonlinear ultrasonic detection of plasticity and fatigue," J. Acoust. Soc. Am. 126, EL117-EL122 (2009).

23. F. D. Murnaghan, Finite deformation of elastic solid, John Wiley, New York, 1951.

24. V. A. Korneev, K. T. Nihei, and L. R. Myer, "Nonlinear interaction of plane elastic waves," Tech. Rep. LBNL-41914, Lawrence Berkeley National Laboratory, USA, 1998.

25. J. R. Asay and A. H. Guenther, "Ultrasonic studies of 1060 and 6061-T6 aluminum,“ J. Appl. Phys. 38, 4086-4088 (1967).

26. I. A. Beresnev, "Interaction of two spherical elastic waves in a nonlinear five-constant medium," J. Acoust. Soc. Am. 94, 340-3404 (1993).

27. R. Greiner and F. R. Schwarzl, "Thermal contraction and volume relaxation of amorphous polymers," Rheol. Acta 23, 378-395 (1984).

28. B. E. Read, G. D. Dean, P. E. Tomlins, and J. L. Lesniarek-Hamid, "Physical ageing and creep in PVC," Polymer 33, 2689-2698 (1992).

29. A. M. Lindrose, "Ultrasonic wave and moduli changes in a curing epoxy resin - Ultrasonic techniques are examined as a means for monitoring reaction extent and the development of solid-phase moduli in a curing epoxy," Exp. Mech. 18, 227-232 (1978).

30. S. I. Rokhlin, D. K. Lewis, K. F. Graff, and L. Adler, "Real-time study of frequency dependence of attenuation and velocity of ultrasonic waves during the curing reaction of epoxy resin,” J. Acoust. Soc. Am. 79, 1786-1793 (1986).

31. I. Alig, K. Nancke, and G. P. Johari, "Relaxations in thermosets. XXVI. Ultrasonic studies of the temperature dependence of curing kinetics of diglycidyl ether of bisphenol-A with catalyst," J. Polym. Sci., Part B: Polym. Phys. 32, 1465-1474 (1994).

32. M. Matsukawa and I. Nagai, "Ultrasonic characterization of a polymerizing epoxy resin with imbalanced stoichiometry," J. Acoust. Soc. Am. 99, 2110-2115 (1996).

33. S. Dixon, C. Edwards, and S. B. Palmer, "A technique for accurate shear wave velocity measurements of thin epoxy resin samples using electromagnetic acoustic transducers (EMATs)," Meas. Sci. Technol. 12, 615-621 (2001).

34. J. C. Bacri, J. M. Courdille, J. Dumas, and R. Rajaonarison, "Ultrasonic waves: A tool for gelation process measurements," J. Phys. Lett-Paris 41, 369-372 (1980).

35. C. Y. Shigue, R. G. S Dos Santos, C. A. Baldan, and E. Ruppert-Filho, "Monitoring the epoxy curing by the dielectric thermal analysis method," IEEE T. Appl. Supercon. 14, 1173 1176 (2004).

36. Warm-curing epoxy system based on Araldite ${ }^{\circledR}$ LY 1564 SP / Hardener XB3486 / Hardener XB3487. Huntsman datasheet, (2004).

37. D. J. O'Brien, P. T. Mather, and S. R. White, "Viscoelastic properties of an epoxy resin during cure," J. Compos. Mat. 35, 883-904 (2001).

38. A. Demčenko, E. Žukauskas, R. Kažys, and A. Voleišis, "Interaction of the A0 lamb wave mode with a de-lamination type defect in GLARE3-3/2 composite material," Acta Acust. United AC 92, 540-548 (2006). 


\title{
Chapter 5
}

\section{Isothermal epoxy-cure monitoring using nonlinear ultrasonics $^{1}$}

\begin{abstract}
Isothermal curing of LY $1564 \mathrm{SP}$ resin in an aluminum-adhesive-aluminum laminate is investigated, using a nonlinear ultrasonic immersion technique, to prove its applicability for this type of dynamic material transformation. For verification and comparison, epoxy-cure kinetics and rheological behavior are measured using differential scanning calorimetery (DSC) and dynamic mechanical analysis (DMA). Results reveal that the nonlinear ultrasonics, based on noncollinear wave mixing, can successfully be applied to in situ epoxy-cure monitoring-for example, to adhesive bonds - with reliable detection of gelation and vitrification time instants.
\end{abstract}

${ }^{1}$ Reproduced from: V. Koissin, A. Demčenko, V. A. Korneev, Isothermal epoxy-cure monitoring using nonlinear ultrasonics, International Journal of Adhesion and Adhesives, 52, 11-18 (2014). 


\subsection{Introduction}

Ultrasonic measurements are widely used to detect dynamic changes and transition points in polymer materials. For example, they are successfully employed to monitor solidification and shrinkage processes [1,2], polymerization [3], physical ageing [4], and epoxy cure [5-8]. The main advantages of the ultrasonic techniques include relatively low cost, high sensitivity, and in-line and real-time measurement possibilities. The curing processes inherent for epoxy resins are the practically important example, because measuring the cure characteristics helps to develop an optimal cure process, which would achieve the best material performance. The use of ultrasonics also enables real-time quality control. The reported results demonstrate that ultrasonic measurements, which employ longitudinal and/or shear waves, are applicable for monitoring of thin epoxy layers $[8,9-14]$ and for detection of gelation time when a viscous epoxy transforms into an elastic gel [5, 7, 15-20].

Nonlinear ultrasonics can often be more sensitive to material properties than linear ultrasonics. Historically, nonlinear ultrasonics usually employs a multiple harmonic generation of a single monochromatic wave, rather than other nonlinear measurement techniques. These harmonic generation measurements are relatively easy to implement. However, data from such measurements can be difficult to interpret, because of similar nonlinearity effects occurring in an acoustic channel, electronics, or a surrounding medium that masks a target signal. Fortunately, one wave-mixing technique [21] is free of these disadvantages, allowing for easy frequency-domain separation of a target sum and/or difference frequencies generated in the specimen from the multiples generated by other sources. Moreover, this wave-mixing technique, in its noncollinear form (when the primary beams interact at non-zero angles), further improves detection of the target waves, because such waves are also separated in space from other signals.

Despite the high potential of noncollinear wave mixing for nondestructive testing applications, noncollinear wave mixing is still not verified well enough for epoxy-cure monitoring. Also, there is at this time insufficient information about ultrasonic detection of the vitrification time (i.e., when the mobility of reactive groups vanishes and the epoxy undergoes a rubber-glass transition, then quickly approaches a solid state [22]). In this paper, we present an experimental study aiming at a partial filling of this knowledge gap. The presented nonlinear elastic wave-mixing technique enables monitoring of the epoxy cure in a thin layer (about $0.2 \mathrm{~mm}$ thick), with a robust detection of the characteristic points (gelation and vitrification). The importance of this method is illustrated, showing that the nonlinear-elastic material response has a higher sensitivity to the epoxy rheology compared to the linear response. Independent verifications are performed, with commonly used rheometry (dynamic mechanical analysis, DMA) and differential scanning calorimetry (DSC) measurements of the isothermal epoxy cure. Finally, the advantages and disadvantages of the three methods are compared. 


\subsection{Noncollinear ultrasonic wave mixing}

In isotropic nonlinear materials (described with the third-order elastic constants $l, m, n[21])$, the resonant conditions might exist wherein two elastic waves could possibly interact to generate scattered waves with mixed (sum and difference) frequencies. These conditions are

$\omega_{g}=\omega_{1} \pm \omega_{2}$,

$\mathbf{k}_{g}=\mathbf{k}_{1} \pm \mathbf{k}_{2}$

where frequencies $\omega_{1}, \omega_{2}$, and $\omega_{g}$ represent two initial waves and the resonant wave, respectively. The parameters $\mathbf{k}_{1}, \mathbf{k}_{2}$, and $\mathbf{k}_{g}$ are their wave vectors. Even if the resonant conditions were satisfied, the scattered wave amplitude can be zero for all parameter combinations (polarization restriction). In [21], it is shown that only 10 of 54 possible combinations of two initial compressional L, and/or shear SV, and/or shear SH waves generate scattered resonance waves.

Two wave interaction cases-

$\mathrm{SV}\left(\omega_{1}\right)+\mathrm{L}\left(\omega_{2}\right) \rightarrow \mathrm{L}\left(\omega_{1}+\omega_{2}\right)$

$\operatorname{SV}\left(\omega_{1}\right)+\operatorname{SV}\left(\omega_{2}\right) \rightarrow \mathrm{L}\left(\omega_{1}+\omega_{2}\right)$

appear to be the most suitable for nondestructive testing purposes [23]. These interactions can be used in single-sided or double-sided-access measurement modes (see Fig. 5.1), using either contact or immersion ultrasonic measurement techniques. This property enables us to find incident angles of primary waves such that the generated longitudinal wave strikes the specimen/liquid interface perpendicularly. This perpendicular incidence also allows us to achieve the highest energy rate for the nonlinear wave and helps to simplify the acoustic channel, because there is no need to rotate the receiver at a specific angle.

Figure 5.1 shows a submerged wave-mixing technique scheme with two modifications, using either reflected or transmitted scattered waves. For thick objects, the transmitted wave might be preferred, because the target scattered wave has a shorter path (i.e., less attenuation) and can be detected more readily. The advantage of the reflected wave scheme is in its single-side access to the specimen.

Interaction $\operatorname{SV}\left(\omega_{1}\right)+\operatorname{SV}\left(\omega_{2}\right) \rightarrow \mathrm{L}\left(\omega_{1}+\omega_{2}\right)$ between two shear waves appears most promising, because in this case it maintains a wave mode separation. However, this interaction requires a large angle between the two interacting waves (usually more than $120^{\circ}$ ). Therefore, it cannot be used for materials having low ultrasonic wave velocities; a conventional immersion measurement technique should be employed instead. This angle restriction can be overcome, however, by employing the interaction $\operatorname{SV}\left(\omega_{1}\right)+\mathrm{L}\left(\omega_{2}\right) \rightarrow \mathrm{L}\left(\omega_{1}+\omega_{2}\right)$, between shear and longitudinal waves. Note that both chosen interactions are the functions of one third-order elastic constant $m$ only, as illustrated in Table 2 in [21]. Imaging and testing of two other elastic constants, $l$ and $n$, require other interactions. 


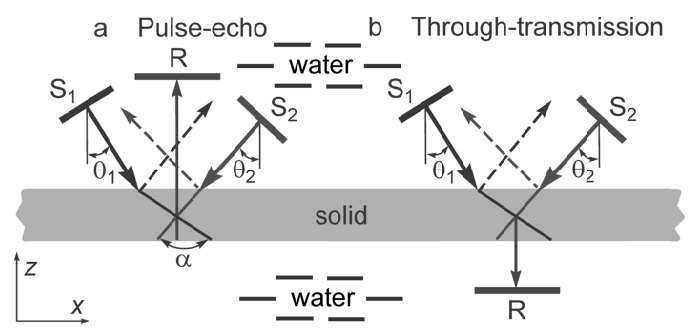

Figure 5.1. Pulse-echo and through-transmission arrangement of transducers for single-side and double-side access measurements. Shown are the scattered wave receiver R, the pump wave sources $S_{1,2}$ having inclination angles $\theta_{1,2}$, respectively. $\alpha$ is the wave interaction angle. Red lines show propagation paths of the resonant wave. Dashed lines mark the specularly reflected pump waves.

The interaction (5.4) between two shear waves was employed for the epoxy-cure monitoring. The corresponding nonlinear wave amplitude coefficient (with dimension length $\left.{ }^{-3}\right)$ is [21]

$W=D_{\mathrm{L}} \frac{1+d}{2 \gamma^{2}}\left(C_{1} \cos 2 \alpha+C_{2} \cos ^{2} \alpha-C_{3} \sin ^{2} \alpha\right) \approx D_{\mathrm{L}} \frac{1+d}{2 \gamma^{2}} m \cos 2 \alpha$,

where the following notations are used:

$D_{\mathrm{L}}=\frac{d}{4 \pi v_{\mathrm{L}}^{2} \rho}\left(\frac{\omega_{1}}{v_{g}}\right)^{3}$

$\gamma=\frac{v_{\mathrm{S}}}{v_{\mathrm{L}}}$

$d=\omega_{2} / \omega_{1}$.

Parameter $\alpha$ is the wave interaction angle, $v_{\mathrm{L}}$ and $v_{\mathrm{S}}$ are the longitudinal and shear wave velocities in a medium, respectively, $\rho$ is the material density, and $v_{g}$ is the nonlinear wave velocity in a medium (in our case $v_{g}=v_{\mathrm{L}}$ ). The constants $C_{i}$ have simple relations:

$C_{1}=\mu+\frac{A}{4}, C_{2}=\lambda+\mu+\frac{A}{4}+B, C_{3}=\frac{A}{4}+B, C_{4}=B+2 C, C_{5}=\lambda+B$,

with third-order elastic constants and Lamé parameters $\lambda$ and $\mu$. Prediction of the nonlinear wave amplitude coefficient enables us to choose the measurement conditions under which the highest nonlinear wave amplitude is expected, and maintains the best signal-to-noise ratio. Note that the nonlinear wave amplitude coefficient has a dependence on the $\omega_{1}^{3}$ (see Eq. 5.5), indicating that the noncollinear wave interaction is more strongly pronounced at higher frequencies.

Table 5.1. Material properties used in the nonlinear wave analysis.

\begin{tabular}{lllllll}
\hline \hline Material & $\lambda, \mathrm{GPa}$ & $\mu, \mathrm{GPa}$ & $l, \mathrm{GPa}$ & $m, \mathrm{GPa}$ & $n, \mathrm{GPa}$ & $\rho, \mathrm{kg} / \mathrm{m}^{3}$ \\
\hline Aluminum & 54.308 & 27.174 & -281.5 & -339 & -416 & 2704 \\
\hline \hline
\end{tabular}



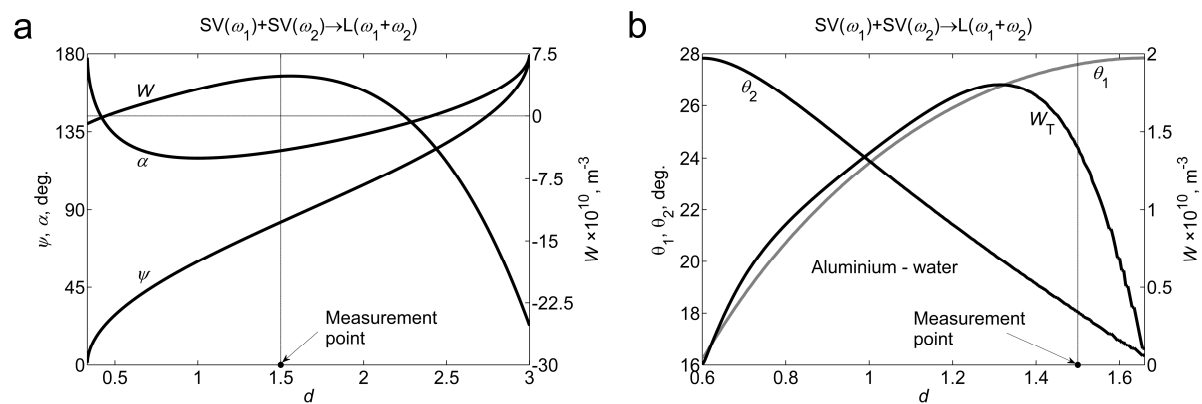

Figure 5.2. Predicted nonlinear wave amplitude coefficient $W$ versus frequency ratio $d$ for $\mathrm{SV}\left(\omega_{1}\right)+\mathrm{SV}\left(\omega_{2}\right) \rightarrow \mathrm{L}\left(\omega_{1}+\omega_{2}\right)$ wave mixing in aluminum (a); where $\alpha$ is the wave interaction angle and $\psi$ is the resonant wave propagation angle. Fig. 5.2b shows the optimized parameters when the nonlinear wave strikes the aluminum/water interface perpendicularly. $W_{\mathrm{T}}$ is the nonlinear wave amplitude coefficient when the energy transmission coefficients between interfaces (water - aluminum and aluminum - water) are taken into prediction account. Also shown are inclination angles $\theta_{1}$ and $\theta_{2}$ for the pump waves.

An example of a nonlinear wave amplitude calculation is shown in Fig. 5.2 for aluminum studied in [24]; its properties are listed in Table 5.1.

Prediction of the nonlinear wave amplitude is carried out when attenuation is not taken into account and $\omega_{1}$ is $4 \mathrm{MHz}$. Figure 5.2a shows the predicted nonlinear wave amplitude coefficient $W$, the nonlinear wave scattering angle $\psi$, and the wave interaction angle $\alpha$ over the entire allowed frequency range [21]. The scattering angle $\psi$ is calculated between the first pump-wave vector of frequency $\omega_{1}$ and the nonlinear wave vector [21]. When ultrasonic experiments are performed using the immersion technique, it is useful to employ a procedure that allows tuning an acoustical channel for noncollinear wave mixing [23]. The optimized parameters (the nonlinear wave amplitude coefficient $W_{\mathrm{T}}$, and the inclination angles $\theta_{1}$ and $\theta_{2}$ for the pump-wave sources) when the nonlinear wave strikes the aluminum/water interface perpendicularly for the through-transmission mode are shown in Fig. 5.2b. $W_{\mathrm{T}}$ is the nonlinear waveamplitude coefficient when the energy-transmission coefficients between the liquidsolid $\left(\mathrm{T}_{1}\right.$ and $\left.\mathrm{T}_{2}\right)$, and the solid-liquid $(\mathrm{T})$ interfaces are taken into account. Therefore, the amplitude function is $W_{\mathrm{T}}=W \times \mathrm{T}_{1} \times \mathrm{T}_{2} \times \mathrm{T}$-presented in [23] in detail.

As seen in Fig. 5.2, the predicted maximum of the nonlinear wave amplitude coefficient in the frequency ratio range 0.6-1.66 is shifted from the initial frequency ratio $(d=1.56$, Fig. 5.2a) to the frequency ratio $d=1.32$. This shift occurs because of the energy transmission and reflection coefficient between the water-aluminum and aluminum-water interfaces.

Since commercially available ultrasonic transducers of standard frequencies are available, it is practical to choose the frequency ratio of pump (primary) waves in such a way that both the performance of the transducers and the sensitivity of the receiver to the nonlinear wave stay high. With this in mind, we set the frequency ratio $\omega_{2} / \omega_{1}$ to 1.5 , and the corresponding frequencies of the pump waves to $6 \mathrm{MHz}$ and $4 \mathrm{MHz}$, 
respectively (see Fig. 5.2). A nonlinear wave of a $10 \mathrm{MHz}$ frequency has good separation from the 4 and $6 \mathrm{MHz}$ harmonics of the pump waves. Thus, the informative signal can be filtered easily from the unwanted harmonics in the raw acoustic signal. In the case of the frequency ratio $d=1.32$ (when the maximum nonlinear wave amplitude is expected in $0.6<d<1.66$ ), the frequency separation becomes worse.

It is seen (Fig. 5.2b) that when the frequency ratio is 1 , the inclination angles of both pump-wave sources are equal. This situation provides simplicity for the acoustical channel configuration; however, the frequency separation is lost here.

\subsection{Ultrasonic measurement setup}

The $\operatorname{SV}\left(\omega_{1}\right)+\operatorname{SV}\left(\omega_{2}\right) \rightarrow \mathrm{L}\left(\omega_{1}+\omega_{2}\right)$ wave-mixing process is used to monitor the isothermal epoxy curing. An arrangement of ultrasonic transducers is shown in Fig. 5.3, for the immersion noncollinear wave-mixing measurements in the through-transmission mode.

The test parameters are listed in Table 5.2, with the following notations: $f_{1}$ and $f_{2}$ are frequencies of the pump waves generated by sources $\mathrm{S}_{1}$ and $\mathrm{S}_{2}$, respectively. $N_{1}$ and $N_{2}$ are the numbers of cycles of the used pump-wave generation. Inclination angles $\theta_{1}$ and $\theta_{2}$, as well as vertical offsets $\Delta z_{1}$ and $\Delta z_{2}$, respectively, are also related to the sources $\mathrm{S}_{1}$ and $\mathrm{S}_{2}$. The distance $\Delta x$ between the pump-wave sources, as well as the distance $\Delta z$ between receiver $\mathrm{R}$ and the specimen surface, is also shown in this figure.

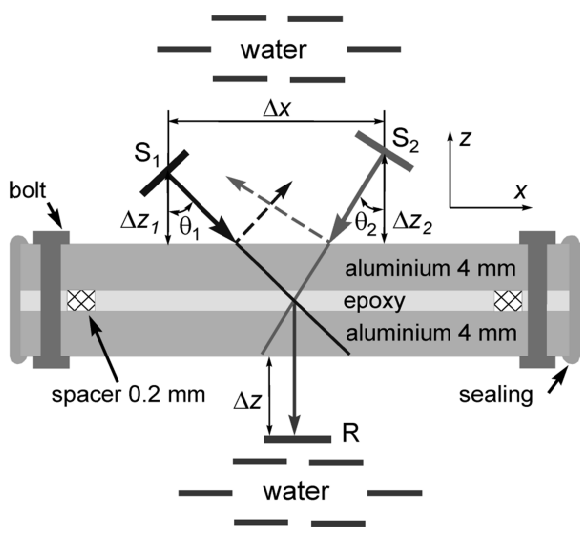

Figure 5.3. Experimental arrangement of ultrasonic transducers for the noncollinear wave mixing in the through-transmission measurement mode. Dashed lines mark the specularly reflected pump waves. Not scaled.

Table 5.2. Parameters used for the noncollinear wave mixing experiments.

\begin{tabular}{|c|c|c|c|c|c|c|c|c|c|c|}
\hline $\begin{array}{l}f_{1}, \\
\mathrm{MHz}\end{array}$ & $\begin{array}{l}N_{1}, \\
\text { cycles }\end{array}$ & $\begin{array}{l}f_{2}, \\
\mathrm{MHz}\end{array}$ & $\begin{array}{l}N_{2}, \\
\text { cycles }\end{array}$ & $\begin{array}{l}f_{r}, \\
\mathrm{MHz}\end{array}$ & $\begin{array}{l}\theta_{1}, \\
\text { deg. }\end{array}$ & $\begin{array}{l}\theta_{2}, \\
\text { deg. }\end{array}$ & $\begin{array}{l}\Delta z_{1}, \\
\mathrm{~mm}\end{array}$ & $\begin{array}{l}\Delta z_{2}, \\
\mathrm{~mm}\end{array}$ & $\begin{array}{l}\Delta z, \\
\mathrm{~mm}\end{array}$ & $\begin{array}{l}\Delta x, \\
\mathrm{~mm}\end{array}$ \\
\hline 4 & 30 & 6 & 30 & 10 & 22 & 15.5 & 18 & 22 & 80 & 21 \\
\hline
\end{tabular}


Ten-millimeter-diameter planar broadband transducers are used for pump-wave generation. The receiver is a spherically focused broadband sensor having a $10 \mathrm{MHz}$ central frequency. Acquired signals are amplified with a $20 \mathrm{~dB}$ preamplifier, digitized, and filtered using a narrowband filter (with a Kaiser window).

The peak-to-peak amplitude, energy, and change of the time-of-flight are used to parameterize the nonlinear wave signals. In an ideal case, the peak-to-peak amplitude and energy should give identical results. However, they may differ if the ultrasonic signal has a complex wave-shape. Previous studies, [25], show that it is more practical to evaluate the energy of the nonlinear wave signals, as is done for the examples below.

Arrangement of the transducers and specimen is chosen in a way that the central beams of the pump waves intersect in the epoxy layer (Fig. 5.3). Because of this arrangement and the finite beam width (which is of the same order as the transducer diameters), the following three volumes (where the nonlinear wave interactions occur simultaneously) can be separated:

1. In the upper aluminum layer, interaction of the pump waves occurs without any epoxy influence. Consequently, a constant amount of nonlinear wave energy is generated.

2. In the epoxy layer, the nonlinear wave is either not generated or very poorly generated, because the resonant conditions of the wave interaction are chosen for aluminum.

3. In the lower aluminum layer, the resulting amount of nonlinear wave energy is expected to depend strongly on the epoxy layer properties. Because of changes in the longitudinal and shear-wave velocities during the epoxy curing, transmission and refraction of the ultrasonic waves vary between the epoxy and aluminum interfaces. Hence, the resonant conditions of the wave interaction are not completely fulfilled here (i.e., generation of the nonlinear wave is ineffective). The amount of the generated wave energy also varies significantly in this volume, owing to changes in the acoustic properties of epoxy.

\subsection{Ultrasonic monitoring of epoxy cure}

The studied epoxy is a typical commercial system comprised of $3 / 4$ Araldite $®$ LY 1564SP resin and 1/4 XB 3486 hardener, by mass [26].

This mix is degassed for 20 minutes, spread on a $4 \mathrm{~mm}$ thick aluminum plate, and then covered with a second identical aluminum plate. Before this, to provide a uniform thickness for the epoxy layer, a $0.2 \mathrm{~mm}$ thick and $10 \mathrm{~mm}$ wide double-sided tape is placed along the plate perimeter. The whole "sandwich" is fixed with bolts, and its edges are sealed using a tacky "gum" to isolate the epoxy from water, as schematically illustrated in Fig. 5.3. These manipulations take about $10 \mathrm{~min}$.

Then, the specimen is immediately placed in a water bath under an acoustic channel, and monitoring of the curing process is performed at $24.3^{\circ} \mathrm{C}$ or at $40^{\circ} \mathrm{C}$, with a 30 sec sampling rate.

As mentioned in Section 5.3 above, three parameters of the nonlinear ultrasonic signal are analyzed: the peak-to-peak amplitude, $A_{\mathrm{pp}}$, energy, $E$, and change in the 
group time-of-flight, $\Delta t$. This last parameter is determined using the first measurement signal as the reference. For brevity, details of the chemical reactions during the epoxy cure are not discussed in the present paper; they can be obtained in the literature, e.g. [10, 27-29].

Test data for the $24.3^{\circ} \mathrm{C}$ case are presented in Fig. 5.4a. They clearly show three characteristic points at $1.3 \mathrm{~h}, 6.7 \mathrm{~h}(10 \mathrm{~h})$, and $20 \mathrm{~h}$. The first peak at $1.3 \mathrm{~h}$ is well indicated by all three parameters. The minimum at $6.7 \mathrm{~h}$ is indicated by the peak-topeak amplitude and energy. However, this peak is shifted at about $10 \mathrm{~h}$ in the time-offlight curve.

Note that these ultrasonic measurements are performed in a large water bath, without a forced control of temperature, which changed slightly during the day-night cycle. This caused small "jumps" in the curves, seen (for example) in Fig. 5.4a between $25 \mathrm{~h}$ and $37 \mathrm{~h}$. The results also show that the temperature variation does not influence the measurements when the epoxy-cure process is intensive, i.e., within 0-23 h interval.

Figure 5.4a also shows a small deviation (different slopes) occurring between the peak-to-peak amplitude and energy curves within a 10-20 h interval. The third characteristic point (at about $20 \mathrm{~h}$ ) is not easily seen in the energy and amplitude curves, but the time-of-flight curve shows a distinct phase change here. The energy and peak-topeak amplitude show a trend toward becoming constant after passing this point. Also, the time-of-flight curve shows continuous ageing of epoxy after the change of phase at about $20 \mathrm{~h}$.
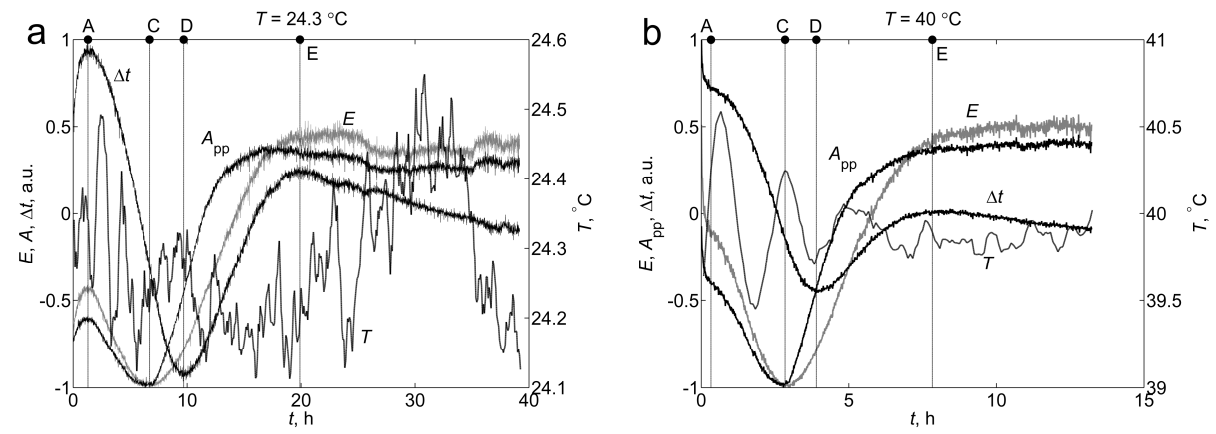

Figure 5.4. Dynamics of the nonlinear ultrasonic signal parameters during the epoxy curing at $24.3^{\circ} \mathrm{C}$ (a) and $40^{\circ} \mathrm{C}$ (b). The parameters, except for the temperature, are scaled by their maxima and centered.

Test data for the $40^{\circ} \mathrm{C}$ case are presented in Fig. 5.4b. The curing process is accelerated by the higher temperature, in comparison with the $24.3^{\circ} \mathrm{C}$ case. The initial linear decrease in the energy and amplitude is caused by a lower initial temperature of the specimen (which was brought from room temperature into heated water). Note that these ultrasonic measurements are performed in a small water bath with a forced control of temperature and magnetic stirrer. A cyclic variation of the temperature within a $0-5 \mathrm{~h}$ interval clearly shows the forced heating of the water bath when the temperature equilibrium is lost. 


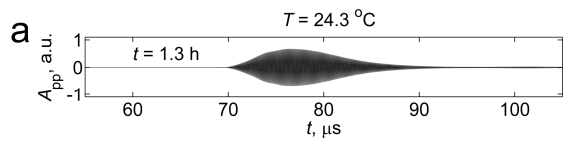

$\mathrm{b}$
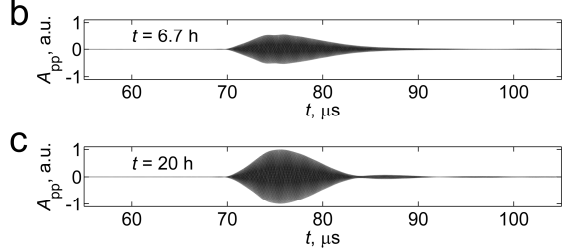

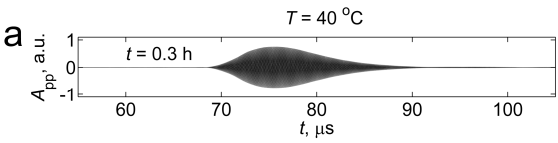

$\mathrm{b}$
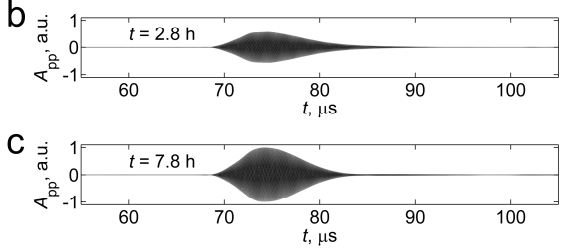

Figure 5.5. Typical nonlinear ultrasonic signals during epoxy curing at $24.3^{\circ} \mathrm{C}$ (left) and $40^{\circ} \mathrm{C}$ (right): maximum viscosity (a), gel onset (b) and vitrification (c).

The following characteristic points can be derived from Fig. $5.4 \mathrm{~b}: 0.3 \mathrm{~h}, 2.8 \mathrm{~h}(3.9$ $\mathrm{h}$ ) and $7.8 \mathrm{~h}$. However, the first point $(0.3 \mathrm{~h})$ is not so well pronounced, if we compare it with the $24.3^{\circ} \mathrm{C}$ case $(1.3 \mathrm{~h})$. This point is now seen only indirectly, as a local inflection of the curves.

Figure 5.5 shows typical nonlinear ultrasonic signals $\left(A_{\mathrm{pp}}\right)$ at these characteristic points. The signals are scaled by the maximum amplitude measured at $20 \mathrm{~h}$ and $7.8 \mathrm{~h}$ for the $T=24.3^{\circ} \mathrm{C}$ and $T=40^{\circ} \mathrm{C}$ cases, respectively. As seen, the informative signal duration becomes shorter, thus indicating solidification of the epoxy.

\subsection{DMA monitoring of epoxy cure}

We performed an alternative isothermal cure characterization using an Anton Paar®MCR501 parallel plate rheometer. Similar equipment is widely used for this purpose — see, for example [30] — and its results can easily be interpreted in rheological terms (viscosity, damping, etc.).

First, a $26 \mathrm{~mm}$ diameter ring is mounted on the bottom plate of the rheometer and partially filled with a 3-4 mm epoxy layer (previously degassed during $20 \mathrm{~min}$ ). Then, a $25 \mathrm{~mm}$ diameter top parallel plate is sunk into this ring until it contacts the epoxy. Since these preparations require a little more time compared to the ultrasonic tests, the delay before the test was about $15 \mathrm{~min}$.

After closing a heating chamber around the specimen and setting the gained temperature (this takes other $5 \mathrm{~min}$ ), we measured the shear viscosity at a $1 \mathrm{~Hz}$ frequency and a $1.8^{\circ}$ amplitude of rotational oscillations. Results are shown in Figs. 5.6 and 7 for the $25^{\circ} \mathrm{C}$ and $40^{\circ} \mathrm{C}$ cases, respectively. The following characteristic points and their physical backgrounds can be observed:

1. The first extremum, point A, corresponds to the minimal viscosity (as well as the storage modulus and torque). This obviously occurs not directly after mixing of the resin and hardener, but rather (due to inertia of the chemical processes) is postponed for some time: about $2 \mathrm{~h}$ at $25^{\circ} \mathrm{C}$. This roughly corresponds to $1.3 \mathrm{~h}$ noted above when discussing Fig. 5.4a, after the ultrasonic 
tests. This effect is almost invisible under the $40^{\circ} \mathrm{C}$ test conditions, probably due to accelerated processes. Some minor inflections in the storage modulus and the damping factor curves are seen in Fig. 5.7 at about $1 \mathrm{~h}$, but are difficult to interpret. In the ultrasonic tests discussed above, this effect also can be masked by a rapid decrease in the nonlinear wave amplitude, due to an increase in temperature within the measurement cell. Initial cell temperature was about $24^{\circ} \mathrm{C}$.

2. After a while, at point $\mathrm{B}\left(\sim 4 \mathrm{~h}\right.$ at $\left.25^{\circ} \mathrm{C}\right)$, the reaction rate seems to increase. This is seen as a minor local maximum of viscosity (and of the storage modulus, as well as torque) or a minimum of the loss modulus and damping factor ( $\tan \delta$, which is a ratio of the loss and storage moduli), again for the $25^{\circ} \mathrm{C}$ case only. Then the loss and storage moduli start to grow rapidly. Point $\mathrm{B}$ is not detected well for the $40^{\circ} \mathrm{C}$ case, likely owing to the absence of any pronounced reaction-rate change in this case. Only barely visible "jumps" seen in Fig. 5.7 for the viscosity, torque, and loss modulus curves might potentially be attributed to point $\mathrm{B}$.

3. The next extremum (point $\mathrm{C}$ ) seems to be the onset of gelation; it occurs at about 7 $\mathrm{h}$ at $25^{\circ} \mathrm{C}$ or $2.5 \mathrm{~h}$ at $40^{\circ} \mathrm{C}$. At this moment, the storage modulus starts to decrease locally, and the viscosity growth rate becomes yet higher (as well as that for the torque and damping factors). This feature corresponds well to the $6.7 \mathrm{~h}$ and $2.8 \mathrm{~h}$ points noted above when discussing Fig. 5.4 (ultrasonic tests). For the $40^{\circ} \mathrm{C}$ case, only the storage-modulus decrease is seen well; the other changes (in the viscosity, torque, and damping) are barely visible in this case, obviously due to a quick transition to the next step in the material transformation.

4. The following extremum (point D) occurring at about $10-11 \mathrm{~h}$ at $25^{\circ} \mathrm{C}$ or $3.2 \mathrm{~h}$ at $40^{\circ} \mathrm{C}$, is the peak of gelation and, therefore, of the damping factor as well, as adopted in ASTM D4473-90. Afterwards, the damping ability of the material rapidly vanishes. All other rheometry variables increase in magnitude, especially the storage modulus (representing the elastic portion of the stored energy). Point D is also visible in Fig. $5.4\left(10 \mathrm{~h}\right.$ or $3.9 \mathrm{~h}$ estimated for the $25^{\circ} \mathrm{C}$ and $40^{\circ} \mathrm{C}$ cases, respectively).

5. The last extremum is the onset of vitrification, point $\mathrm{E}$, at about $17 \mathrm{~h}$ for $25^{\circ} \mathrm{C}$ or $7-8 \mathrm{~h}$ for $40^{\circ} \mathrm{C}$. Rheometry is automatically stopped at this stage, due to exceeding the allowable torsional moment. When the specimens are then taken out of the machine, they appear completely solidified. This final point also agrees well with the vitrification times derived from Fig. 5.4 (roughly $20 \mathrm{~h}$ or $7.8 \mathrm{~h}$, respectively). 

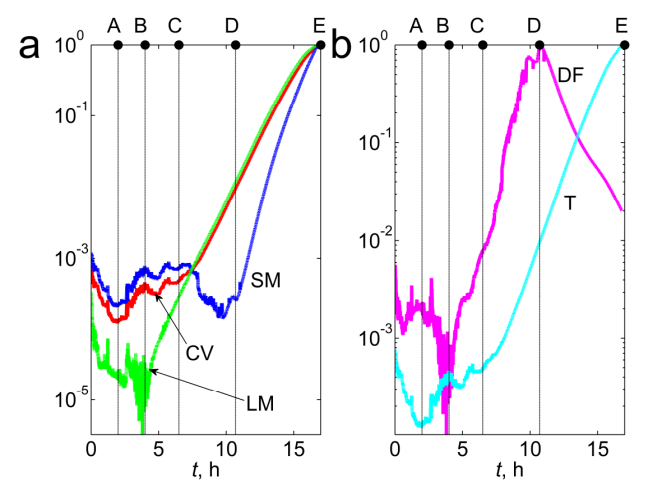

Figure 5.6. Cure monitoring using DMA, $25^{\circ} \mathrm{C}$ case. The data are log-scaled and normalized to their maximums. CV is the complex viscosity, SM is the storage modulus, LM is the loss modulus, $\mathrm{DF}$ is the damping factor and $\mathrm{T}$ is the torque.
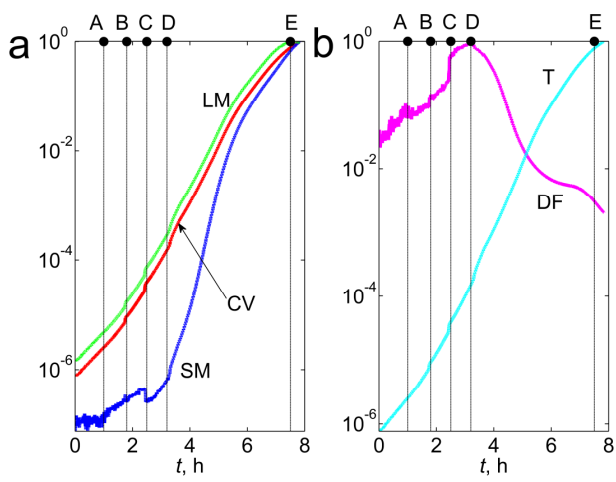

Figure 5.7. Cure monitoring using DMA, $40^{\circ} \mathrm{C}$ case. The data are log-scaled and normalized to their maximums. Notations are the same as in Fig. 5.6.

\subsection{DSC monitoring of epoxy cure}

Additional independent verification is performed with the isothermal calorimetric analysis, [31, 32], using a Mettler Toledo® 882e apparatus. The specimens are 8-10 mg epoxy drops placed in standard aluminum cups, after a 20 min degassing. Two or three specimens are tested in each series, in the nitrogen atmosphere, at different temperatures ranging from 25 to $100^{\circ} \mathrm{C}$. A $10^{\circ} \mathrm{C} / \mathrm{min}$ rate is used at the initial heating stage (from the room temperature to the gained one). Then, the heat generated in the specimen by the curing reaction is recorded during a prescribed time.

Typical changes in the heat flow over time are presented in Fig. 5.8a. These curves clearly show only one point positioned at about $0.7 \mathrm{~h}$ (both for the $25^{\circ} \mathrm{C}$ and $40^{\circ} \mathrm{C}$ cases) or lefty for higher temperatures. According to the rheometry tests (Section 5), this point is hardly related to point A, 
which is positioned further to the right. However, it is logically possible that this exotherm peak is a precursor of the maximal viscosity.

Vitrification is shown by these curves (presumably when they approach the horizontal asymptote) at $\sim 15 \mathrm{~h}$ or $\sim 25 \mathrm{~h}$. This, of course, differs substantially from the vitrification points derived above in the ultrasonic and rheometry tests; possible reasons for this discrepancy are discussed in Section 7.

Numerical derivatives of the curves (Fig. 5.8b), smoothed using $5^{\text {th }}$-order polynomials, reveal a little more information. First, there are minimums of the tangent, e.g., at about $3.3 \mathrm{~h}$ for both the $25^{\circ} \mathrm{C}$ and $40^{\circ} \mathrm{C}$ cases. The curves also show a change in slope at about $8-10 \mathrm{~h}$ or at $6-8 \mathrm{~h}$ for the $25^{\circ} \mathrm{C}$ or $40^{\circ} \mathrm{C}$ cases, respectively. As mentioned in Section $5,10-11 \mathrm{~h}$ at $25^{\circ} \mathrm{C}$ or $3.2 \mathrm{~h}$ at $40^{\circ} \mathrm{C}$ is the peak of gelation (point D). However it is still not clear what can happen at $3.3 \mathrm{~h}$ for the $25^{\circ} \mathrm{C}$ case.
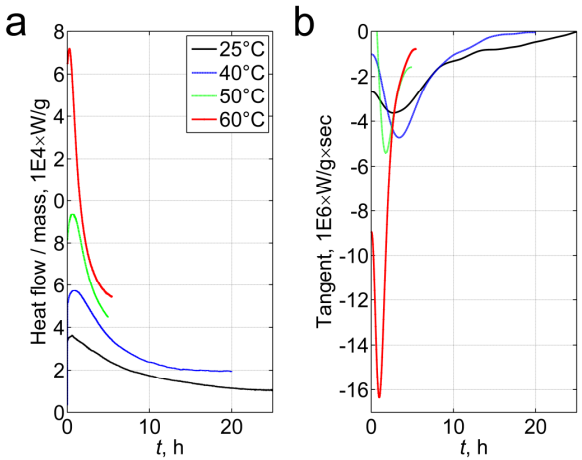

Figure 5.8. Cure monitoring using DSC, at different temperatures. Heat flow (a) and its time derivative (b), normalized to the specimen mass.

\subsection{Comparison of the test methods}

The methods used in our study-nonlinear ultrasonics, DMA, and DSC-are compared in Table 3 according to their ability to detect the characteristic points of the epoxy cure. Of course, other methods such as dielectric tests $[22,33,34]$ or magnetic resonance [33-35] could also be used and compared; however, the present study compares only the most common ones (DMA and DSC). All three methods are expected to characterize the epoxy from an uncured to completely cured state, in a single test. However, they have different sensitivities to the material properties, at least for the studied material and used equipment.

DSC seems to show the lowest applicability to the epoxy-cure monitoring. First, it is not a surprise that the gelation point is only barely visible with DSC, since gelation does not significantly affect the heat flow [29]. However, it has a large impact on the mechanical response, as shown here by the DMA and nonlinear ultrasonic tests. 
Table 5.3. Ability of the used test methods to detect characteristic points during the epoxy cure ("+" means ability, and "-" means disability; for the linear ultrasonics, data are taken from $[5$, $15-19,34])$.

\begin{tabular}{lllll}
\hline \hline Method & Max. viscosity, A & Gel onset, C & Gel peak, D & Vitrification, E \\
\hline DSC & - & - & + & barely visible \\
DMA & + & + & + & + \\
Linear ultrasonics & - & + & - & + \\
Nonlinear ultrasonics & + & + & + & + \\
\hline \hline
\end{tabular}

Although it should be revealed in DSC curves by a glass/rubber thermal transition, the vitrification point is also barely visible, because of the low reaction rate at the end of curing [29]. At the same time, the DMA and nonlinear ultrasonics reveal this point well, again due to a distinct mechanical background. The Temperature Modulated Differential Scanning Calorimetery (TMDSC) can provide better sensitivity for the vitrification [36], but this method is more complicated and still not widely used.

Comparison between DMA and nonlinear ultrasonics (which may in fact be considered as a contactless high-frequency DMA) favors nonlinear ultrasonics. First of all, it detects well (in $\Delta t$ curve) the vitrification point in both tested cases $\left(25^{\circ} \mathrm{C}\right.$ and $40^{\circ} \mathrm{C}$ ), whereas DMA is automatically stopped (because of a too thick a gel) for the $25^{\circ} \mathrm{C}$ case several hours before the vitrification.

The time point when the epoxy reaches the maximal viscosity is also seen more clearly in the nonlinear ultrasonic results, especially for the $25^{\circ} \mathrm{C}$ case. Generally, the curves produced by the nonlinear ultrasonics are smoother than the DMA curves and are easier to analyze, due to their clear sinusoidal shapes and inflections.

The only constraint of the proposed method seems to be in its limited temperature range, since high-cure temperatures (say, over $50^{\circ} \mathrm{C}$ ) cause an extensive formation of bubbles in the water bath. However, this range can be extended somewhat by using some chemical additives for the water or even by employing another liquid as the coupling media. Ultimately, the tests can be performed even in air, using an air-coupled ultrasonic measurement technique. Also, it is possible to employ contact transducers for the wave mixing.

Last but not least, since both methods produce mechanical excitation in the specimens, concern might be raised about its effect on the test results. This is not applicable for the gelation point, because it has an isoconversion nature and thus is frequency independent [29]. However, the time of maximal viscosity may be accelerated, and the vitrification time may be either retarded (due to disturbed crosslinking) or accelerated (e.g., due to better diffusion of the hardener) [37, 38]. The latter effect may be suspected of having occurred in the present tests (see Table 5.3). However, high-power ultrasonics (which could cause a cavitation) were not used here. Also, the ultrasonic sampling rate was low (once every $30 \mathrm{sec}$ ), much lower than that in the performed DMA tests (every $1 \mathrm{sec}$ ). At the same time, the effect of sonification (if any) is about the same as that of the low-frequency oscillations in DMA.

Therefore, the observed discrepancy in the vitrification times (Table 5.4), should rather be attributed to differences in the physical backgrounds of the used test methods. It should also be noted again that no generally accepted criterion exists to define the gelation and vitrification points [29], especially in DSC. Because of this (and also 
because of the different effects measured with different methods) and depending on the temperature range, DSC can show these points earlier than DMA, or vice versa [27].

Table 5.4. Comparison of the characteristic points detected with the used methods.

\begin{tabular}{lllllllll}
\hline \hline & \multicolumn{2}{l}{ Max. visc., A } & \multicolumn{2}{l}{ Gel onset, C } & \multicolumn{2}{l}{ Gel peak, D } & \multicolumn{2}{l}{ Vitrif., E } \\
\hline Temperature $T$ & $25^{\circ} \mathrm{C}$ & $40^{\circ} \mathrm{C}$ & $25^{\circ} \mathrm{C}$ & $40^{\circ} \mathrm{C}$ & $25^{\circ} \mathrm{C}$ & $40^{\circ} \mathrm{C}$ & $25^{\circ} \mathrm{C}$ & $40^{\circ} \mathrm{C}$ \\
DSC & $0.7 \mathrm{~h}$ & $0.8 \mathrm{~h}$ & $\mathrm{n} / \mathrm{a}$ & $\mathrm{n} / \mathrm{a}$ & $8 \mathrm{~h}-10 \mathrm{~h}$ & $3 \mathrm{~h}$ & $25 \mathrm{~h}$ & $15 \mathrm{~h}$ \\
DMA & $2 \mathrm{~h}$ & $\mathrm{n} / \mathrm{a}$ & $7 \mathrm{~h}$ & $2.5 \mathrm{~h}$ & $10 \mathrm{~h}-11 \mathrm{~h}$ & $2 \mathrm{~h}$ & $17 \mathrm{~h}$ & $7 \mathrm{~h}-8 \mathrm{~h}$ \\
Nonlinear ultrasonics & $1.3 \mathrm{~h}$ & $0.3 \mathrm{~h}$ & $6.7 \mathrm{~h}$ & $2.8 \mathrm{~h}$ & $10 \mathrm{~h}$ & $9 \mathrm{~h}$ & $20 \mathrm{~h}$ & $7.8 \mathrm{~h}$ \\
\hline \hline
\end{tabular}

Outlining all the tested temperatures, a time-temperature-transformation (TTT) diagram is presented in Fig. 5.9 for the gelation and vitrification times, which are taken at characteristic points D and E, respectively. Naturally, these values shift to shorter times with increasing cure temperature. Inflection of the vitrification curve is not seen here; it likely occurs above $100^{\circ} \mathrm{C}$.

DSC data are quite close to DMA and nonlinear ultrasonic results in the $40^{\circ} \mathrm{C}$ case. For a lower temperature (the $25^{\circ} \mathrm{C}$ case), the discrepancy is larger and persists up to 2.5 $\mathrm{h}$. This difference can also be caused by the slightly different temperatures of the epoxy cure $\left(24.3^{\circ} \mathrm{C}\right.$ in the ultrasonic measurements and $25^{\circ} \mathrm{C}$ in the DSC and DMA measurements).

The gel time is also represented in Fig. 5.9 by the manufacturer's data [26], shifted to the right compared to the measured gel time, possibly because of a slightly different criterion used to define this point.

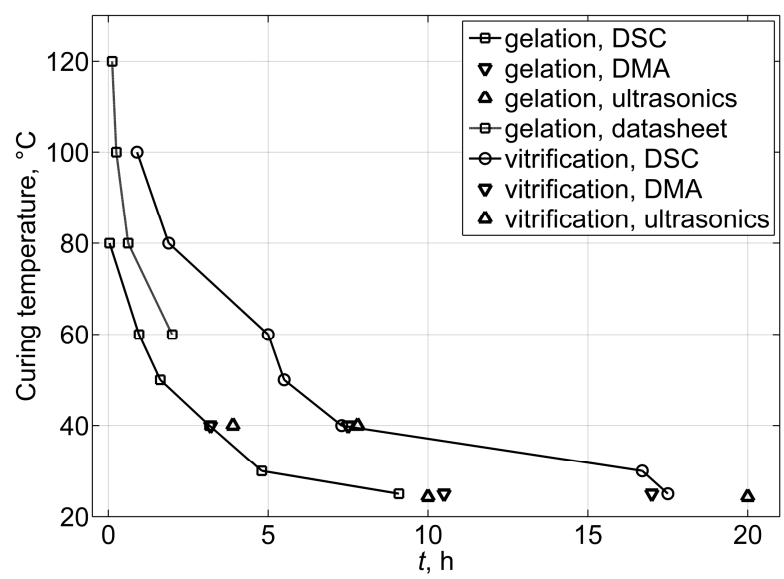

Figure 5.9. TTT diagram for isothermal cure of LY1564SP/XB3486 epoxy. 


\subsection{Conclusions}

An immersion nonlinear ultrasonic-measurement technique is presented in this study, with application to in situ cure monitoring of epoxy resins or similar materials. It is demonstrated that the nonlinear ultrasonics-based on a noncollinear wave mixing and detecting changes in the $2^{\text {nd }}$ - and $3^{\text {rd }}$-order elastic constants-can be very sensitive to the material transformations inherent in the cure process. At the same time, some of these transformations can be barely visible using conventional linear ultrasonics, or DMA, or DSC techniques. The main results of our study are outlined as follows:

1) Elastic wave mixing using the immersion method shows effective monitoring capabilities for the epoxy cure. This nonlinear ultrasonic technique enables a reliable detection of several characteristic points of the cure process, such as the time of maximal viscosity, gel time, and vitrification time.

2) The ultrasonic test data agree well with the data obtained using a conventional DSC and parallel-plate DMA methods. Moreover, the nonlinear ultrasonics detect certain characteristic points more effectively than the other two methods.

3) The following advantages can be achieved using the nonlinear ultrasonic technique presented here: wave-mode and frequency separations, elimination of a surrounding medium influence, steering (scanning) a scattered wave and controlling the intersection volume location, single-sided or double-sided measurements, and an effective detector mode (for example, no informative signal excitation until the material properties are homogenous).

\section{Acknowledgments}

Dr. Ir. Roy Visser and Mr. Bert Vos (University of Twente) are gratefully acknowledged for their help with DMA and DSC tests. This work was partially supported by the Director, Office of Energy Research, Office of Basic Energy Sciences, Engineering and Geosciences Division, of the U.S. Department of Energy under Contract No.DE-ACO2-05CH11231.

\section{References}

1. H. Wang, B. Cao, C. K. Jen, K. T. Nguyen, and M. Viens, "On-line ultrasonic monitoring of the injection molding process," Polym. Eng. Sci. 37, 363-376 (1997).

2. Y. Ono, B. R. Whiteside, E. C. Brown, M. Kobayashi, C.-C. Cheng, C.-K. Jen, and P. D. Coates, "Real-time process monitoring of micromoulding using integrated ultrasonic sensors," T. I. Meas. Control 29, 383-401 (2007).

3. P. Pawelzyk, M. L. Toledo, and N. Willenbacher, "Ultrasonic in-line monitoring of styrene miniemulsion polymerization," Chem. Eng. J. 219, 303-310 (2013).

4. A. Demčenko, R. Akkerman, P. B. Nagy, and R. Loendersloot, "Non-collinear wave mixing for non-linear ultrasonic detection of physical ageing in PVC," NDT \& E Int. 49, 34-39 (2012). 
5. A. M. Lindrose, "Ultrasonic wave and moduli changes in a curing epoxy resin - Ultrasonic techniques are examined as a means for monitoring reaction extent and the development of solid-phase moduli in a curing epoxy," Exp. Mech. 18, 227-232 (1978).

6. S. I. Rokhlin, K. Lewis, K. F. Graff, and L. Adler, "Real-time study of frequency dependence of attenuation and velocity of ultrasonic waves during the curing reaction of epoxy resin," $J$. Acoust. Soc. Am. 79, 1786-1793 (1986).

7. R. J. Freemantle and R. E. Challis, "Combined compression and shear wave ultrasonic measurements on curing adhesive," Meas. Sci. Technol. 9, 1291-1302 (1998).

8. S. Dixon, C. Edwards, and S. B. Palmer, "A technique for accurate shear wave velocity measurements of thin epoxy resin samples using electromagnetic acoustic transducers (EMATs)," Meas. Sci. Technol. 12, 615-621 (2001).

9. W. P. Winfree, "Ultrasonic characterization of changes in viscoelastic properties during cure," In proc. of IEEE Ultrasonic Symposium, 1: 866-869 (1983).

10. M. Frigione, A. Maffezzoli, D. Acierno, V. A. M. Luprano, and G. Montagna, "Nondestructive and in-situ monitoring of mechanical properties buildup in epoxy adhesives for civil applications by propagation of ultrasonic waves," Polym. Eng. Sci. 40, 656-664 (2000).

11. C. Pindinelli, G. Montagna, V. A. M. Luprano, and A. Maffezzoli, "Network development during epoxy curing: experimental ultrasonic data and theoretical predictions," Macromol. Symp. 180, 73-88 (2002).

12. S. Dixon, D. Jaques, and S. B. Palmer, "The development of shear and compression elastic moduli in curing epoxy adhesives measured using non-contact ultrasonic transducers," J. Phys. D: Appl. Phys. 36, 753-759 (2003).

13. S. Dixon, D. Jaques, S. B. Palmer, and G. Rowlands, "The measurement of shear and compression waves in curing epoxy adhesives using ultrasonic reflection and transmission techniques simultaneously," Meas. Sci. Technol. 15, 939-947 (2004).

14. W. Bohmeyer, K. Lange, W. Stark, and G. Teteris, "Application of ultrasonic cure monitoring of thermosets in research and production," In proc. of CompNDT (2011).

15. J. C. Bacri, , J. M. Courdille, J. Dumas, and R. Rajaonarison, "Ultrasonic waves: A tool for gelation process measurements," J. Phys. Lett-Paris 41, 369-372 (1980).

16. S. S. Yoon, W. J. Yu, and H. C. Kim, "Phase transition of epoxy resin during isothermal curing monitored by ultrasonic velocity measurements," J. Mater. Sci. Lett. 11, 1392-1394 (1992).

17. I. Alig, K. Nancke, and G. P. Johari, "Relaxations in thermosets. XXVI. Ultrasonic studies of the temperature dependence of curing kinetics of diglycidyl ether of bisphenol-A with catalyst," J. Polym. Sci. Part B: Polym. Phys. 32, 1465-1474 (1994).

18. M. Matsukawa and I. Nagai, "Ultrasonic characterization of a polymerizing epoxy resin with imbalanced stoichiometry," J. Acoust. Soc. Am. 99, 2110-2115 (1996).

19. S. R. White, P. T. Mather, and M. J. Smith, "Characterization of the cure-state of DGEBADDS epoxy using ultrasonic, dynamic mechanical, and thermal probes," Polym. Eng. Sci. 42, 51-67 (2002).

20. J. Mc Hugh, W. Stark, and J. Doring, "Evaluation of the cure behaviour of epoxy resin using rheometric and ultrasonic techniques," In proc of Nondestructive Characterization of Materials XI, 651-658 Edt. R.E. Green, Springer-Verlag, (2003).

21. V. A. Korneev and A. Demčenko, "Possible second-order nonlinear interactions of plane waves in an isotropic solid," J. Acoust. Soc. Am. 135, 591-598 (2014).

22. C. Y. Shigue, R. G. S. Dos Santos, C. A. Baldan, and E. Ruppert-Filho, "Monitoring the epoxy curing by the dielectric thermal analysis method," IEEE T. Appl. Supercon. 14, 1173$1176(2004)$.

23. A. Demčenko, V. Koissin, and V. A. Korneev, "Noncollinear wave mixing for measurement dynamic processes in polymers: physical ageing in thermoplastics and epoxy cure," Ultrasonics, 54 685-693 (2014). 
24. J. R. Asay and A. H. Guenther, "Ultrasonic studies of 1060 and 6061-T6 aluminum," J. Appl. Phys. 38, 4086-4088 (1967).

25. A. Demčenko, M. Ravanan, H. A. Visser, R. Loendersloot, and R. Akkerman, "Investigation of PVC physical ageing in field test specimens using ultrasonic and dielectric measurements," In proc. of the IEEE International Ultrasonics Symposium, 1909-1912 (2012).

26. Warm-curing epoxy system based on Araldite ${ }^{\circledR}$ LY 1564 SP / Hardener XB 3486 / Hardener XB 3487. Huntsman datasheet (2004).

27. J. Lange, N. Altmann, C. T. Kelly, and P. J. Halley, "Understanding vitrification during cure of epoxy resins using dynamic scanning calorimetry and rheological techniques," Polymer 41, 5949-5955 (2000).

28. Isothermal cure of an epoxy by Dynamic Mechanical Analysis. Application note. PerkinElmer ${ }^{\mathrm{TM}}$ Instruments 2000.

29. B. Bilyeu, W. Brostow, and K. P. Menard, "Separation of gelation from vitrification in curing of a fiber-reinforced epoxy composite," Polym. Composite. 23, 1111-1119 (2002).

30. D. J. O'Brien, P. T. Mather, and S. R. White, "Viscoelastic properties of an epoxy resin during cure," J. Compos. Mat. 35, 883-904 (2001).

31. R. A. Fava, "Differential scanning calorimetry of epoxy resins," Polymer 9, 137-151 (1968).

32. S. Sourour, M. R. Kamal, "Differential scanning calorimetry of epoxy cure: isothermal cure kinetics," Thermochim. Acta, 14, 41-59 (1976).

33. R. E. Challis, R. J. Freemantle, R. P. Cocker, D. L. Chadwick, D. J. Dare, C. Martin, A. Mahendrasingam, and W. Fuller, "Ultrasonic measurements related to evolution of structure in curing epoxy resins," Plast. Rubber Comp. 29, 109-118 (2000).

34. R. E. Challis, M. E. Unwin, D. L. Chadwick, R. J. Freemantle, I. K. Partridge, D. J. Dare, and P. I. Karkanas, "Following network formation in an epoxy/amine system by ultrasound, dielectric, and nuclear magnetic resonance measurements: A comparative study," J. Appl. Polym. Sci. 88, 1665-1675 (2003).

35. G. LaPlante, J. C. García-Naranjo, and B. J. Balcom, "Real-time cure monitoring of an epoxy/polyamidoamine system with unilateral magnetic resonance," NDT \& E Int. 44, 329 $334(2011)$

36. S. X. Xua, Y. Li, and Y. P. Feng, "Temperature modulated differential scanning calorimetry: on system linearity and the effect of kinetic events on the observed sample specific heat," Thermochim. Acta 359, 43-54 (2000).

37. G. J. Price, "Recent developments in sonochemical polymerization," Ultrason. Sonochem. 10, 277-283 (2003).

38. S. Sharma and I. Luzinov, "Ultrasonic curing of one-part epoxy system," J. Compos. Mater. 45, 2217-2224 (2011). 


\title{
Chapter 6
}

\section{Noncollinear wave mixing for nonlinear ultrasonic detection of physical ageing in $\mathrm{PVC}^{1}$}

\begin{abstract}
This work considers the characterization of linear PVC acoustic properties using a linear ultrasonic measurement technique and the noncollinear ultrasonic wave mixing technique for measurement of the physical ageing state in PVC. The immersion pulseecho measurements were used to evaluate phase velocity dispersion and attenuation of longitudinal waves in PVC test specimens. The suggested noncollinear ultrasonic wave mixing technique measurement technique was verified on measurements of laboratory and field PVC test specimens. The measurement results confirm that the ultrasonic wave mixing technique is suitable to estimate the physical ageing state of PVC.
\end{abstract}

${ }^{1}$ Reproduced from: A. Demčenko, R. Akkerman, P. B. Nagy, and R. Loendersloot "Non-collinear wave mixing for non-linear ultrasonic detection of physical ageing in PVC," NDT and E International, 49, 34-39 (2012). 


\subsection{Introduction}

Polyvinylchloride (PVC) is an amorphous polymer offering good performance at low cost. As such, it is widely used (about one quarter of the global annual polymer production is PVC), especially in infrastructural and building applications, e.g. in water and gas distribution networks. From the moment when an amorphous polymer is cooled down through the glass transition region, it undergoes a process that is called physical ageing or structural relaxation [1], in which the polymer chains slowly move towards their thermodynamically favored positions. This process is characterized by timedependent changes of bulk properties such as specific volume, enthalpy, entropy, mechanical and dielectric response, which attempt to establish thermodynamic equilibrium. More specifically, the yield stress increases over time, accompanied by a decrease of fracture toughness due to localization of the plastic deformations [2]. This implies that PVC structures such as supply systems for gas and water will get more susceptible to third party damage over time. The degraded parts of these supply systems need to be replaced in a timely fashion to prevent the risks involved with pipe failure. However, up to now there is no nondestructive inspection system available to identify the necessity of replacement or the residual lifetime of (parts of) these pipeline networks.

Measurements of the ultrasonic wave velocity and attenuation are widely used for characterization of acoustic properties of polymers [3]. In this study an ultrasonic longitudinal wave was used for the initial characterization of PVC test samples in terms of phase velocity dispersion and attenuation of the wave.

The ageing-induced changes in the linear elastic properties of PVC are small and it is hard to detect them in situ when the plastic construction is embedded or/and when only single-sided access to the structure is possible. The (linear) elastic polymer properties of PVC have been studied widely using ultrasonic measurement techniques [4-11], but none of these references consider the process of physical ageing of PVC. Therefore the measurement results may vary slightly when repeating the measurement. Physical ageing was, however, investigated with other measurement techniques for a wide range of glassy polymers. In particular, physical ageing of PVC was investigated by means of:

- measurement of the creep compliance [12-17];

- measurement of the heat distortion temperature [18];

- differential scanning calorimetry [19-22];

- dynamic mechanical spectroscopy (dynamic mechanical analysis) [23];

- tensile test measurements [2, 24, 25];

- micro-indentation tests [26].

Obviously, most of the listed measurement techniques are hardly suited for nondestructive field inspection of physical ageing in polymers, or the measurement technique is limited when the critical spots can be in the centre of the material. For example, micro-indentation tests correlate with the physical state ageing in PVC, but this measurement technique is limited to the surface properties of the polymer structure. The literature indicates that the measured tensile compliance loss as a function of frequency has a peak that is almost unaffected by the PVC physical ageing over a wide 
range of ageing time $\left(10^{-8}-10^{6} \mathrm{~s}\right)$ at $23^{\circ} \mathrm{C}$ [12]. The reported investigations were performed over a wide frequency range, from $0.01 \mathrm{~Hz}$ to $5 \mathrm{MHz}$ and a part of the measurements was carried out using ultrasonic waves. The tensile compliance loss peak was obtained around $30 \mathrm{kHz}$. The reported low frequency of the peak and low sensitivity of acoustic waves to physical ageing of PVC show that linear acoustic measurements are not suitable for determination of the physical ageing state in PVC. There is too little information in the open literature about the possibilities to estimate the physical ageing state in various polymers using an ultrasonic measurement technique.

It is well known that nonlinear ultrasonic measurements are more sensitive to certain material properties in comparison with linear ultrasonic measurements. Three different "classic" nonlinear wave approaches are used in characterization of material properties: a) acousto-elasticity, b) wave mixing and c) resonance frequency shift and modification of the quality factor of vibrating bars, when the acoustic amplitude increases [27]. The second approach was used here, and will be discussed in more detail.

Two different approaches can be distinguished in wave mixing: collinear wave mixing, better known as harmonic generation, and noncollinear wave mixing, when two waves intersect at a certain angle and a third wave is generated in the intersection volume. More than two waves can be mixed in the general case. Previous work shows that the measurements based on harmonic generation are able to detect fatigue [28-31] and physical ageing [32-36] in solids. Most of the reported studies show that most of the harmonic generation investigations were carried out with metallic alloys, except the investigation of hydrothermal ageing of metal-epoxy bonds [36]. Notably, no change in nonlinearity of the metal-epoxy bond was observed due to hydrothermal ageing.

Experimental results of nondestructive testing and material evaluation using noncollinear wave mixing are reported only for metallic alloys, see e.g. references [3739]. Recently, the noncollinear wave mixing technique was assessed for fatigue detection purposes [39].

Here a noncollinear wave mixing method was selected for the investigation of physical ageing in PVC. The noncollinear wave mixing technique has the following advantages over the harmonic generation technique (or collinear wave mixing):

- $\quad$ possibility of wave mode separation;

- possibility of frequency separation;

- elimination of the surrounding medium influence;

- $\quad$ possibility to steer a scattered wave (spatial separation);

- possibility to control the location of the intersection volume;

- $\quad$ possibility to use a low power ultrasonic measurement technique;

- possibility of single-sided or double-sided access.

However, the noncollinear wave mixing technique is more complex compared to the harmonic generation technique. The technique requires special conditions such that resonance between the interacting waves will occur in order to generate the interaction wave. 


\subsection{Measurement of phase velocity and attenuation of longitudinal waves}

An immersion pulse-echo measurement setup was used to measure longitudinal wave phase velocity dispersion and attenuation. A broadband transducer of $2.25 \mathrm{MHz}$ centre frequency with an active area diameter of $10 \mathrm{~mm}$ was used to generate and to receive longitudinal waves. The transducer was positioned perpendicularly to the surface of the test specimen maintaining $30 \mathrm{~mm}$ distance between the transducer and the test specimen. The transducer was excited using a single rectangular pulse of $2 \mathrm{MHz}$.

The phase velocity of the longitudinal wave was derived from the measurement data employing a phase spectrum method [40]. The attenuation of the longitudinal wave in the test specimen was estimated using a spectral approach as presented in [41]. Influences of diffraction and mismatch of acoustic impedances between the test specimens and water were compensated in the measured attenuation data [41].

\subsection{Noncollinear wave mixing measurement method}

The synchronism conditions for two interacting phonons $\mathbf{k}_{1}$ and $\mathbf{k}_{2}$ can be written in terms of conservation laws for quasi-momentum and energy of interacting phonons [37, 42, 43]:

$\mathbf{k}_{1} \pm \mathbf{k}_{2}=\mathbf{k}_{3}$

$\omega_{1} \pm \omega_{2}=\omega_{3}$,

where $\mathbf{k}_{i}(i=1,2,3)$ is the wave-vector of the phonon, $\omega_{i}$ is the angular frequency of the phonon and $\omega_{i}=2 \pi f_{i} . f_{i}$ is the frequency. The synchronism conditions are necessary, but not sufficient. The allowed interaction cases and their conditions are presented in literature $[42,44]$, and will not be repeated here. The interaction between shear and longitudinal waves was found most suitable to evaluate PVC when using immersion transduction for the measurements. The wave interaction process is denoted by $\operatorname{SV}\left(\omega_{1}\right)+\mathrm{L}\left(\omega_{2}\right) \rightarrow \mathrm{L}\left(\omega_{1}+\omega_{2}\right)$, where $\mathrm{SV}\left(\omega_{1}\right)$ and $\mathrm{L}\left(\omega_{2}\right)$ are the shear and longitudinal pump waves, respectively, and $\mathrm{L}\left(\omega_{1}+\omega_{2}\right)$ is the longitudinal response wave. The frequencies of the two pump waves were selected such that the response wave would strike the PVC/water interface perpendicularly. Fig. 6.1 presents the arrangement of the transducers in the measurement set-up for a test specimen of $25 \mathrm{~mm}$ thickness. Two broadband transducers of $2.25 \mathrm{MHz}$ centre frequency with an active area diameter of $10 \mathrm{~mm}$ were used to generate the pump waves. The shear wave pump transducer was inclined at an angle $\theta_{\mathrm{S}}=53^{\circ}$ and driven by a burst of 30 cycles of rectangular pulses of $f_{1}=1.8 \mathrm{MHz}$ and $0.2 \mathrm{~V}$ amplitude. The longitudinal wave pump transmitter was inclined at an angle $\theta_{\mathrm{L}}=32^{\circ}$ and driven by a burst of 30 cycles rectangular pulses of $f_{2}=2.7 \mathrm{MHz}$ and $0.2 \mathrm{~V}$ amplitude. Both pump wave signals were amplified using broadband RF amplifiers. A gain of $40 \mathrm{~dB}$ was used in the experiments. The values of angles $\theta_{\mathrm{S}}$ and $\theta_{\mathrm{L}}$ are approximate, because fine adjustment of the angles was performed manually using rotary stages with a tuning resolution of $0.08^{\circ}$. The generated wave of $4.5 \mathrm{MHz}$ was received by the broadband $5 \mathrm{MHz}$ centre frequency 
with an active area diameter of $10 \mathrm{~mm}$ receiver on the opposite side of the test specimen. A home-made preamplifier of $20 \mathrm{~dB}$ was used for amplification of ultrasonic signals. A through-transmission mode was used in order to achieve a better signal to noise ratio, as the energy reflection coefficient from the PVC and water interface is low. The received signals were filtered using a narrowband FIR filter with a Kaiser window and stored on a personal computer for further analysis.

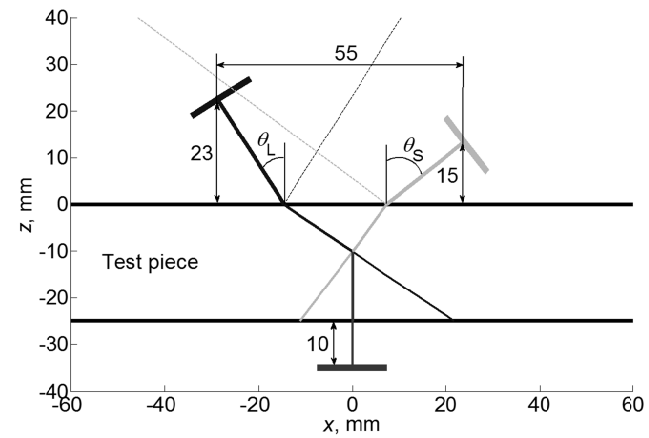

Figure 6.1. Arrangement of transducers for the noncollinear wave mixing process $\operatorname{SV}\left(\omega_{1}\right)+$ $\mathrm{L}\left(\omega_{2}\right) \rightarrow \mathrm{L}\left(\omega_{1}+\omega_{2}\right)$ in PVC. The dashed lines indicate the specularly reflected pump waves.

\subsection{Test specimens}

Two sets of PVC test specimens were prepared for measurements with the noncollinear wave mixing technique: the "laboratory" and the "field" specimens. The laboratory PVC test specimens were prepared from a commercially available extruded flat plate of $25 \mathrm{~mm}$ thickness. The new plate was without induced fatigue and should have uniform elastic properties and little thickness variation. This was not to be expected in the used PVC specimens. The dimensions of the prepared samples were $25 \mathrm{~mm} \times 25 \mathrm{~mm} \times 200 \mathrm{~mm}$. The test specimens were heated above the glass transition temperature of $\mathrm{PVC}$ at $110^{\circ} \mathrm{C}$ for one hour to erase the previous thermal history of PVC. After heating, the samples were quenched immediately in antifreeze fluid of $-30^{\circ} \mathrm{C}$, thus completing the rejuvenation process of the samples. Knowing that the glass transition temperature is about $80^{\circ} \mathrm{C}$ or more in PVC [45], the test specimens were annealed at a temperature of $60^{\circ} \mathrm{C}$ for a range of time intervals. Annealing at higher temperatures (but below the glass transition temperature) leads to accelerated physical ageing. The time intervals are listed in Table 6.1.

Table 6.1. Annealing time intervals of the PVC test specimens for noncollinear wave mixing experiments and measured phase velocity and attenuation of longitudinal wave at $2 \mathrm{MHz}$.

\begin{tabular}{|c|c|c|c|c|c|c|c|c|c|c|c|c|c|}
\hline$t[\mathrm{~h}]$ & 3 & 6 & 10 & 14 & 24 & 48 & 96 & 192 & 672 & 1008 & 1680 & 2352 & 2976 \\
\hline$c, \mathrm{~m} / \mathrm{s}$ & 2315 & 2313 & $23 \overline{12}$ & 2314 & 2310 & $\overline{2314}$ & 2313 & $231 \overline{5}$ & 2319 & $\overline{2319}$ & $2 \overline{2325}$ & 2322 & 2322 \\
\hline$\alpha, \mathrm{dB} / \mathrm{m}$ & 443 & 455 & 456 & 441 & 452 & 451 & 455 & 457 & 453 & 451 & 443 & 447 & 449 \\
\hline
\end{tabular}


The second set of PVC test specimens was prepared from an old PVC pipe that had been in use for drinking water supply service for several decades. The pipe had an external diameter of $600 \mathrm{~mm}$ and a wall thickness of nominally $18 \mathrm{~mm}$. Sixteen bar shaped test specimens were cut from the pipe in circumferential direction, approximately covering one quarter of the circumference (see Fig. 6.2). In order to maximize the amplitude of the received signal, the vertical distance between the transmitters and the top surface of test specimens was increased by $7 \mathrm{~mm}$ (compare Fig. 6.1) and the incident angles of the pump waves were changed to $\theta_{\mathrm{S}}=50^{\circ}$ and $\theta_{\mathrm{L}}=31^{\circ}$. Thus, the interaction volume of the pump waves was steered to the middle of the test specimens, and a difference in acoustical properties was accounted for, as will be discussed later. As such, the need for this modification already clearly indicates a difference between the elastic properties of the laboratory and the field PVC test specimens.

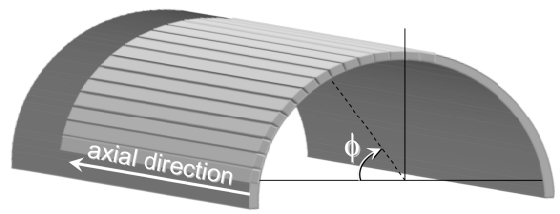

Figure 6.2. PVC field test specimens obtained from a pipe segment of $600 \mathrm{~mm}$ diameter.

\subsection{Measurement results}

Knowing that the elastic properties of polymers are strongly dependent on temperature [46], the temperature of the immersion fluid was monitored during the experiments using a digital thermometer with a thermocouple. The temperature of the water was $20.0^{\circ} \mathrm{C} \pm 0.1^{\circ} \mathrm{C}$ and $20.9^{\circ} \mathrm{C} \pm 0.3^{\circ} \mathrm{C}$ in all pulse-echo measurements and noncollinear wave mixing experiments, respectively. To minimize random noise errors in a spectral analysis of ultrasonic signals of pulse-echo measurements, the ultrasonic signals were averaged from 256 signals. There was no averaging applied during capturing and processing of the ultrasonic signals in the presented results of the noncollinear wave mixing measurements.

Averaged values of the phase velocity measurement in both groups (laboratory and field) of test samples are presented in Fig. 6.3. A difference is observed between the phase velocities of the longitudinal waves in the laboratory and field PVC test samples. The error bars show significant scatter of the phase velocity in the field PVC test specimens. This higher scattering is caused by a non-uniformity of thickness and surface properties of the PVC test specimens. The mean standard deviations are $\pm 4 \mathrm{~m} / \mathrm{s}$ and $\pm 7 \mathrm{~m} / \mathrm{s}$ for the laboratory and field test samples, respectively. The difference between the velocities confirms the need of fine readjustment of incident angles in noncollinear wave mixing experiments for evaluation of the laboratory and field PVC test specimens. 
The absolute values of the measured phase velocity are listed together with the attenuation in the laboratory samples at the central frequency of $2 \mathrm{MHz}$ in Table 6.1. The cross-correlation coefficient between the phase velocity and attenuation is 0.45 . This low correlation confirms the earlier reported low sensitivity of acoustic waves to physical ageing of PVC [12], clearly showing that the linear ultrasonic waves are not sufficiently sensitive to physical ageing of the polymer.

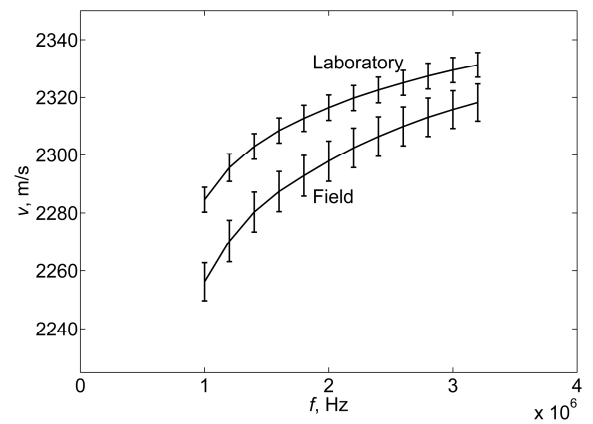

Figure 6.3. Averaged phase velocity dispersion curves of longitudinal wave in the laboratory and field PVC samples, respectively.

The measured attenuation of the longitudinal waves shows more attenuation in the field test samples of PVC (see Fig. 6.4). Standard deviations are $8.5 \mathrm{~dB} / \mathrm{m}$ and $17 \mathrm{~dB} / \mathrm{m}$ in the laboratory and field test specimens of PVC, respectively.

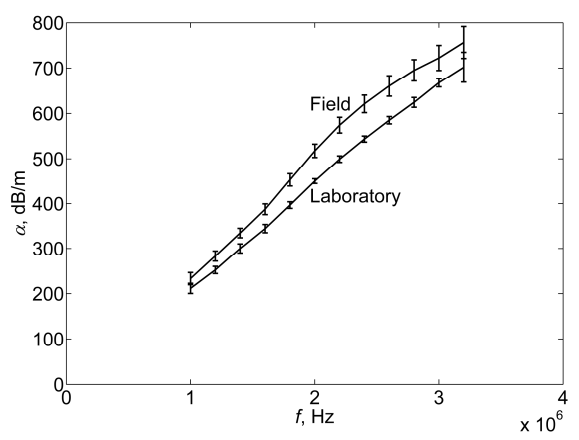

Figure 6.4. Averaged attenuation of longitudinal wave in the laboratory and field PVC samples, respectively.

The measured attenuation was fitted by a linear polynomial using a least-squares method. The following equations are obtained for laboratory and field test specimens of PVC, respectively: 
$\alpha_{1}=228.97[\mathrm{~dB} / \mathrm{m} / \mathrm{MHz}] f$,

$\alpha_{\mathrm{f}}=247.60[\mathrm{~dB} / \mathrm{m} / \mathrm{MHz}] f$,

where $f$ is the frequency. Evaluated $R$ squared values $\left(R^{2}\right)$ are 0.9875 and 0.9867 for Eq. 6.3 and 6.4, respectively.

Various measurements were made to assess the repeatability of the noncollinear wave mixing experiments, including complete disassembly and re-assembly of the measurement set-up. The repeatability was found to be good, with standard deviations of the measured peak-to-peak amplitudes within $1.33 \%$. for measurements on 'the same spot', for both laboratory and field specimens. The measurement results of the laboratory PVC test specimens obtained using the noncollinear wave mixing measurement method are presented in Fig. 6.5. These results show the relative changes in the peak-to-peak amplitude (see Fig. 6.6d) of the generated wave versus the annealing time of the PVC test specimens, $\Delta A=\left(A_{\mathrm{pp}}-A_{0 \mathrm{pp}}\right) / A_{0 \mathrm{pp}}$. The reference amplitude $A_{0 \mathrm{pp}}$ was measured in the rejuvenated sample 6 hours after extraction of the rejuvenated sample from the quenching liquid and $A_{\mathrm{pp}}$ was measured in the annealed test specimens. The measured peak-to-peak amplitude $A_{0 \mathrm{pp}}$ was $41.68 \mathrm{mV}$. The amplitude of the mixed wave is strongly affected by the annealing time (see Fig. 6.5). Up to $85 \%$ difference in ultrasonic signal amplitudes was obtained between the rejuvenated and strongly physically aged PVC samples. A $30 \%$ difference was observed between the slightly (a few hours) and strongly annealed (thousands of hours) PVC samples. Moreover, the measurement results show that the wave mixing technique becomes insensitive or saturated to the physical ageing state of PVC for the long annealing times more than $10^{3} \mathrm{~h}$ at $60^{\circ} \mathrm{C}$.

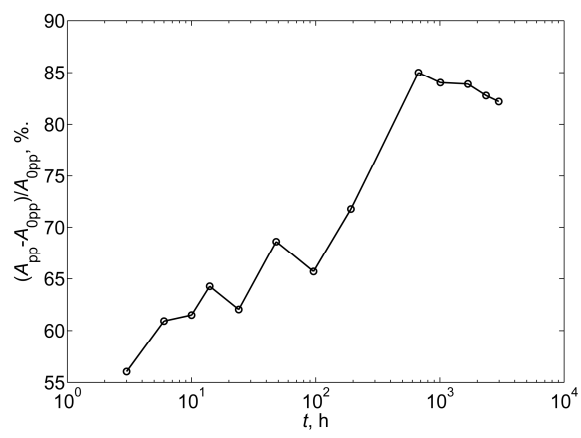

Figure 6.5. Dependence of change in peak-to-peak amplitude of the nonlinearly generated wave on the annealing time of PVC laboratory test specimens. 
Fig. 6.6a shows a raw time-domain ultrasonic signal when PVC test piece of $192 \mathrm{~h}$ annealing time was used in the noncollinear wave mixing experiments. Filtered components of two pump waves are presented in Fig. 6.6b and Fig. 6.6c. One can see that amplitudes of the pump wave signals are low in a comparison with the nonlinear wave signal presented in Fig. 6.6d. This difference (low amplitude) is caused by the following reasons: a) the ray-paths of the pump waves do not strike the receiver surface perpendicularly and the central beams deviate from the receiver (see Fig. 6.1); b) the sensitivity of the receiver is lower to the $1.8 \mathrm{MHz}$ and $2.7 \mathrm{MHz}$ pump waves than the 4.5 MHz nonlinear wave; c) an amplification flatness of the preamplifier. A comparison of the signals presented in Fig. 6.6a and Fig. 6.6d shows that the nonlinear wave component dominates in the raw ultrasonic signal. It means that the noncollinear measurements can be performed without a signal filtering when two conditions are satisfied: a) there is a good spatial separation of the informative signal and b) a nonlinear wave component dominates in the informative signal.

The PVC field test specimens were measured initially in the axial direction of the pipe (Fig. 6.2) to check homogeneity of the elastic properties. The nonlinear measurements were carried out at 14 discrete points with a step of $5 \mathrm{~mm}$ in all 16 samples.

Fig. 6.7 shows the standard deviations of the measured peak-to-peak amplitude (scaled to the maximum amplitude at $\phi=43.87^{\circ}$ ) in the axial direction and the distribution of these measurement results in the circumferential direction (Fig. 6.2). The results show that the maximum standard deviation in the extrusion direction is $3 \%$. The maximum measured standard deviation in the axial direction is significantly smaller than the peak-to-peak amplitude maximum change of $10 \%$ in the circumferential direction. The variation in circumferential direction is attributed to thickness variation and weld lines (or 'spiderlines') induced during manufacturing by the extrusion process, which will lead to a variation in morphology and material properties.

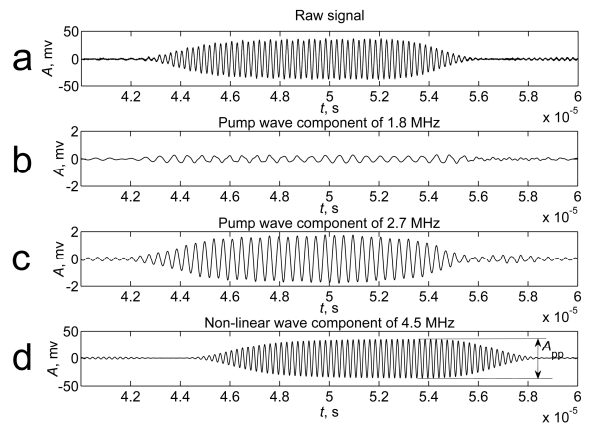

Figure 6.6. Raw time-domain signal (a) and its components: pump wave of $1.8 \mathrm{MHz}$ (b), pump wave of $2.7 \mathrm{MHz}$ (c), nonlinear wave of $4.5 \mathrm{MHz}$ (d). 


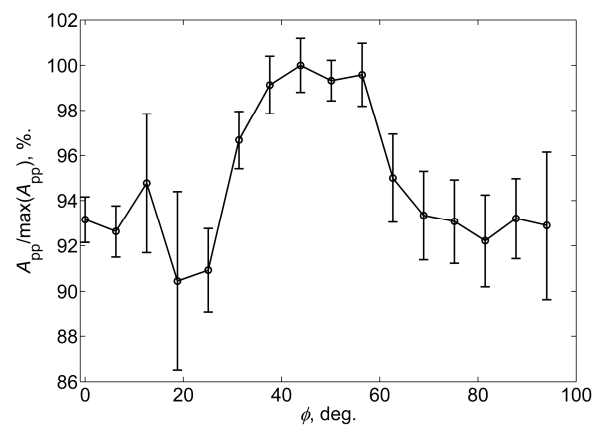

Figure 6.7. Variations of peak-to-peak amplitude in the PVC field test samples, where $\phi$ is the angle in the circumferential direction of the pipe. The error bars indicate the standard deviation per specimen in axial direction. The amplitudes are scaled to the maximum amplitude at $\phi=40^{\circ}$.

The measurement results of the field test specimens before and after rejuvenation are presented in Fig. 6.8. The results were scaled by the maximum peak-to-peak amplitude of each measurement series separately. The curves with rectangular and circular mark the normalized measurement results before and after rejuvenation, respectively. In this case, 5:30 h passed after extraction of the rejuvenated samples from the quenching liquid. Good agreement was found between the repetition and distributions of the measurement results, with one possible outlier at $64^{\circ}$. Effects other than rejuvenation are apparently absent, such as variation in the set-up or specimen geometry.

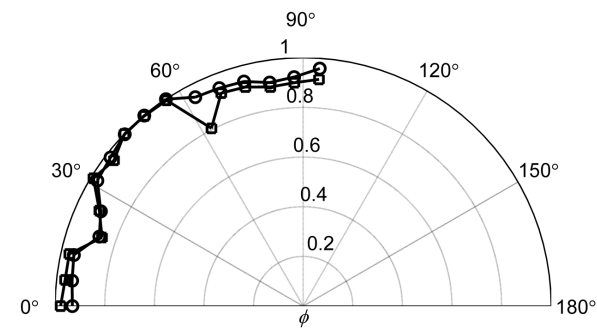

Figure 6.8. Distribution of the peak-to-peak amplitude in the circumferential direction of the PVC field test specimens. The curves with rectangular and circular points denote the normalized measurement results before and after rejuvenation, respectively, each scaled to the maximum amplitude of the series.

Although the distributions in Fig. 6.8 are very similar, the absolute values of the amplitudes of the response decrease strongly due to rejuvenation. The relative change of amplitude, $\Delta A=\left(A_{\mathrm{pp}}-A_{0 \mathrm{pp}}\right) / A_{0 \mathrm{pp}} \times 100 \%$, in the PVC field test specimens is presented in Fig. 6.9, again as a function of the circumferential position. The measurement results show that this relative change is in the range of $20-30 \%$ for most of the test specimens. The measurements confirm that the PVC pipe was physically aged during its prior service in water supply. 


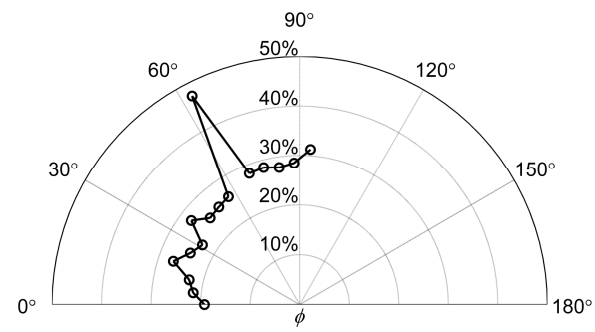

Figure 6.9. Relative decrease in peak-to-peak amplitude of the generated wave after rejuvenation of the PVC field test samples.

Previously it was shown that hardness measurement results correlate with the yield strength observed in tensile testing [26]. Therefore the noncollinear wave mixing results were verified partially employing micro-indentation experiments. The hardness of a laboratory specimen of the longest annealing time was measured. Sequentially, the PVC test specimen was rejuvenated and its hardness measured. A $30 \%$ difference was obtained between the measured hardness in the sample. A similar experiment was repeated with a field test sample of PVC. In this case a 5\% difference in the hardness of the sample was estimated. These changes are proportional to the measurement results obtained by noncollinear wave mixing experiments when $85 \%$ and $20-30 \%$ were estimated in the laboratory and field test specimens, respectively (see Table 6.2). A cross-correlation coefficient between the ultrasonic and hardness measurement results varies in the range of $60-70 \%$ (depending on the measurement position) when the measurements are carried out in the unprocessed field test samples. The experimental procedure and results of the micro-indentation experiments will be reported more in detail in the near future.

Table 6.2. Measured changes in the PVC specimens.

\begin{tabular}{lll}
\hline \hline & Noncollinear ultrasonics & Hardness \\
\cline { 2 - 3 } Laboratory & $85 \%$ & $30 \%$ \\
Field & $20-30 \%$ & $5 \%$ \\
\hline \hline
\end{tabular}

\subsection{Conclusions}

Linear ultrasonic measurements and noncollinear wave mixing ultrasonic measurements have been performed for contactless measurement of the state of physical ageing of PVC. The measurements of longitudinal wave phase velocity dispersion and attenuation can be used to identify differences between linear properties of plastics of the same polymer, but these measurements are insensitive to the physical ageing state of PVC (see Table 6.1).

The noncollinear ultrasonic wave mixing process $\operatorname{SV}\left(\omega_{1}\right)+\mathrm{L}\left(\omega_{2}\right) \rightarrow \mathrm{L}\left(\omega_{1}+\omega_{2}\right)$ does lead to significant sensitivity to physical ageing. The suggested method has been verified experimentally on two different groups of PVC test specimens: laboratory and 
field. It was shown that the ultrasonic signal amplitudes can change up to $85 \%$ from rejuvenated to artificially aged PVC test specimens in the laboratory test specimens. A difference up to $30 \%$ was obtained measuring the field test samples.

\section{Acknowledgment}

This work was performed in collaboration with Vitens and ApplusRTD within the 'Innowator' project IWA-08019 as funded by the Dutch Ministry of Economic Affairs by means of Agentschap NL. This support is gratefully acknowledged.

\section{References}

1. P. Cortés and S. Montserrat, "Physical aging studies of amorphous linear polyesters. Part II. Dependence of structural relaxation parameters on the chemical structure," J. Polym. Sci. Part B: Polym. Phys. 36, 113-126 (1998).

2. H. A. Visser, T. C. Bor, M. Wolters, J. G. F. Wismans, and L. E. Govaert, "Lifetime assessment of load-bearing polymer glasses: The influence of physical ageing," Macromol. Mater. Eng. 295, 1066-1081 (2010).

3. J. E. Mark, "Physical Properties of Polymers Handbook," 2nd ed. New York: Springer; 2007.

4. S. Koda, K. Yamashita, K. Matsumoto, and N. Hiroyasu, "Characterization of polyvinylchloride by means of sound velocity and longitudinal modulus measurements," Jpn. J. Appl. Phys. 1, 32, 2234-2237 (1993).

5. A. B. Temsamani, S. Vandenplas, and L. Van Biesen, "Optimal model for the diffraction effect in the ultrasonic field of piston transducers," J. Comput. Acoust. 9, 461-476 (2001).

6. A. A. Higazy, M. E. Kassem, A. Y. Kandeil, and R.R. Zahran, "Ultrasonic characterization, hardness and dielectric properties of $\gamma$-irradiated poly vinyl chloride," Mater. Lett. 20, 237244 (1994).

7. I. I. Perepechko and P.D. Golub, "The acoustic properties of polymers with an asymmetric potential barrier at liquid-helium temperatures," Polym. Mech. 9, 663-664 (1975).

8. I. I. Perepechko and P. D. Golub, "Viscoelastic parameters of certain polymers in the temperature interval 4.2-240K," Polym. Mech. 9, 534-538 (1975).

9. B. Pouet and N. J. P. Rasolofosaon, "Ultrasonic intrinsic attenuation measurement using laser techniques," Ultrason. 1, 545-549 (1989).

10. R. Kono, "The dynamic bulk and shear viscosities of polyvinylchloride," J. Phys. Soc. Jpn. 16, 1793-1794 (1961).

11. R. Kono, "The dynamic bulk and shear viscosity of high polymers," J. Phys. Soc. Jpn. 16, 1580-1586 (1961).

12. B. E. Read, G. D. Dean, P. E. Tomlins, and J. L. Lesniarek-Hamid, "Physical ageing and creep in PVC," Polymer 33, 2689-2698 (1992).

13. P. E. Tomlins, B. E. Read, and G. D. Dean, "The effect of temperature on creep and physical ageing of poly(vinyl chloride)," Polymer 35, 4376-4381 (1994).

14. B. E. Read, G. D. Dean, and P. E. Tomlins, "Creep and physical aging of PVC: dependence on stress and temperature," J. Non-Cryst. Solids. 172-174, 562-568 (1994).

15. H. H. D. Lee and F. J. McGarry, "A creep apparatus to explore the quenching and ageing phenomena of PVC films," J. Mater. Sci. 26, 1-5 (1991).

16. L. C. E. Struik, "Physical aging in plastics and other glassy materials," Polym. Eng. Sci. 17, 165-173 (1977). 
17. J. L. G. Ribelles, R. Diaz-Calleja, R. Ferguson, and J. M. G. Cowie, "Glass transition and physical ageing in plasticized poly(vinyl chloride)," Polymer 28, 2262-2266 (1987).

18. S. Zerafati and J. Black, "Effect of physical aging on the impact retention and heat distortion temperature of vinyl products," J. Vinyl. Additive. Technol. 4, 240-245 (1998).

19. N. Yarahmadi, I. Jakubowicz, and T. Hjertberg, "The effects of heat treatment and ageing on the mechanical properties of rigid PVC," Polym. Degrad. Stabil. 82, 59-72 (2003).

20. L.-A. Fillot, P. Hajji, C. Gauthier, and K. Masenelli-Varlot, "Thermomechanical history effects on rigid PVC microstructure and impact properties," J. Appl. Polym. Sci. 104, 20092017 (2007).

21. C. Tsitsilianis, M. Tsapatsis and Ch. Economou, "Effects of crystallinity on ageing phenomena in poly(vinyl chloride)," Polymer 30, 1861-1866 (1989).

22. R. E. Wetton, R. D. L. Marsh, J. C. Duncan, and G. M. Foster, "Effect of physical ageing of polymers on dielectric permittivity and loss values over wide temperature and frequency ranges," Dielect. Mater. Measurem. App. 363, 65-68 (1992).

23. R. Flores, J. Perez, P. Cassagnau, A. Michel, and J. Y. Cavaillé, " $\alpha$ Mechanical relaxation in poly(vinyl chloride): effect of ageing and crosslinking," Polymer 35, 2800-2807 (1994).

24. Jr. E. R. Harrell and R. P. Chartoff, "Effects of thermal and mechanical history on the viscoelastic properties of rigid poly(vinyl chloride)," J. Macromol. Sci. Phys. 14, 277-305 (1997).

25. A. Cross, R. N. Hawarda, and N. J. Mills, "Post yield phenomena in tensile tests on poly(vinyl chloride)," Polymer 20, 288-294 (1979).

26. H. A. Visser, "Lifetime assessment of uPVC gas pipes," $\mathrm{PhD}$ thesis, University of Twente, Enschede, The Netherlands (2010).

27. V. Gusev, V. Tournat, and B. Castagnède, "Nonlinear acoustic phenomena in microinhomogenous media," In M. Bruneau, C. Potel editors. Materials and Acoustics Handbook, London, Wiley-ISTE, 433-471 (2009).

28. J.-Y. Kim, L. J. Jacobs, J. Qu, and J. W. Littles, "Experimental characterization of fatigue damage in a nickel-base superalloy using nonlinear ultrasonic waves," J. Acoust. Soc. Am. 120, 1266-1273 (2006).

29. A. Kumar, C. J. Torbet, J. W. Jones, and T. M. Pollock, "Nonlinear ultrasonics for in situ damage detection during high frequency fatigue," J. App. Phys. 106, 024904-1-024904-9 (2009).

30. A. Kumar, C. J. Torbet, T. M. Pollock, and J. W. Jones, "In situ characterization of fatigue damage evolution in a cast $\mathrm{Al}$ alloy via nonlinear ultrasonic measurements," Acta. Mater. 58, 2143-2154 (2010).

31. J. Frouin, S. Sathish, T. E. Matikas, and J. K. Na, "Ultrasonic linear and nonlinear behavior of fatigued Ti-6Al-4V," J. Mater. Res. 14, 1295-1298 (1999).

32. D. J. Barnard, G. E. Dace, and O. Buck, "Acoustic harmonic generation due to thermal embrittlement of inconel 718," J. Nondestruct. Eval. 16, 67-75 (1997).

33. A. Metya, M. Ghosh, N. Parida, and S. P. Sagar, "Higher harmonic analysis of ultrasonic signal for ageing behaviour study of C-250 grade maraging steel," NDT\&E Int. 41, 484-489 (2008).

34. K.-Y. Jhang, "Applications of nonlinear ultrasonics to the NDE of material degradation," IEEE T. Ultrason. Ferr. 47, 540-548 (2000).

35. J. H. Cantrell and W. T. Yost, "Effect of precipitate coherency strains on acoustic harmonic generation,” J. App. Phys. 81, 2957-2962 (1997).

36. C. Bockenheimer, D. Fata, W. Possart, M. Rothenfusser, U. Netzelmann, H..Schaefer, "The method of non-linear ultrasound as a tool for the non-destructive inspection of structural epoxy-metal bonds - A résumé," Int. J. of Adhes. Adhes. 22, 227-233 (2002).

37. Y. Hiki and K. Mukai, "Ultrasonic three-phonon process in copper crystal," J. Phys. Soc. Jpn. 34, 454-461 (1973). 
38. F. R. Rollins, L.H. Taylor, and P. H. Todd, "Ultrasonic study of three-phonon interactions. II. Experimental results," Phys. Rev. 136, A597-A601 (1964).

39. A. J. Croxford, P. D. Wilcox, B. W. Drinkwater, and P. B. Nagy, "The use of non-collinear mixing for nonlinear ultrasonic detection of plasticity and fatigue," J. Acoust. Soc. Am. 126, EL117-EL122 (2009).

40. W. Sachse and Y. H. Pao, "On the determination of phase and group velocities of dispersive waves in solids," J. App. Phys. 49, 4320-4327 (1978).

41. P. He and J. Zheng, "Acoustic dispersion and attenuation measurement using both transmitted and reflected pulses," Ultrasonics 39, 27-32 (2001).

42. J. D. Childress and C. G. Hambrick, "Interactions between elastic waves in an isotropic solid," Phys. Rev. 136, A411-A418 (1964).

43. L. K. Zarembo and V. A. Krasil'nikov, "Nonlinear phenomena in the propagation of elastic waves in solids," Sov. Phys. Usp. 13, 778-797 (1971).

44. L. H. Taylor and F. R. Rollins, "Ultrasonic study of three-phonon interactions. I. Theory," Phys. Rev. 136, A591-A596 (1964).

45. W. Martienssen and H. Warlimont, "Springer handbook of condensed matter and materials data," Berlin, Springer (2005).

46. P. B. Nagy, "Fatigue damage assessment by nonlinear ultrasonic materials characterization," Ultrasonics 36, 375-381 (1998). 


\section{Chapter 7}

\section{Discussion}

This study was performed using an analysis of nonlinear wave amplitudes and reflection-transmission coefficients between solid-liquid and liquid-solid interfaces. A ray acoustic method was used for the wave propagation analysis. Digital signal processing was performed using Matlab software. Ultrasonic measurements were verified and interpreted using dielectric measurements, dynamic mechanical analysis (DMA) and differential scanning calorimetry (DSC).

In Chapter 2 the presented analytical expressions of the nonlinear wave amplitude coefficients can be used for modeling and analysis of wave interactions in isotropic solids. These coefficients are useful for development and tuning of acoustic channels for nonlinear ultrasonic measurements under specific conditions. Reported works show that the governing vector expression of the nonlinear wave amplitude coefficients is limited to the isotropic materials, therefore the corresponding expression should be derived for anisotropic materials. This would lead to the development and tuning of optimal acoustic channels for the nonlinear ultrasonic measurements of composite structures, which are frequently anisotropic. Moreover, the composite structures are usually thin, therefore the wave interaction volume can be too small to ensure that the generated nonlinear wave signal would be discriminated from the acoustic noise. Two ways are possible for the improvement of the noncollinear wave mixing technique in thin structures: a) to optimize the measurement conditions taking into account the selfresonances of the thin structures, and b) to employ the noncollinear wave mixing between guided waves or a guided wave and bulk wave. The first way may improve the signal-to-noise ratio employing the maximum energy transmission from ultrasonic transducers to the thin structure. The second way can help to generate a nonlinear guided wave which may be stronger than the corresponding bulk wave signal.

Inhomogeneous structures can be treated as a special case between the isotropic and anisotropic materials. Inspection of these materials using the noncollinear wave mixing technique can be difficult due to the interpretation of the response signal from the inhomogeneous materials. Therefore, development of sophisticated digital signal processing techniques is required for the reliable interpretation of the nonlinear wave signals.

The measured third order elastic constants for PVC (Chapter 2) fill the gap in the material properties database available in the literature. When the third order elastic constants are known, it is possible to compare material nonlinearity between different plastics. An accessible database would make it possible to choose a polymer with a specific nonlinearity from a wide range of polymers. This is important and can be useful for development and verification of different nonlinear measurement techniques at the initial phase of the development of the measurement techniques. Moreover, more accurate numerical models can be developed for wave propagation analysis and acoustic 
response prediction from structures under interest when the third order elastic constants are known.

In this work, Chapters 3-6, the experimental results (phase velocity, physical ageing, epoxy cure), obtained by means of the implemented noncollinear wave mixing techniques and immersion ultrasonics, indicate the potential to develop new measurement methods or an extension of the suggested methods for investigation and characterization of engineering materials. For example, the new measurement methods can be developed for characterization of: a) fluids with variable properties; b) multiphase materials; c) solid materials with cracks.

Due to the high sensitivity of the nonlinear ultrasonics to various material properties and phase transitions in the materials, dedicated sensors can be developed for real-time and in-line measurements of various fluid concentrations or for monitoring of chemical reactions in fluids. The epoxy cure monitoring shows (Chapter 4 and 5) that a thin layer of material ( $0.2 \mathrm{~mm}$ epoxy layer thickness) is sufficient for the detection of changes in this material. In the simplest way, the fluid properties can be measured in the same wave as the epoxy cure, i.e. a thin fluid layer can be introduced between two aluminum plates and the nonlinear wave response can be measured from the system (aluminum plate - fluid - aluminum plate).

The epoxy cure studies in this work prove that the nonlinear ultrasonics is able to detect transition points which are hardly detectible by the linear ultrasonics. Therefore, these preliminary studies with the epoxy cure monitoring show a high potential of the nonlinear ultrasonic technique for the detection of various transition points in various polymers during the polymerization processes. Moreover, the epoxy cure measurement results also indicated the presence of an ageing process in the epoxy which was not further investigated in this study.

Multiphase materials, which can be porous and filled with gas, can be characterized using air-coupled ultrasonics when immersion or contact transduction cannot be used. The porous materials saturated by air demonstrate a strong and complex nonlinear acoustic response, therefore experimental studies of such types of materials using the noncollinear wave mixing technique will be needed to understand wave propagation and changes in the material properties under different conditions such as porosity, mechanical loading of the porous materials, etc. When the filler is a fluid, the immersion ultrasonic measurements can be used.

Crack detection and visualization in solids is one of the typical fields where the nonlinear ultrasonics is currently being used. Most of the reported work is limited to harmonic generation technique, therefore the noncollinear wave mixing technique possibilities to detect and visualize cracks and micro-cracks need to be explored. Hence, the following questions arise which should be answered: a) What is a spatial resolution of the technique? b) How does the crack orientation influence the nonlinear wave response? The question of the spatial resolution is important for visualization of inhomogeneities in structures. The initial nonlinear ultrasonic $\mathrm{C}$-scanning experiments reported in Chapter 4 proved the suitability of this technique for detection and visualization of inhomogeneities in layered structures. However, for the estimation of the true dimensions of the inhomogeneities, it is necessary to investigate the spatial resolution of the nonlinear acoustic channel and to determine optimal conditions to achieve the highest resolution of the measurement system. It is expected that a nonlinear 
ultrasonic response from a crack will be strongly dependent on the spatial resolution and the crack orientation with respect to plane of pump waves.

The developed and presented physical ageing measurement method (Chapter 4 and 6) can be used to develop devices for design and investigation of new and existing polymer mixtures in terms of physical ageing. The developed method is applicable for nondestructive inspection of thermoplastic engineering structures such as pipelines to monitor physical ageing and fatigue, and to inspect kissing bonds (for example, where two thermoplastic pipes are welded). Usually the linear ultrasonic measurements are not sufficiently sensitive or efficient for detection of these properties. However, for field inspections, advanced acoustic channels should be used which involve phased arrays for the nonlinear wave generation and reception. The use of the phased arrays would lead to the following advantages of the advanced acoustic channel: a) electronic beam steering of the initial waves can make the acoustic channel adaptive to different materials and geometries; b) reception of the acoustic signals using the phased array enables advanced signal processing such as signal focusing and averaging. The multichannel reception possibility would minimize the influence of the informative signal deviation from a predicted direction on the acoustic response from the inspected structure. However, control of the phased arrays and interpretation of the measurement data also require sophisticated algorithms which would be able to use all advantages of the advanced acoustic multichannel. 


\section{Chapter 8}

\section{General conclusions}

Noncollinear wave mixing techniques have been analyzed analytically and experimentally with application to isotropic materials. A measurement setup has been developed and implemented for measurement of material nonlinearities using immersion ultrasonic techniques. In this study the performed analytical analysis and experimental studies have led to the following conclusions:

1. The plane-wave noncollinear interaction theory has been revised. Analytical expressions of the nonlinear wave amplitude coefficients have been derived and presented for practical analysis of all possible noncollinear wave interaction cases in isotropic solids.

2. A procedure has been proposed and implemented to select optimal measurement conditions when the noncollinear wave interaction theory is employed. The presented procedure has been demonstrated and used as a guide in the reported experimental work.

3. A measurement method, based on the noncollinear plane wave interaction theory, has been developed and implemented to measure the bulk wave phase velocity in an isotropic solid when the longitudinal or shear wave velocity is known. This method does not require estimation of the phase time-of-flight and the wave propagation path of the ultrasonic wave in the specimen. It is only necessary to measure the incident angles of the pump waves in order to determine the longitudinal or shear wave phase velocity. The method has been verified experimentally by measuring the shear wave phase velocity in aluminum.

4. A measurement method, based on the noncollinear plane wave interaction theory, has been developed and implemented to measure the isothermal epoxy curing process in a thin adhesive layer (thickness about $0.2 \mathrm{~mm}$ ). The epoxy curing process has been measured experimentally at $24.3{ }^{\circ} \mathrm{C}$ and $40{ }^{\circ} \mathrm{C}$. Four typical phase transformation points have been estimated from the measurement data: maximum viscosity, gel onset, gel peak and vitrification.

5. A measurement method, based on the noncollinear plane wave interaction theory, has been developed and implemented to detect and measure the process parameters of physical ageing in thermoplastic polymers. The physical ageing process parameters have been monitored experimentally for PVC and PMMA. 


\section{Chapter 9}

\section{Recommendations}

This study has led to the following recommendations for further research:

1. The governing vector expression of the nonlinear wave amplitude coefficients should be extended for the anisotropic materials. This would give a possibility to optimize an acoustic channel for the nonlinear ultrasonic measurements of composite structures, which are frequently anisotropic.

2. Optimization of the measurement conditions for the noncollinear wave mixing in thin structures should be studied in more depth. This investigation would provide new knowledge on the conditions, possibilities and limitations to perform nonlinear ultrasonic measurements in thin structures employing the self-resonances of the structures or guided waves.

3. The epoxy cure monitoring technique can be extended to epoxy ageing monitoring. This investigation will provide new knowledge about the longterm epoxy resin performance or the full life cycle of an epoxy bonded structure.

4. The spatial resolution limits of the noncollinear wave mixing technique should be investigated. Currently it is unclear which spatial resolution can be achieved and which conditions are needed for this.

The noncollinear wave mixing technique has many other potential application areas, apart from the cases studied in this thesis. In particular, the technique has good potential for development of new measurement methods and sensors with the following applications:

5. Characterization of fluids with variable properties such as concentrations, transitions due to chemical reactions, etc.

6. Characterization of multiphase materials such as porous media. This will provide knowledge about porosity, mechanical loading of the porous materials, etc.

7. Possibilities to detect and visualize crack-like defects of different orientation should be investigated. This study will provide new knowledge on the noncollinear wave response at different orientation of the defects.

8. Possibilities of the phased arrays for the nonlinear ultrasonic acoustic channel should be investigated when measurements are performed from the inhomogeneous (defective) structures and/or complex geometries (for example, wavy surface). 


\section{UNIVERSITY OF TWENTE.}

ISBN: 978-90-365-3761-2 